\title{
Respiratory impedance measurements in clinical lung function testing
}

Citation for published version (APA):

Wesseling, G. J. (1993). Respiratory impedance measurements in clinical lung function testing. [Doctoral Thesis, Maastricht University]. Datawyse / Universitaire Pers Maastricht. https://doi.org/10.26481/dis.19930429gw

Document status and date:

Published: 01/01/1993

DOI:

10.26481/dis.19930429gw

Document Version:

Publisher's PDF, also known as Version of record

\section{Please check the document version of this publication:}

- A submitted manuscript is the version of the article upon submission and before peer-review. There can be important differences between the submitted version and the official published version of record.

People interested in the research are advised to contact the author for the final version of the publication, or visit the DOI to the publisher's website.

- The final author version and the galley proof are versions of the publication after peer review.

- The final published version features the final layout of the paper including the volume, issue and page numbers.

Link to publication

\footnotetext{
General rights rights.

- You may freely distribute the URL identifying the publication in the public portal. please follow below link for the End User Agreement:

www.umlib.nl/taverne-license

Take down policy

If you believe that this document breaches copyright please contact us at:

repository@maastrichtuniversity.nl

providing details and we will investigate your claim.
}

Copyright and moral rights for the publications made accessible in the public portal are retained by the authors and/or other copyright owners and it is a condition of accessing publications that users recognise and abide by the legal requirements associated with these

- Users may download and print one copy of any publication from the public portal for the purpose of private study or research.

- You may not further distribute the material or use it for any profit-making activity or commercial gain

If the publication is distributed under the terms of Article $25 \mathrm{fa}$ of the Dutch Copyright Act, indicated by the "Taverne" license above, 
Respiratory impedance measurements in clinical lung function testing 
CIP-DATA KONINKLIJKE BIBLIOTHEEK, DEN HAAG

Wesseling, Geertjan

Respiratory impedance measurements in clinical lung function testing / Geertjan Wesseling. - Maastricht :

Universitaire Pers Maastricht. - Ill.

Thesis Maastricht. - With ref. - With summary in Dutch.

ISBN 90-5278-073-0

Subjects headings: respiratory impedance / lung function

/ respiratory medicine.

(c) 1993, Geertjan Wesseling

Produktie: Marie-France Deckers

Omslagillustratie: Pieter Maarten Wesseling

Boekverzorging: Datawyse, Maastricht

This study was performed at the Department of Pulmonary Diseases, University Hospital Maastricht, The Netherlands. 


\section{Respiratory impedance measurements in clinical lung function testing}

\section{PROEFSCHRIFT}

ter verkrijging van de graad van doctor aan de

Rijksuniversiteit Limburg te Maastricht, op gezag van de Rector Magnificus, Prof.mr. M.J. Cohen, volgens het besluit van het College van Dekanen, in het openbaar te verdedigen

op donderdag, 29 april 1993 om 16.00 uur

door

Geertjan Wesseling

geboren te Den Dolder op 19 juni 1956

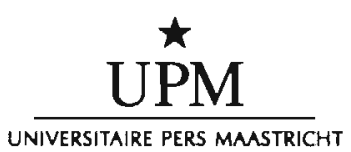




\section{Promotor:}

Prof.dr. E.F.M. Wouters

Beoordelingscommissie:

Prof.dr. J.M.A. van Engelshoven, voorzitter Dr. J.A. van Noord, De Weverziekenhuis Heerlen

Dr. D.S. Postma, Rijksuniversiteit Groningen

Prof.dr. H.A.J. Struijker Boudier

Dr. F.T.J. Verstappen 
Aan mijn ouders

Voor:

Jetske

Pieter Maarten

Frederik 


\section{Contents}

\section{List of abbreviations}

\section{Chapter I}

General introduction and aim of the study

1.1. General introduction

1.2. Input and transfer impedance

1.3. Aim of the study

\section{Chapter II}

Clinical applications of input impedance measurements; a review

2.1. Introduction

2.2. Respiratory impedance in normal subjects

2.3. Respiratory impedance in healthy children

2.4. Influence of toxic inhalants on total respiratory impedance

2.5. Respiratory impedance in obstructive airways disease

2.6. Respiratory impedance in miscellaneous disorders

2.7. Conclusions

2.8. Respiratory impedance measurements in the assessment of bronchial responsiveness

2.9. Provocation studies in children

2.10. Effects of bronchodilators

2.11. Interpretation of the frequency dependence of impedance in clinical conditions

\section{Chapter III}

Oscillatory mechanics of the respiratory system in neuromuscular disease

\section{Chapter IV}

The forced oscillation technique and spirometry in cold air provocation tests 


\section{Chapter VI}

Inhaled budesonide in chronic bronchitis. Effects on respiratory impedance

\section{Chapter VII}

Effects of inhalation of beta2 sympathicomimetic and anticholinergic agents on the impedance of the respiratory system in normal subjects

\section{Chapter VIII}

A comparison of the effects of anticholinergic and beta 2 agonist and combination therapy on respiratory impedance in COPD

Summary and conclusions

Samenvatting en conclusies

List of publications

Dankwoord 


\section{List of abbreviations}

$\begin{array}{ll}\text { COPD } & \text { Chronic Obstructive Pulmonary Disease } \\ C_{\mathrm{A}} & \text { Airway compliance } \\ C_{\mathrm{L}} & \text { Lung compliance } \\ C_{\mathrm{W}} & \text { Chest wall compliance } \\ E_{\mathrm{rs}} & \text { Elastance of the respiratory system } \\ \mathrm{FD} & \text { Frequency dependence } \\ \mathrm{FEV} & \text { Forced expiratory volume in one second } \\ \mathrm{FOT} & \text { Forced oscillation technique } \\ \mathrm{FRC} & \text { Functional residual capacity } \\ f_{0} & \text { Resonant frequency } \\ (\mathrm{s}) G_{\mathrm{aw}} & \text { (specific) airway conductance } \\ G_{\mathrm{rs}} & \text { Total respiratory conductance } \\ \mathrm{He}-\mathrm{O}_{2} & \text { Helium-oxygen } \\ \mathrm{IHCA} & \text { Isocapnic hyperventilation with cold air } \\ \mathrm{IMBC} & \text { Indirect maximum breathing capacity } \\ \mathrm{IVC} & \text { Inspiratory vital capacity } \\ \mathrm{MDI} & \text { Metered dose inhaler } \\ \mathrm{MEF} & \text { Maximum expiratory flow } \\ \mathrm{MEFV} & \text { Maximum expiratory flow volume } \\ \mathrm{PC} & \text { Provocative concentration } \\ \mathrm{PD} & \text { Provocative dose } \\ \mathrm{PEFR} & \text { Peak expiratory flow rate } \\ \mathrm{PEFV} & \text { Partial expiratory flow volume } \\ \mathrm{P}_{\mathrm{E}, \mathrm{max}} & \text { Maximum expiratory mouth pressure } \\ \mathrm{P}_{\mathrm{I}, \mathrm{max}} & \text { Maximum inspiratory mouth pressure } \\ \mathrm{P}_{\mathrm{rc}} \mathrm{O}_{2} & \text { Transcutaneous oxygen tension } \\ \mathrm{P}-\mathrm{V} & \text { Pressure-volume } \\ R_{\mathrm{aw}} & \text { airway resistance } \\ R_{\mathrm{L}} & \text { Lung tissue resistance } \\ R_{\mathrm{rs}} & \text { Total resistance of the respiratory system } \\ \mathrm{RV} & \text { Residual volume } \\ R_{\mathrm{w}} & \text { Chest wall resistance } \\ \mathrm{S}_{\mathrm{a}} \mathrm{O}_{2} & \text { Arterial oxygen saturation } \\ \mathrm{SD} & \text { Standard deviation } \\ \mathrm{TLC} & \text { Total lung capacity } \\ \mathrm{VC} & \text { Vital capacity } \\ \dot{\mathrm{V}}_{\mathrm{E}, \mathrm{max}} & \text { Maximum expiratory flow } \\ X_{\mathrm{rs}} & \text { Total reactance of the respiratory system } \\ \mathrm{Z}_{\mathrm{rs}} & \text { Impedance of the respiratory system } \\ & \end{array}$




\section{Chapter I}

General introduction and aim of the study 


\section{General introduction and aim of the study}

\subsection{General introduction}

The measurement of lung function is an important tool in the assessment of health and disease in respiratory medicine. A great variety of lung function methods is available to the clinical pulmonologist and each has its merits and drawbacks. Lung function tests are rarely diagnostic when considered in isolation and in every patient a choice has to be made from the existing facilities to support or reject a specific diagnosis. In this context, lung function measurements may help in the demonstration of an obstructive or restrictive lung function impairment, and the quantitation of its severity. An important class of lung function tests makes up the assessment of bronchial hyperresponsiveness and also, the investigation of the reversibility of existing abnormalities is part of every day clinical practice. As a rule, the most useful clinical information is obtained from the most easily performed tests. Therefore, tests based on forced expiratory manoeuvres have become the principal method in the evaluation of lung function. These tests, especially when performed using a simple spirometer are available in virtually any hospital, and can be performed in the hospital, the out-patient clinic, and even in the general practitioner's office ${ }^{1}$. Yet, in spite of their prominent place in clinical practice, tests employing forced expiratory manoeuvres know a number of disadvantages, which may be of influence on the outcome and the interpretation of the results. Parameters obtained from forced expiratory manoeuvres are the result of several factors including the calibre of the airways, the size and the elastic properties of the lungs, and the collapsibility of the airway walls. Furthermore, the measurements are highly effort dependent. Forced expiratory manoeuvres require the full active cooperation from the patient and evidence has been presented of the effect of forced respiratory manoeuvres on bronchial smooth muscle tone ${ }^{2-4}$. Repeated forced expiratory manoeuvres may have a profound effect on the outcome of bronchial provocation studies as was demonstrated by Wilson $e t a l^{5}$ in normal subjects.

A number of other methods can be used in the evaluation of lung function, most notably in situations when cooperation with tests requiring full expirations is insufficient. This may be the case in children and in the elderly, and in serial determinations for instance in provocation studies, when exhaustion may influence the outcome of the tests. In these instances, measurements of airway resistance and conductance are of value and body-plethysmography has become 
an increasingly accepted instrument in studying the mechanical characteristic of the respiratory system. Still, this technique requires expensive and complicated equipment, positioning of the patient in a narrow cubicle and the equipment demands careful calibration.

Apart from the quantitative assessment of various aspects of lung function, several techniques have been developed for the determination of the localisation of lung function properties along the tracheobronchial tree. One method to study the contribution of different parts of the bronchial system to airflow characteristics is the use of gas mixtures of different densities ${ }^{6,7}$. This is based on the concept that changing the physical properties of the inspired gas can change the relative contribution of the central and peripheral airway resistance to total pulmonary resistance. Although potentially useful for the response localisation in the lung function laboratory, the use of gas mixtures with different densities is controversial, and the technique is time-consuming since the gas mixture has to be inspired to reach an equilibrium before the measurements.

The properties of the small airways may also be studied with the measurement of dynamic compliance ${ }^{8}$. Dynamic compliance tends to fall with increasing ventilatory frequency and the extent to which this occurs may be a valuable test of small airway function. Yet, the use of an oesophagus balloon, required for this technique, has a number of drawbacks. Introduction of the catheter requires the administration of local anaesthetics and results in discomfort. Careful positioning and filling of the balloon is necessary, which may have large influences on the outcome of the measurement. Information on the relative contribution of central and peripheral airway segments may also be derived from the measurement of changes in anatomical dead space as a measure of large airway effects 9 and the volume at which phase IV of the nitrogen wash-out curve occurs indicating peripheral airway effects ${ }^{10}$.

Some of the disadvantages of lung function techniques described above may be evaded by the technique of forced oscillations ${ }^{11}$. This technique allows the determination of the mechanical properties and the frequency dependent behaviour of the respiratory system during spontaneous breathing. No forced expiratory manoeuvres or any other form of active cooperation of the subject is required, and information on the localisation of lung function characteristics may be directly obtained from this method. The technique has been used in clinical practice by various investigators, but several aspects of the use of the method in clinical practice are still unclear. For instance, little is known on the relationship between forced oscillometry data and other lung function measurements, especially in provocation studies. 


\subsection{Input and transfer impedance}

The pressure oscillations used for the technique of forced oscillations may be applied at different places or ports of the respiratory system and the flow can be measured at different sites, namely the airway opening and the chest wall ${ }^{12}$. When pressure and flow are measured at the same port, their relationship is termed "input impedance"; when they are measured at different sites, it is called "transfer impedance". The most commonly used technique is the measurement of the input impedance at the mouth. With this technique the impedance measurements can be easily performed with little discomfort for the subject and no further modifications of the equipment. The use of the transfer impedance has certain technical advantages, but requires extensive technical modifications of the equipment ${ }^{13}$.

In the studies described in this thesis only input impedances at the mouth are employed.

\subsection{Aim of the study}

The technique of forced oscillations forms a promising method to evaluate the mechanical characteristics of the respiratory system as a function of frequency, and to obtain qualitative and quantitative information on the flow-resistive properties of the respiratory system at different frequencies during tidal breathing, thus avoiding the effects of forced expiratory manoeuvres. Due to the simplicity of the measurements, the technique is well suited for use in clinical practice.

In chapter II a review of the literature on clinical applications of the technique is presented.

The aim of the study described in this thesis was to use the technique as a means of evaluating pathophysiological processes under various clinical conditions in respiratory medicine. Because no active cooperation of the subject is required for measurements using the technique of forced oscillations, the method may be especially usefull in subjects not able to give active cooperation and whose lung function is not easily assessed using other techniques. Therefore, in chapter III the results are presented of impedance measurements in severely disabled patients with various neuromuscular disorders.

In chapter IV the changes in impedance of the respiratory system resulting from provocation with a physical bronchoconstrictive stimulus, isocapnic hyperventilation with cold air, are analysed in asthmatic subjects with an established hyperresponsiveness of the bronchial system.

Next, the effects of this bronchoconstrictive stimulus, and of an inhaled beta2 sympaticomimetic drug, a bronchodilating agent, was studied in patients with 
chronic bronchitis with normal spirometric findings, in order to evaluate whether impedance measurements can reveal abnormalities that go unobserved with spirometry (chapter V).

In an attempt to study whether changes in the respiratory impedance can be detected over a longer period of time in such patients with chronic bronchitis with normal spirometric values, the effects of a six weeks' treatment period with an inhaled anti-inflammatory drug was studied. This study is reported in chapter VI. So far, long term intervention studies in which the effects of the intervention is evaluated using the technique of forced oscillations have not been published in the literature.

Several investigators have demonstrated that in normal subjects inhaled bronchodilators, especially beta 2 sympathicomimetic drugs, result in relatively large increases in airway dimensions during quiet breathing without much change in flow rates on maximum efforts. Furthermore, it has been suggested that different types of brochodilators, more specifically beta2 sympaticomimetic and anticholinergic drugs, have qualitatively different effects resulting from different preferential sites of action along the tracheobronchial tree. Qualitative and quantitative differences in the effects of both types of drugs may also be found in patients with COPD. Therefore, the technique of forced oscillations was used to evaluate the effects of these bronchodilators on impedance and spirometry in normal subjects (chapter VII) and in patients with severe COPD (chapter VIII) are presented, with the purpose of investigating whether quantitative or qualitative differences exist between these classes of bronchodilators. 


\section{References}

\section{Hutchinson J.}

On the capacity of the lungs and on the respiratory functions with a view of establishing a precise and easy method of detecting disease by the spirometer.

Trans Med Chir Soc Lond 1846; 29: 137-252.

2. Gayrard P, Orehek J, Grimaud C, Charpin J.

Bronchoconstrictor effects of a deep inspiration in patients with asthma.

Am Rev Respir Dis 1975; 111: 433-439.

3. Higenbottam T, Clark TJH.

Practical importance of a preceding full inhalation or exhalation upon the measurement of airway resistance.

Clin Sci 1980; 58: 249-253.

4. Orehek J, Nicoli MM, Delpierre S, Beaupré A.

Influence of the previous deep inspiration on the spirometric measurement of provoked bronchoconstriction in asthma.

Am Rev Respir Dis 1981; 123: 269-272.

5. Wilson M, Phagoo SB, Silverman M.

$\mathrm{FEV}_{1}$ manoeuvres persistently attenuate the response to methacholine challenge in normal subjects.

Am Rev Respir Dis 1991; 143: A410.

6. Despas PJ, Leroux M, Macklem PT.

Site of airway obstruction in asthma as determined by measuring maximal expiratory flow breathing air and a helium-oxygen mixture.

I Clin Invest 1075; 51: 30253012 .

7. Barnett TB.

Effects of helium and oxygen mixtures on pulmonary mechanics during airway constriction. J Appl Physiol 1967; 22: 707-713.

8. Ingram $R M$ jr, $O^{\prime} \mathrm{Cain} C F$.

Frequency dependence of compliance in apparently healthy smokers versus nonsmokers.

Bull Eur Physiopathol Respir 1971; 7: 195-210.

9. Fowler WS.

Lung function studies. 1l. The respiratory dead space.

Am J Physiol 1948; 154: 405-416.

10. Macklem PT.

Airway obstruction and collateral ventilation.

Physiol Rev 1971; 51: 368-436.

11. Dubois AB, Brody AW, Lewis DH, Burgess BF.

Oscillation mechanics of lungs and chest in man.

J Appl Physiol 1956; 8: 587-594.

12. Pestin R.

Methods for measuring total respiratory impedance by forced oscillations.

Bull Eur Physiopathol Respir 1986; 22: 621-631.

13. Peslin R, Duvivier C, Didelon J, Gallina C.

Respiratory impedance measured with a head generator to minimize upper airway shunt. J Appl Physiol 1985; 59: 1790-1795. 
Chapter II

Clinical applications of input impedance measurements:

A review. 


\title{
Clinical applications of input impedance measurements:
}

\author{
A review.
}

\subsection{Introduction}

In 1956 Dubois et al $^{1}$ described a method employing forced sinusoidal pressure oscillations to determine the mean resistance and reactance of the respiratory system. Initially, the measurements were performed during breathholding at a single frequency at a time. Mead $^{2}$ demonstrated that impedance can also be measured when forced oscillations are superimposed on spontaneous breathing. To assess the variations of impedance with frequency, various frequencies had to be applied in succession. Michaelson $e t \mathrm{al}^{3}$ introduced the random noise oscillation technique: oscillations of different frequencies are applied simultaneously, and a fast Fourier system is used to analyse the pressure and flow signals measured.

A further development of the technique makes use of a forced pseudo-random noise signal ${ }^{4}$, each frequency starting at a different randomly selected moment. This results in a small peak-to-peak size of the overall signal, improving the signal to noise ratio.

The experimental setup is similar to the description given by Grimby $e t a l^{5}$ (figure 1). The apparatus consists of a loudspeaker, which amplifies and transmits the signal generated by an oscillator, a high impedance side tube which enables the subject to breath spontaneously and a screen type pneumotachograph. Mouth pressure relative to athmospheric pressure and air flow, transduced to a pressure signal are recorded by two identical transducers and fed into an analysing system, dividing pressure and flow. The instantaneous relationship between pressure and flow is called the impedance $\left(Z_{\mathrm{rs}}\right)$, reflecting the total mechanical characteristics of the respiratory system. This impedance can be divided into two components. One is the in phase component, sometimes referred to as the "real" part of impedance, or resistance $\left(R_{\mathrm{rs}}\right)$. This component is due to the overall flow-resistive properties of the total respiratory system. The second, out of phase component, sometimes called the "imaginary" part, is called the reactance $\left(X_{\mathrm{rs}}\right)$. The reactance $\left(X_{\mathrm{rs}}\right)$ is determined by the inertial and elastic properties of the system. A negative reactance is found at lower frequencies since at lower frequencies the reactance is based mainly on the capacity of the system. At higher frequencies the reactance is influenced predominantly by 


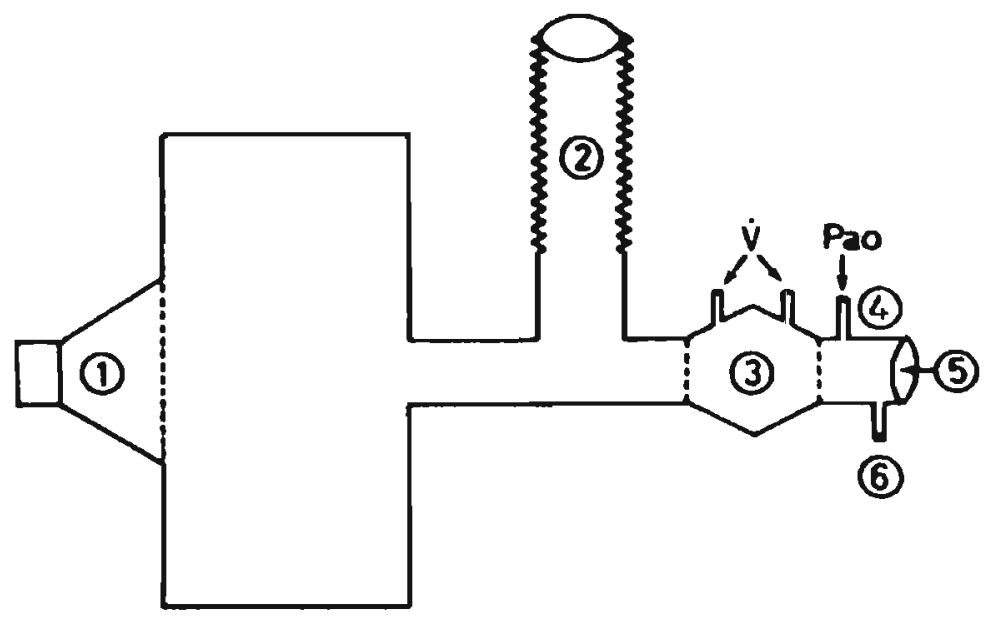

Figure 1:

1: loudspeaker; 2: impedance tube; 3: pneumotachograph; 4: bias flow; 5: mouth piece; 6: pressure transducer.

the inertial qualities of the system. The reactance then becomes positive. The frequency at which the reactance is zero is called the resonant frequency. Input impedance measurements by means of forced oscillations have been used by many authors to evaluate the mechanical characteristics of the respiratory system during spontaneous quiet breathing, in healthy subjects and in patients with varied pulmonary disorders, and also to assess the response of the respiratory system to broncho-active agents.

\subsection{Respiratory impedance in normal subjects}

At the oscillatory frequencies predominantly used in awake normal subjects the resistance of the respiratory system is usually found to increase slightly with increasing frequency $3,4,6-11$. Michaelson $e t a l^{3}$ measured the respiratory impedance from 3 to $52 \mathrm{~Hz}$ in 10 healthy subjects. At the lowest frequencies $R_{\mathrm{rs}}$ decreased with increasing frequency. At frequencies above $5 \mathrm{~Hz} R_{\mathrm{rs}}$ increased somewhat with increasing frequency. At lower frequencies the reactance $\left(X_{\mathrm{rs}}\right)$ was negative and $X_{\mathrm{rS}}$ changed from negative to positive at frequencies between 5 and $9 \mathrm{~Hz}$.

Làndsér $e t a l^{4}$ measured respiratory resistance and reactance in healthy adults at frequencies ranging from 2 to $30 \mathrm{~Hz}$ and observed a decrease in resistance with 
increasing frequency up to $8 \mathrm{~Hz}$ in 2 out of 10 healthy subjects. At higher frequencies resistance increased slightly with frequency in 8 of 10 subjects.

Nagels et $a l^{6}$ determined the impedance in 15 healthy adults between 2 and 32 $\mathrm{Hz}$ at 3 different lung volumes. Values of $R_{\mathrm{rs}}$ were highest at $25 \%$ of the vital capacity (VC) and lowest at $70 \% \mathrm{VC}$. At all lung volumes $R_{\mathrm{rs}}$ increased with increasing frequency.

Wouters $\mathrm{et} \mathrm{al}^{7}$ demonstrated an increase in $R_{\mathrm{rs}}$ with increasing frequency in 20 healthy adults in the extended frequency range of 4 to $52 \mathrm{~Hz}$. Similar observations were reported by others ${ }^{8-10}$.

In normal subjects reactance is slightly negative at lower frequencies and at higher frequencies reactance becomes positive. Most authors have reported that reactance changes from negative to positive at frequencies around $8 \mathrm{~Hz}^{3,4,7-9,11}$. Several investigators have studied the frequency dependence of resistance at frequencies within the range of normal breathing in healthy subjects. Above 2 $\mathrm{Hz}$ the contribution of the tissue resistance to the total resistance to breathing is probably negligible ${ }^{12}$. At lower frequencies, lung and chest wall tissues exhibit a visco-elastic and plastic behaviour. Hantos et al $^{13}$ measured respiratory impedance in 5 healthy adults using a pseudorandom noise signal with frequencies ranging from 0.25 to $5 \mathrm{~Hz}$ during apnoea. It was observed that $R_{\mathrm{rs}}$ is much higher at frequencies below $2 \mathrm{~Hz}$, mainly due to the frequency dependence of the chest wall resistance. Chest wall resistance $\left(R_{\mathrm{w}}\right)$ decreased from about $0.3 \mathrm{kPa} / \mathrm{l} / \mathrm{s}$ at $0.25 \mathrm{~Hz}$ to about $0.05 \mathrm{kPa} / \mathrm{l} / \mathrm{s}$ at $5 \mathrm{~Hz}$. Between $0.25 \mathrm{~Hz}$ and $2 \mathrm{~Hz}$ the decrease in $R_{\mathrm{w}}$ amounted to almost $90 \%$ of the corresponding fall in $R_{\mathrm{rs}}$. Between 2 and $5 \mathrm{~Hz}$ this value was still $65 \%$.

Albright and Bondurant ${ }^{14}$ also observed a decrease in chest wall resistance with increasing frequency between 0.3 and $2 \mathrm{~Hz}$, while chest wall elastance increased with frequency during relaxation at FRC.

Navajos et $a l^{15}$ studied the respiratory impedance in anaesthesized paralysed patients, thus ruling out the influence of muscular activity and upper airway shunt in a frequency spectum of 0.25 to $32 \mathrm{~Hz}$. As was found in awake, spontaneously breathing subjects, a marked, negative frequency dependence of resistance was found at low frequencies. Mean $R_{\mathrm{rs}}$ decreased by $63 \%$ when frequency increased from 0.25 to $2 \mathrm{~Hz}$. These authors found that mean values of $R_{\mathrm{rs}}$ between 0.25 to $4 \mathrm{~Hz}$ were $\pm 0.1 \mathrm{kPa} / \mathrm{l} / \mathrm{s}$ higher than Hantos et al ${ }^{13}$ observed in 5 healthy awake subjects in the sitting position. Although measurements of impedance in intubated patients eliminate upper airway impedance (through which a reduction of $\pm 0.018 \mathrm{kPa} / \mathrm{l} / \mathrm{s}$ can be expected ${ }^{16}$ ), an increase in oscillatory resistance will be the result of changing from sitting to supine position because of the changes in FRC induced by postural change.

Measuring lung impedance in healthy spontaneous breathing humans by forced oscillations from 0.01 to $0.1 \mathrm{~Hz}$, Suki et al $^{17}$ found a sharp decrease in the real part of $Z_{\mathrm{rs}}$ from $0.97 \mathrm{kPa} / \mathrm{l} / \mathrm{s}$ at $0.01 \mathrm{~Hz}$ to $0.27 \mathrm{kPa} / \mathrm{l} / \mathrm{s}$ at $0.03 \mathrm{~Hz}$ and than to 0.23 
$\mathrm{kPa} / \mathrm{l} / \mathrm{s}$ at $0.1 \mathrm{~Hz}$. The imaginary part of $Z_{\mathrm{rs}}$ was much larger than the real part and increased with increasing frequency.

\subsection{Respiratory impedance in healthy children}

Several investigators have reported impedance values in healthy children. Stanescu e $_{\text {al }}{ }^{18}$ studied 130 children aged 3 to 14 years at oscillatory frequencies between 4 and $9 \mathrm{~Hz}$. These authors found that $R_{\mathrm{rs}}$ at both 4 and $9 \mathrm{~Hz}$ progressively decreases with increasing height and age. Girls were found to have a slightly, though not significantly higher $R_{\mathrm{rs}}$ than boys. In boys $R_{\mathrm{rs}}$ at $9 \mathrm{~Hz}$ was lower than $R_{\mathrm{rs}}$ at $4 \mathrm{~Hz}$. This frequency dependence of resistance was more marked in children with higher resistance values. To explain these findings, these authors suggested that with growth the contribution of the peripheral resistance to the total resistance decreases. In 16 healthy children ( $3-5 \mathrm{yr}$ old) Williams et $\mathrm{l}^{19}$ found a larger resistance and inertance and a smaller compliance than in the adult lung. Linear regression analysis showed that resistance and compliance correlated with either height or forced vital capacity, with r-values in the range of 0.77 to 0.89 . Resonant frequency was approximately proportional to body weight to the minus one-third power.

Hantos $e a^{20}$ observed that smaller children had higher resistance values and a more negative reactance. In all children in this study, a decrease in resistance with increasing frequency was evident. In the tallest children reactance became positive between 9 and $10 \mathrm{~Hz}$.

Duiverman $e t a l^{21}$ observed higher $R_{\mathrm{rs}}$ values in boys than in girls, but at the age of 8 the $R_{\mathrm{rs}}$ values of boys were equal to girls. Frequency dependence of $R_{\mathrm{rs}}$ was found in boys up to the age of approximately 5 years but not in girls of that age. In older children, as is the case in adults, no frequency dependence of resistance was found. At all ages reactance values were significantly lower in boys than in girls. $X_{\mathrm{rs}}$ values increased with increasing age. Overweight was associated with higher $R_{\mathrm{rs}}$ values but virtually no change in $X_{\mathrm{rs}}$. Clément $e t a l^{22}$ confirmed earlier findings that $R_{\mathrm{rs}}$ decreases and $X_{\mathrm{rs}}$ increases during growth, and that frequency dependence of resistance decreases. Fisher $e a^{23}$ found that in taller children of identical age $R_{\mathrm{rs}}$ is systematically lower and $X_{\mathrm{rs}}$ higher. In girls, higher weights tended to be associated with lower reactance values and after 12 years of age the resistance at frequencies up to $12 \mathrm{~Hz}$ tended to increase with weight.

Peslin et $a l^{24}$ measured input impedance obtained with pressure fluctuations applied around the head using a head generator aimed to reduce the transmural pressure across the cheeks. In spite of the difference in methodology and in accordance with others ${ }^{18,21,23}$, these investigators observed a decrease in $R_{\mathrm{rs}}$ with increasing age at all frequencies. Body height had less influence on $X_{\mathrm{rS}}$ than on 
$R_{\mathrm{rs}}$ but $X_{\mathrm{rs}}$ increased faster with increasing frequency than was reported in adults $^{25}$.

Based on a study in 60 healthy and 60 asthmatic children aged 5 to 8 years, Buhr et $a^{26}$ concluded that the diagnostic value of forced oscillometry, body-plethysmography and spirometry is similar, but in this study $29 \%$ of the investigated children failed to perform valid spirometry.

In all studies impedance measurements were performed without difficulties in children from the age of 2.5 to 3 years onwards, whereas spirometry may be hazardous in children of this age.

\subsection{Influence of toxic inhalants on total respiratory impedance}

Exposure of the respiratory system to toxic inhalants, beit voluntarily as in cigarette smoking or unwillingly such as in occupational or environmental exposure, forms a continuous threat to the integrity of the respiratory system. Characterisation of the mechanical impedance of the respiratory system by means of the technique of forced oscillations may provide a valuable tool in the assessment of abnormalities resulting from exposure to smoke, pollution, or occupational hazards.

Kjeldgaard et $a l^{27}$ demonstrated that frequency dependence of oscillatory resistance is a sensitive index for differentiating smokers from non-smokers. A similar finding was reported by Hayes et $a^{28}$. These authors observed significant differences in frequency dependence of oscillatory resistance, resonant frequency and conductance normalized by height between asymptomatic smokers and a control group. Jiemspirong et $\mathrm{al}^{29}$ observed that, in contrast to men, asymptomatic current female smokers showed elevated $R_{\text {rs }}$ values when compared to non smoking women.

Others ${ }^{30,31}$ concluded that the technique of forced oscillations lacks the sensitivity to detect the effects of smoking in otherwise normal subjects. Decramer et $a l^{32}$ also found no differences in baseline impedance values between smokers and non-smokers, but reported that bronchial provocation with isocapnic hyperventilation with cold air resulted in a marked frequency dependence of resistance in smokers which was not observed in non-smokers. Also, a much larger decrease in reactance values was found after cold air provocation in smokers than in non-smokers. Similar observations were reported by Quaedvlieg and Wouters ${ }^{33}$.

The deleterious effect of smoking was recently confirmed by Michels $e t a l^{34}$ who found impedance changes reflecting peripheral airway constriction 20 minutes after the smoking of a single cigarette and an even longer-lasting constrictory effect on the central airways. 
Brochard $e a^{35}$ studied the effects of occupational exposure to inhaled irritants in subjects working in a gas manufacturing plant. In workers exposed to respiratory irritants significant differences in forced oscillation parameters were observed compared with non-exposed subjects. They inferred that the slope of the resistance versus frequency curve appeared to be sensitive in detecting occupational chronic bronchitis at an early stage. Furthermore these investigators demonstrated that occupational exposure to inhaled respiratory irritants results in differences in the changes in frequency dependence of $R_{\mathrm{rs}}$ and resonant frequency between air and $\mathrm{HeO}_{2}$ breathing, and concluded that the forced oscillation technique "affords sufficient sensitivity to distinguish subjects exposed to respiratory irritants at a stage when MEFV parameters are not yet modified".

Peslin et $a l^{25}$ compared the findings of input impedance obtained with a head generator and transfer impedance with the head of the subject exposed to ambient pressure and pressure variations around the chest in 39 healthy males and in 140 iron miners. Maximum expiratory flow indices were significantly lower in iron miners. Among input impedance indices, resistance was increased by almost $30 \%$ in miners and exhibited a slightly positive frequency dependence, while it hardly varied at all with frequency in control subjects. No differences in the imaginary part of input impedance were observed. For transfer impedance, most indices of $R_{\mathrm{rs}}$ and $X_{\mathrm{rs}}$ differed significantly. Smoking further enhanced the differences between the control subjects and the iron miners.

In a study on impedance characteristics in children, Peslin $e t a l^{24}$ interestingly reported, that in children living in polluted areas the frequency dependence of resistance differed significantly from that found in children living elsewhere and suggested that this finding could represent the only and early manifestation of peripheral airway obstruction.

\subsection{Respiratory impedance in obstructive airways disease}

\section{Asthma}

A clinical diagnosis of bronchial asthma is usually based on a history of wheeze, chest tightness and dyspnoea, with cough as a common feature. Characteristically, episodes with these complaints are followed by symptom-free periodes. Thus, under baseline conditions and in a symptom-free interval, normal lung function characteristics can be present in patients with asthma. Indeed, several investigators ${ }^{8,36-38}$ have reported normal spirometric and flow-volume parameters in symptom-free asthmatics. Comparisons of impedance data of normal subjects and symptom-free asthmatics are scarce, and in most studies on the issue some degree of respiratory function abnormality is present in the subjects. Clément et $a l^{8}$ reported impedance characteristics of 83 men with 
complaints of recurrent wheezing or dyspnoea (73 subjects) or cough and expectoration ( 10 subjects) or both ( 39 subjects). Compared with the data found in 442 healthy male subjects reported in the same study, the forced expiratory volume in 1 second was slightly lower in the patients with respiratory complaints $(4.02 \pm 0.71 \mathrm{l}$ versus $4.36 \pm 0.57 \mathrm{l})$. In the symptomatic patients a slightly negative frequency dependence of $R_{\mathrm{rs}}$ was found, whereas in healthy subjects no frequency dependence of resistance was observed. In the symptomatic subjects reactance values were lower than in healthy subjects and consequently, resonant frequency was higher.

Wouters $e t a l^{37}$ and van Noord $e t a l^{38}$ presented baseline impedance values in asthmatic subjects within normal range in studies on bronchial challenge testing in bronchial asthma.

\section{COPD}

Several studies have provided values for respiratory impedance in the presence of airflow obstruction. Michaelson $e t a l^{3}$ studied 1 subject with chronic obstructive pulmonary disease. $R_{\mathrm{rs}}$ was found to be markedly higher at lower frequencies than at higher frequencies and thus, a negative frequency dependence of resistance was observed. Reactance was highly negative at lower frequencies and $X_{\text {rs }}$ remained negative up to a frequency of about $20 \mathrm{~Hz}$. Similar characteristics were reported by Làndsér et $a l$ in 10 patients with COPD.

Clément $e t a l^{8}$ presented data on a group of 43 subjects with obstructive airways disease with a moderate reduction in FEV 1 (50-77\% of predicted) and a second

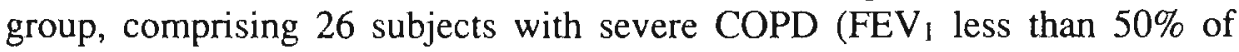
predicted). In both groups a markedly negative frequency dependence of resistance was observed. In the group with moderately severe airflow obstruction resonant frequency was increased to around $20 \mathrm{~Hz}$, in the group with severe airflow obstruction $X_{\text {rs }}$ was still negative at the highest evaluated frequency (24 $\mathrm{Hz}$ ). Using forced pseudo-random noise oscillations with an extended frequency spectrum (up to $52 \mathrm{~Hz}$ ), Wouters $e t a l^{39}$ found a similar negative frequency dependence of resistance in 20 patients with severe COPD, and a resonant frequency of around $28 \mathrm{~Hz}$.

Cauberghs and Van de Woestijne ${ }^{40}$ also demonstrated a negative frequency dependence of $R_{\mathrm{rs}}$ when impedance was measured by applying oscillations at the mouth in patients with moderate airflow obstruction. This negative frequency dependence of resistance tended to disappear when impedance was measured using a head generator, whilst this was not observed in patients with severe airflow obstruction.

Ying $e t a l^{41}$ measured the total respiratory input and transfer impedance from 4 to $30 \mathrm{~Hz}$ in 9 patients with severe COPD. These authors observed that in patients with severe COPD, $R_{\mathrm{rs}}$ was increased at all frequencies and that in some of the patients the resistance versus frequency curve obtained with measurements 
using sinusoidal oscillations applied around the chest, exhibited a sigmoid shape which was not observed in normal subjects.

\subsection{Respiratory impedance in miscellaneous disorders}

Many disease processes influence lung function; diseases of pulmonary origin, and also non-respiratory diseases. Therefore, various disease processes may influence respiratory impedance. Generally non-specific findings are reported. Van Noord et at $t^{42}$ obtained respiratory impedance data in 54 patients with interstitial lung diseases and no signs of airflow obstruction. In these patients with a total lung capacity (TLC) less than $80 \%$ of predicted a decrease in $X_{\mathrm{rs}}$ especially at low frequencies was demonstrated whereas only minor changes in $R_{\mathrm{rs}}$ were observed. In patients with a TLC of less than $50 \%$, an increase in $R_{\mathrm{rs}}$ at lower frequencies resulting in negative frequency dependence of resistance was found. When TLC was above $80 \%$ of predicted no distinct changes in $R_{\mathrm{rs}}$ and $X_{\mathrm{rs}}$ occurred. Tight correlations between TLC and VC on the one hand and the average $X_{\mathrm{rs}}$ and the frequency dependence of both $R_{\mathrm{rs}}$ and $X_{\mathrm{rs}}$ were demonstrated. Comparable findings were reported by others ${ }^{23,43}$.

In patients with acute myocardial infarction with acute left ventricular failure Depeursinge et at $t^{44}$ found a negative frequency dependence of $R_{\mathrm{rs}}$ associated with a low reactance and resonant frequencies ranging from 22 to $38.5 \mathrm{~Hz}$. In a control group consisting of patients with uncomplicated acute myocardial infarction a parallel increase in $R_{\mathrm{rs}}$ over the whole frequency range was generally observed and the resonant frequency was lower than $14 \mathrm{~Hz}$.

The effects of upper airway obstruction on respiratory impedance were studied by Van Noord et $a l^{45}: R_{\mathrm{rs}}$ increased more at lower than at higher frequencies resulting in frequency dependence of $R_{\mathrm{rs}}$, and $X_{\mathrm{rs}}$ simultaneously decreased similar to the impedance characteristics observed in patients with chronic obstructive pulmonary disease. In a separate study these authors ${ }^{46}$ reported impedance findings in patients with ankylosing spondylitis and kyphoscoliosis. In ankylosing spondylitis patients $R_{\mathrm{rs}}$ curves were nearly all within the normal range, as were $X_{\mathrm{rs}}$ curves, whereas in kyphoscoliosis patients in whom a more restrictive spirometric impairment was present, mean $R_{\mathrm{rS}}$ was clearly increased.

Negative frequency dependence of $R_{\mathrm{rs}}$ was relatively minor. Mean $X_{\mathrm{n}}$ was decreased with a shift of the resonant frequency to higher frequencies. 


\subsection{Conclusions}

Determination of the impedance of the respiratory system using forced oscillations enables the assessment of its mechanical characteristics during spontaneous quiet breathing at several frequencies simultaneously. In normal adults a slight increase in oscillatory resistance is generally observed in the frequency range of 4 to $30-52 \mathrm{~Hz}$. In these subjects reactance is usually slightly negative at lower frequencies and changes from negative to positive at frequencies between 5 and $10 \mathrm{~Hz}$. When signals consisting of frequencies below $4 \mathrm{~Hz}$ are applied it is observed that at the lowest frequencies, between 0.25 and $2 \mathrm{~Hz}, R_{\mathrm{rs}}$ is sharply increased when compared with higher frequencies.

In healthy children a negative frequency dependence of resistance is evident, combined with decreased reactance values. With growth this pattern changes progressively, advancing to that found in healthy adults.

A number of authors have described the effects of toxic inhalants such as cigaret smoke, occupational irritants and air pollution, on respiratory impedance and demonstrated that impedance may be found altered at a stage when expiratory flow volume data are not yet influenced.

In patients with airflow obstruction, negative frequency dependence of resistance is invariably found, coupled with decreased values for reactance and an increased resonant frequency. A number of varied disease entities result in distinct, generally non-specific, alterations of impedance characteristics.

\subsection{Respiratory impedance measurements in the assessment of bronchial responsiveness}

Measurement of the response of the respiratory system in bronchoprovocation testing can be performed using several techniques. Tests of forced expiration such as the forced expiratory volume in 1 second, the peak expiratory flow or maximum expiratory flow-volume parameters are widely used because of their simplicity and reproducibility ${ }^{47}$.

However, measurements using forced expirations involve a number of potential disadvantages. Active cooperation of the subject is required, deep maximum respiratory manoeuvres may influence bronchial smooth muscle tone ${ }^{48-51}$, and repeated forced expirations may exhaust the subject. Impedance measurements using the forced oscillation technique avoid these disadvantages and may therefore be of particular value in the assessment of bronchial responsiveness. A number of investigators ${ }^{9,32,36,52-59}$ have provided data of respiratory resistance and reactance in various forms of challenge procedures. In most instances no data on healthy control subjects are provided. 
Davidson $e a^{52}$ compared the total respiratory impedance at $10 \mathrm{~Hz}$ in a single healthy subject after histamine inhalation and found close correlations between the impedance and both $R_{\text {aw }}$ measured in a bodyplethysmograph and the total respiratory resistance measured with the Mead-Whittenberger technique ${ }^{60}$.

Kabiraj $e t a l^{53}$ found low but statistically significant correlations between the changes in the oscillatory resistance at $10 \mathrm{~Hz}$ and in FEV 1 and PEFR resulting from methacholine inhalation in 14 patients with asthma. They concluded that the oscillometric method seems best suited for provocation tests where airways obstruction is induced from normal resistance values. Snashall et $a l^{54}$ compared spirometry and the respiratory impedance at $10 \mathrm{~Hz}$ in the assessment of airway responsiveness to histamine in 24 asthmatic patients and stated that impedance is a more sensitive index than $\mathrm{FEV}_{\mathrm{l}}$, because a smaller dose of histamine gives a diagnostic result. Tjwa et $a l^{55}$ measured the respiratory resistance at 3,5 and $7 \mathrm{~Hz}$ following provocation with inhaled histamine in 20 patients with acute or chronic bronchitis, 8 patients with bronchial asthma and 42 patients with other lung diseases. Based on their findings, these authors could not differentiate between these disease entities and concluded that impedance measurements

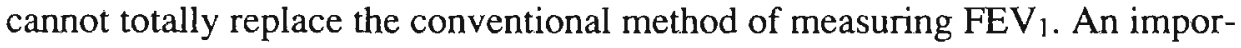
tant limiting factor appeared to be the large number of false negative reactions observed. A number of patients exhibited a decrease in $\mathrm{FEV}_{1}$ of more than $20 \%$ with the occurrence of severe dyspnoea in the absence of an increase in the oscillatory resistance. A similar problem has been encountered by others ${ }^{56}$.

Pimmel et $a l^{57}$ measured the average resistance between 5 and $9 \mathrm{~Hz}\left(R_{5-9}\right)$, between 20 and $24 \mathrm{~Hz}\left(R_{20-24}\right)$ and the extrapolated resistance at $1 \mathrm{~Hz}\left(R_{1}\right)$ in 22 healthy non-smoking subjects, 10 of whom had a history suggesting childhood asthma. Under baseline conditions resistance was either independent of frequency or it increased slightly as frequency increased. After the inhalation of increasing methacholine concentrations the resistance versus frequency curve progressively changed from a normal configuration to one similar to that seen in obstructive lung disease, with the resistance increased mostly at the lower frequencies. Excellent correlations were found between $R_{1}$ and $R_{5-9}$ and $R_{\text {aw }}$ measured in a bodyplethysmograph.

Decramer $e t a l^{32}$ used a pseudo-random noise signal with frequencies ranging from 2 to $26 \mathrm{~Hz}$ and compared impedance data thus obtained with $R_{\mathrm{aw}}$, lung volumes and maximum expiratory flow (MEF), before and after cold air hyperventilation in healthy non-smokers, healthy smokers and asthmatics. In nonsmokers $\mathrm{FEV}_{1}$, MEF and $R_{\mathrm{aw}}$ did not change after provocation, whereas $R_{\mathrm{rs}}$ increased significantly without change in the resonant frequency nor in the $R_{\mathrm{rs}}$ frequency relationship. In smokers $R_{\mathrm{rs}}$ also increased but in these subjects a change in the $R_{\mathrm{rs}}$-frequency relationship and a reduction in MEF at $50 \%$ of VC was found. In asthmatics $R_{r s}$ increased by about $100 \%$ of the prechallenge value 
and became highly frequency dependent and $X_{\mathrm{rs}}$ decreased resulting in an increase in resonant frequency.

Chinet $e t a l^{58}$ compared the specific airway conductance ( $\left(\mathrm{s} G_{\mathrm{aw}}\right.$ ) measured with a bodyplethysmograph and the respiratory conductance $\left(G_{\mathrm{rs} 0}\right)$, defined as the reciprocal of the estimate of $R_{\mathrm{rs}}$ at zero frequency (the intercept of the $R_{\mathrm{rs}^{-}}$ frequency regression line), using frequencies from 2 to $25 \mathrm{~Hz}$ during carbachol inhalation in 23 subjects with or without bronchial hyperresponsiveness. A very close correlation was observed between the dose of carbachol and the slope of the dose-response curve obtained with both methods. Feihl et al $l^{56}$ measured respiratory impedance at frequencies ranging from 1 to $50 \mathrm{~Hz}$ in 19 asthmatics during bronchial provocation with house dust mite allergen and compared the findings with those of plethysmography and spirometry. Resistance at lower frequencies increased sharply and reactance decreased, and consequently the resonant frequency increased. These authors found that oscillatory impedance and plethysmography were both more sensitive than spirometry in detecting induced bronchoconstriction.

Van Noord $e t a l^{38}$ measured changes in $R_{\mathrm{rs}}$ and $X_{\mathrm{rs}}$ determined at oscillatory frequencies ranging from 2 to $26 \mathrm{~Hz}, \mathrm{FEV}_{1}$ and specific airway conductance ( $\mathrm{s} G_{\mathrm{aw}}$ ) measured in a bodyplethysmograph, during inhalation of histamine in order to evaluate the sensitivity and reproducibility of the three methods. Histamine challenge caused significant changes in the absolute values of $R_{\mathrm{rs}}$ and $X_{\mathrm{rs}}$ and in the frequency dependence of both. The reciprocal value of the resistance at $6 \mathrm{~Hz}$ was found to be the most suited index of the technique, with a sensitivity for detecting induced changes in bronchial smooth muscle tone intermediate between that of $\mathrm{s}_{\mathrm{aw}}$ and $\mathrm{FEV}_{\mathrm{l}}$. Wouters et $a l^{36}$ studied the impedance of the respiratory system in response to inhaled histamine in 64 asthmatics and 23 control subjects. In the asthmatics $R_{\mathrm{rs}}$ increased significantly at all frequencies but most markedly at the lower frequencies and at all frequencies $X_{\mathrm{rs}}$ decreased. In the control group $R_{\mathrm{rs}}$ increased significantly at 8 and $12 \mathrm{~Hz}$ and $X_{\mathrm{rs}}$ decreased at all frequencies. Before challenge no significant differences in impedance were found between the 2 groups, after challenge the differences in impedance parameters were highly significant.

Van den Elshout et at $t^{61}$ measured variations of respiratory impedance at 3 different lung volumes and observed differences in the changes in impedance in response to changes in lung volume between healthy subjects and asthmatic subjects with bronchial hyperreactivity. In both groups an inverse relation between total respiratory resistance and lung volume was seen. At the functional residual capacity (FRC) minus 11 the average reactance decreased in both groups, as did the reactance at FRC +11 in healthy subjects. In asthmatic subjects the opposite was observed and reactance increased at FRC +11 . Although a fully satisfactory explanation for these findings could not be given by these authors, they suggested that the differences seen in the changes in $X_{\text {rs }}$ measured at FRC 
and at FRC $+1 \mathrm{l}$ between healthy subjects and asthmatic patients might matke this a useful test for detecting bronchial hyperreactivity.

When reviewing the literature on the subject of the use of forced oscillation methods in the assessment of the response of the respiratory system to bronchial provocation, it is noteworthy that although, as was stated above, several authors have reported good correlations between impedance parameters and data obtained by bodyplethysmography, forced expiratory flow-volume measurements and spirometry both in terms of absolute values and concerning threshold values, comparisons between the changes in the various evaluated parameters observed in different catagories of subjects are very scarce. Van den Elshout $e t a l^{59}$ compared the resistance measured by the forced oscillation technique with flow-volume data in an excercise provocation test in 50 asthmatic subjects. In the 36 patients in whom the provocation test was considered positive (an increase in oscillatory restistance at $8 \mathrm{~Hz}$ by $\geq 40 \%$ or a decrease in $F E V_{1}$ and/or PEF by $\geq 10 \%$ ) the relative changes in airway resistance and in flow-volume data were closely correlated: $\mathrm{r}=-0.81$ between $\Delta \mathrm{FEV}_{1}$ and $\Delta R_{r s(8)}$ and $r=-0.83$ between $\triangle P E F R$ and $\triangle R_{r s(8)}(p<0.00001)$. Furthermore these investigators concluded that impedance data obtained by forced oscillometry, especially $R_{\mathrm{rs}(8)}$, are highly sensitive (true positives: $86.1 \%$ ) and specific (true negatives: $92,8 \%$ ) in diagnosing exercise induced bronchoconstriction.

It must be emphasized that the changes in the impedance data observed in bronchial provocation studies are generally obtained in the presence of normal baseline impedance values. Many studies have confirmed that baseline conditions influence the outcome of a bronchoconstrictor challenge. Eiser et at $t^{62}$ obtained responses on $\mathrm{s} G_{\text {aw }}$ for histamine on separate days in both normal and asthmatic subjects. For the asthmatic subjects the correlation was stronger when baseline conditions were similar within subjects. This may also apply to impedance data. Similarly, coefficients of correlation between impedance data obtained from subjects may be poorer in the presence of pre-existing impedance abnormalities. Information on the subject is lacking in the literature, but one may expect that changes in frequency dependence of $R_{\mathrm{rs}}$ are smaller after bronchoprovocation in the presence of increased peripheral airway resistance, when the resistance at lower frequencies is already increased, compared with changes occurring from normal baseline values.

\subsection{Provocation studies in children}

The practical advantages of the technique of forced oscillations over other lung function methods make the technique potentially convenient for the assessment of the response of the respiratoy system to broncho-active agents in children. A 
number of authors have performed bronchial provocation tests with various stimuli using this technique in children.

Solymar et $a f^{63}$ obtained impedance data and forced expiratory flow volume variables before and after allergen provocation in 24 children aged 6 - 14 years, using forced oscillations of 2,4 and $12 \mathrm{~Hz}$ separately. In all cases a significant increase in resistance and impedance at 2 and $4 \mathrm{~Hz}$ was observed after provocation, whereas resistance at $12 \mathrm{~Hz}$ was increased in only half of the cases. The single most sensitive variable was found to be the resistance at $4 \mathrm{~Hz}$ and the forced oscillation technique seemed to be more discriminative than flow volume measurements.

Duiverman $e t a t^{64}$ compared bronchial responsiveness to histamine and methacholine in 19 children aged 3.6 to 7.8 years with a pseudo-random oscillation signal over a frequency spectrum of 2 to $26 \mathrm{~Hz}$. Threshold dose or provocative dose of histamine and methacholine showed a close correlation. The 24 hour interval within-subject reproducibility of histamine doses proved to be good in asthmatic children. In a separate study Duiverman et a $t^{65}$ compared the threshold dose and the provocative dose causing a 20\% fall in $\mathrm{FEV}_{\mathrm{l}}$, a $40 \%$ fall in $\mathrm{MEFV}_{25}$ and $\mathrm{PEFV}_{25}$ and a $40 \%$ increase in average oscillatory resistance and in the resistance at $6 \mathrm{~Hz}$ in 20 asthmatic children aged 9.1 to 16.2 years. The correlation between $\mathrm{PD}_{40}, R_{\mathrm{rs}}(6)$ and $\mathrm{PD}_{20, \mathrm{FEV} 1}$ was very close $(\mathrm{r}=0.84 ; \mathrm{p}<0.001)$.

Lebècque $e t a t^{66}$ compared the changes in $\mathrm{FEV}_{1}$ with the changes in oscillatory resistance during a histamine challenge in 31 children between 7 and 17 years of age. A strong linear relationship existed between the changes in $\mathrm{FEV}_{1}$ and both the resistance at $6 \mathrm{~Hz}$ and the frequency dependence of resistance (defined as the ratio $R_{\mathrm{rs} 6}-R_{\mathrm{rs} 26} / R_{\mathrm{rs} 26}$ ) from baseline to the final value coinciding with a $20 \%$ fall in $\mathrm{FEV}_{1}$, or when the maximum histamine concentration was reached. The patients in this study were subdivided into 2 groups. 17 patients had a positive response to histamine as indicated by a $\mathrm{PC}_{20}$ of $8 \mathrm{mg} / \mathrm{ml}$ or less, 14 patients had a negative test result. In the patients with a positive provocation test, baseline values for frequency dependence of resistance were higher than in the group with a negative provocation test, indicating a certain degree of pre-existing airflow obstruction, which may have been of influence on the outcome of the provocation test.

Yet another method to assess the response in provocation studies is the measurement of transcutaneous oxygen tension $\left(\mathrm{p}_{\mathrm{tc}} \mathrm{O}_{2}\right)$ and arterial oxygen saturation $\left(\mathrm{S}_{\mathrm{a}} \mathrm{O}_{2}\right)$. Wilson et a $l^{67}$ compared $\mathrm{p}_{\mathrm{tc}} \mathrm{O}_{2}$ and $\mathrm{S}_{\mathrm{a}} \mathrm{O}_{2}$ with the oscillatory resistance at $6 \mathrm{~Hz}\left(R_{\mathrm{rs}(6)}\right)$ during methacholine inhalations in asthmatic children and normal adults, and found no significant difference in the inhaled dose of methacholine causing a $40 \%$ increase in $R_{\mathrm{rs}(6)}$ and a $20 \%$ fall in $\mathrm{ptc}_{2} \mathrm{O}_{2}$. 


\subsection{Effects of bronchodilators}

Inhaled bronchodilators modify the bronchial smooth muscle tone in normal subjects ${ }^{68,69}$. The assessment of the effect of inhaled bronchodilators has been found to depend on the method used ${ }^{70-72}$. Several investigators have demonstrated a considerable decrease in airway resistance with comparatively small changes in expiratory flow ${ }^{69,70,73,74}$. Apparently, especially in normal subjects airway smooth muscle relaxation increases airway calibre when air flow rates and transmural pressure across airway walls are low. During forced expiration airway geometry alters because of dynamic compression of large airways ${ }^{70}$. This may result in lower expiratory flow rates. Also, inhaled bronchodilators may reduce lung recoil pressure, which results in a fall in maximum effective driving force for expiratory air flow ${ }^{69}$.

In view of these considerations, the technique of forced oscillations may be of special value in the evaluation of the effect of inhaled bronchodilators in normal subjects, but on this subject little has been reported in the literature. Manço et $a l^{9}$ reported a small decrease in oscillatory resistance at most frequencies after the inhalation of isoproterenol or atropine sulphate in 12 normal subjects. A small decrease in resonant frequency was found after isoproterenol, whereas with atropine resonant frequency did not change significantly.

More data have been presented on the effects of bronchodilating agents on total respiratory impedance in patients with airflow obstruction ${ }^{3,39,53,75-77}$. Characteristically, in patients with airflow obstruction oscillatory resistance at lower frequencies is increased, resulting in a negative frequency dependence of resistance. Furthermore, reactance values are decreased and remain negative up to higher frequencies. Consequently, resonant frequency is higher than in normal subjects. In the presence of fully reversible airflow obstruction, these impedance abnormalities should disappear after the use of an adequate dose of a bronchodilator. Published evidence of fully reversible airflow obstruction confirmed by a complete normalisation of impedance abnormalities is scarce and almost totally restricted to data of provocation studies including the use of an inhaled bronchodilator to reverse the induced bronchoconstriction ${ }^{36,55,56,66}$.

Kabiraj et $a l^{53}$ measured the response to nebulized albuterol in 4 patients with bronchial asthma treated at the hospital for an exacerbation of their disease, using a single oscillatory frequency of $10 \mathrm{~Hz}$. A decrease in resistance was observed which showed a fair correlation with the increase in peak expiratory flow rate $(r=0.59, \mathrm{p}<0.05)$.

Takishima $e t a l^{77}$ measured the bronchodilating effect of acupuncture in patients with acute asthma, and demonstrated that the resistance at $5 \mathrm{~Hz}$ significantly decreased in 10 out of 26 patients following needle acupuncture at therapeutic sites, while $R_{\mathrm{rs}}$ decreased in only one of 17 placebo treatments. 
Reports on the effects of inhaled bronchodilators on total respiratory impedance and its components in COPD are also limited. Holle et $a l^{76}$ measured the respiratory resistance at $10 \mathrm{~Hz}$ before and after the inhalation of salbutamol and observed a significant decrease in resistance in patients with asthma and in patients with chronic bronchitis and emphysema. With the use of a forced random noise signal with frequencies ranging from 3 to $45 \mathrm{~Hz}$, Michaelson and co-workers ${ }^{3}$ analyzed the effect of the inhalation of isoproterenol in one subject with COPD. Resistance became less frequency dependent, and an increase in reactance values and decrease in resonant frequency was found. Similar observations were reported by Làndsér $e t a l^{75}$ in one patient with chronic obstructive lung disease before and after the inhalation of salbutamol.

Wouters et $a l^{39}$ performed impedance measurements before and after salbutamol in 20 patients with COPD, using a pseudo-random noise signal with frequencies between 4 and $52 \mathrm{~Hz}$ and observed only a small decrease in the real part of impedance which was not statistically significant. On the other hand, the changes in the imaginary part of impedance were statistically significant at most frequencies and the resonant frequency decreased significantly. In those 12 patients in whom $\mathrm{FEV}_{1}$ increased by more than $10 \%$ from baseline, the changes in impedance were more pronounced and in these patients resistance values decreased significantly especially at lower frequencies.

\subsection{Interpretation of the frequency dependence of impedance in clinical conditions}

Several investigators have clearly demonstrated that in normal subjects the resistance of the central airways makes up the major part of the total resistance and that airways below $2 \mathrm{~mm}$ in diameter contribute little to total pulmonary resistance $\mathrm{e}^{78-80}$. In patients with airflow obstruction, as for instance in COPD, the increase in resistance is predominantly found in the peripheral airways ${ }^{78-81}$. The technique of forced oscillations forms a potentionally practical method for a qualitative analysis in terms of models of the respiratory system. A number of investigators have presented models incorporating several resistive, capacitative and inertial components. A detailed discussion of these models has been given by Cutillo and Renzetti ${ }^{82}$. Supposing peripheral resistance to be negligible compared to central airway resistance, as may be done in normal subjects, the real part of the respiratory impedance is determined by the resistance of the central airways and the resistance of the chest wall in series. $R_{\mathrm{rs}}$ will than be frequency independent. Frequency dependence of impedance can be explained by including airway wall compliance into the analysis. $\mathrm{Mead}^{2}$ considered the airways as compliant structures, mechanically in parallel with the airspaces. This results in a two-compartment lung model where the two parallel units are 
represented by the expansible airways and by the airspaces. In the presence of an increase in the resistance of the peripheral airways, the total respiratory resistance will be frequency dependent. According to the model presented by Nagels $e t a t^{6}$, frequency dependence of the real part of impedance is only possible by including airway wall compliance into the model. An increase in $C_{\mathrm{A}}$ would result in a decrease in resistance with increasing frequency, more negative reactance values and an increased resonant frequency.

The effects of inertial factors on the mechanical behaviour of the respiratory system were ignored in the models of Otis $e t a l^{83}$ and $\mathrm{Mead}^{2}$, on the assumption that the influence of inertia is negligible up to a frequency of $2 \mathrm{~Hz}$. Obviously, inertial forces have more influence at higher frequencies. Michaelson et $\mathrm{al}^{3}$ demonstrated that peripheral inertia is very small compared with central inertia. In experiments in dogs, Kappos et $a l^{84}$ observed that the total reactance of the respiratory system showed largely negative values at low frequencies, a resonance between 5 and $7 \mathrm{~Hz}$. and an essentially linear increase at higher frequencies. These investigators compartimentalized the total reactance into a peripheral reactance, behaving as a pure compliance, and a central reactance which increases linearly with increasing frequency like a pure inertance. Consequently, this resonant frequency is the result of the summed gas and tissue inertances and the tissue compliance.

Support for these findings can be found by using inspired gasses with different densities. Holle et al ${ }^{85}$ demonstrated a decrease in the oscillatory resistance at $10 \mathrm{~Hz}$ in normal subjects during $\mathrm{He}-\mathrm{O}_{2}$ breathing as a result of the decreased inertia and the phase angle became negative during $\mathrm{He}-\mathrm{O}_{2}$ breathing.

Wouters et al ${ }^{86}$ demonstrated a density dependent decrease in oscillatory resistance in normal subjects during $\mathrm{He}-\mathrm{O}_{2}$ breathing due to decreased turbulence in the larger airways and a density dependent decrease in inductive reactance reflected in a increase in resonant frequency.

An alternative interpretation of the negative frequency dependence of $R_{\mathrm{rs}}$ observed in patients with airflow obstruction is based on the shunt properties of the upper airways ${ }^{10,87}$. Part of the flow generated by the loudspeaker does not enter the lower airways but is lost in motions of the upper extrathoracic airways, most notably the cheeks. This results in an error in the estimation of respiratory impedance. This upper airway artifact tends to exaggerate the negative frequency dependence of $R_{\mathrm{rs}}$ and decrease the imaginary part of impedance. Supporting the cheeks with the palms of the hands does not fully eliminate this error ${ }^{3}$. The use of a head generator as was proposed by Peslin $e t$ al ${ }^{88}$ reduces the motions of the upper airway walls, so that no flow is lost at this level. Cauberghs and van de Woestijne ${ }^{40}$ demonstrated that with this technique negative frequency dependence of resistance disappears in patients with moderate airflow obstruction. In more severe airflow obstruction the negative frequency dependence of $R_{\mathrm{rs}}$ did not disappear when the head generator was used. Further to these 
observations, Ying et $a t^{41}$ measured respiratory input impedance by applying a pressure signal around the head and transfer impedance with a pressure input at the chest in 9 patients with severe COPD and 12 healthy subjects. In agreement with previous studies ${ }^{3,6,40}$ total respiratory compliance and inertance were decreased in patients and effective input resistance was increased, exhibiting a negative frequency dependence. The transfer resistance was also increased in patients and in some COPD patients a sigmoid $R_{\mathrm{rs}}$ versus frequency curve was observed which was not seen in normal subjects ${ }^{41}$. A best fit in model analysis of the impedance values found in COPD patients was obtained with a model where central and peripheral airway resistance was separated by a shunt representing airway wall compliance, similar to the suggestions made by Nagels et $a l^{6}$.

Recently, studies have been reported on the impedance of the respiratory system, employing oscillatory frequencies much higher than those used before. In studies in dogs Jackson and Lutchen ${ }^{89}$ showed that the real part of impedance increases in a substantially curvilinear fashion at frequencies up to $64 \mathrm{~Hz}$. Furthermore, model calculations suggested that at frequencies $>64 \mathrm{~Hz}$ a second and even a third resonance may occur. Dorkin et a ${ }^{90}$ obtained input impedance data in 8 healthy male adults using frequencies from 4 to $200 \mathrm{~Hz}$ and observed resonant frequencies at $8( \pm 2) \mathrm{Hz}, 151( \pm 10) \mathrm{Hz}$ and $182( \pm 16) \mathrm{Hz}$.

In measuring impedance between 5 and $320 \mathrm{~Hz}$ in 10 healthy adults breathing room air or $80 \% \mathrm{He}-20 \% \mathrm{O}_{2}$, Jackson et al ${ }^{9 \mathrm{l}}$ demonstrated a density dependence of the second resonant frequency (which they named the first acoustic resonance or anti-resonance, FAR 1, occurring at around $170 \mathrm{~Hz}$ in this study), and these investigators therefore concluded that this second resonance is not due to tissue elements (as is the case with the first resonant frequency) but is associated with airway acoustic properties. In patients with chronic airflow obstruction Chalker et $a l^{92}$ observed a shift of this first acoustic anti-resonance frequency towards higher frequencies, which may be due to airway wall mechanical properties. 


\section{References}

1. Dubois AB, Brody AW, Lewis DH, Burgess BF. Oscillation mechanics of lungs and chest in man. J Appl Physiol 1956; 8: 587-594.

2. Mead J.

Contribution of compliance of airways to frequency-dependent behaviour of the lungs. J Appl Physiol 1969; 26: 670-673.

3. Michaelson ED, Grassman ED, Peters WR.

Pulmonary mechanics by spectral analysis of forced random noise.

J Clin Invest 1975; 56:1210-1230.

4. Làndsér FJ, Nagels J, Demedts M, Billiet L, Van de Woestijne KP. A new method to determine frequency characteristics of the respiratory system. J Appl Physiol 1976; 41: 101-106.

5. Grimby G, Takishima T, Graham W, Macklem P, Mead J.

Frequency dependence of flow resistance in patients with obstructive lung disease. J Clin Invest 1968; 47: 1455-1465.

6. Nagels J, Làndsér FJ, Van der Linden L, Clément J, Van de Woestijne KP. Mechanical properties of lungs and chest wall during spontaneous breathing. J Appl Physiol 1980; 49: 408-416.

7. Wouters EFM, Làndsér FJ, Polko AH, Visser BF. Physiological analysis of extended-spectrum oscillometry.

Respiration 1988; 54: 263-270.

8. Clément J, Làndsér FJ, van de Woestijne KP.

Total resistance and reactance in patients with respiratory complaints with and without airways obstruction.

Chest 1983; 2: 215-220.

9. Manço JC, Hyatt RE, Rodarte JR.

Respiratory impedance in normal humans: Effects of bronchodilatation and bronchoconstriction.

Mayo Clin Proc 1987; 62: 487-497.

10. Peslin R, Duvivier C, Gallina C, Cervantes P.

Upper airway artifact in respiratory impedance measurements.

Am Rev Respir Dis 1985; 132:712-714.

11. Pride NB.

Forced oscillation techniques for measuring mechanical properties of the respiratory system.

Thorax 1992; 47: 317-320.

12. Saibene F, Mead J.

Frequency dependence of pulmonary quasi-static hysteresis.

J Appl Physiol 1969: 26: 732-737.

13. Hantos Z, Daróczy B, Suki B, Galgóczy G, Csendes T.

Forced oscillatory impedance of the respiratory system at low frequencies.

J Appl Physiol 1986; 60: 123-132.

14. Albright $\mathrm{CD}$, Bondurant $\mathrm{S}$.

Some effects of respiratory frequency on pulmonary mechanics.

J Clin Invest 1965; 44: 1362-1370. 
15. Navajos D, Farré R, Canet J, Rotger M, Sanchis J.

Respiratory input impedance in anaesthesized paralysed patients.

J Appl Physiol 1990; 69: 1372-1379.

16. Liistro G, Stanescu D, Dooms G, Rodenstein D, Veriter C.

Head position modifies upper airway resistance in men.

J Appl Physiol 1988; 64: 1285-1288.

17. Suki B, Peslin R, Duvivier C, Farre R.

Lung impedance in healthy humans by forced oscillations from 0.01 to $0.1 \mathrm{~Hz}$.

J Appl Physiol 1989; 67: 1623-1629.

18. Stanescu D, Moavero NE, Veriter C, Brasseur L.

Frequency dependence of respiratory resistance in healthy children.

J Appl Physiol 1979; 47: 268-272.

19. Williams SP, Fullton JM, Tsai MJ, Pimmel RL, Collier AM.

Respiratory impedance and derived parameters in young children by forced random noise.

J Appl Physiol 1979; 47: 169-174.

20. Hantos Z, Daróczy B, Gyurkovits K.

Total respiratory impedance in healthy children.

Pediatric pulmonology 1985; 1: 91-98.

21. Duiveman EJ, Clément J, Van de Woestijne KP, Neijens HJ, Van den Bergh ACM, Kerrebijn KF.

Forced oscillation technique. Reference values for resistance and reactance over a frequency spectrum of $2-26 \mathrm{~Hz}$ in healthy children aged $2.3-12.5$ years.

Bull Eur Physiopathol Respir 1985; 21: 171-178.

22. Clément J, Dumoulin B, Gubbelmans R, Hendriks S, Van de Woestijne KP.

Reference values of total respiratory resistance and reactance between 4 and $26 \mathrm{~Hz}$ in children and adolesants aged 4-20 years.

Bull Eur Physiopathol Respir 1987; 23: 441-448.

23. Fisher A, Dubois A, Hyde R.

Evaluation of the forced oscillation technique for the determination of resistance to breathing.

J Clin Invest 1968; 47: 2045-2057.

24. Peslin R, Gallina C, Teculescu D, Pham QT.

Respiratory input and transfer impedances in children 9-13 years old.

Bull Eur Physiopathol Respir 1987; 23: 107-112.

25. Peslin R, Pham QT, Teculescu D, Gallina C, Duvivier C.

Comparative value of respiratory input and transfer impedances in field studies.

Bull Eur Physiopathol Respir 1987; 23: 37-42.

26. Buhr W, Reimnitz P, Jörres R, Berdel D.

Sensitivität und Specificität von polyfrequenter Oszillationsmethode, Bodyplethysmog-

raphie und Spirometrie bei Asthmatikern im Alter von 5-8 Jahren.

Pneumologie 1990; 44: 1196-1198.

27. Kjeldgaard JM, Hyde RW, Speers DM, Reichert WW.

Frequency dependence of total respiratory resistance in early airway disease.

Am Rev Respir Dis 1976; 114: 501-508.

28. Hayes DA, Pimmel RL, Fullton JM, Bromberg PA.

Cold air as a bronchial provocation technique.

Chest 1984; 86: 810-814. 
29. Jiemspirong $K$, Hyatt $R E$, Offord $K P$.

Total respiratory resistance by forced oscillation in normal subjects.

Mayo Clin Proc 1976; 51: 553-556.

30. Peslin R, Hannhart B, Pino J.

Impédance mechanique thoraco-pulmaire chez des sujets fumeurs et non-fumeurs.

Bull Eur Physiopathol Respir 1981; 17: 93-105.

31. Làndsér FJ, Clément J, Van de Woestijne KP.

Normal values of total respiratory resitance and reactance determined by forced oscillations. Influence of smoking.

Chest 1982; 81: 586-591.

32. Decramer M, Demedts M, Van de Woestijne KP.

Isocapnic hyperventilation with cold air in healthy non-smokers, smokers and asthmatic subjects.

Bull Eur Physiopathol Respir 1984; 20: 237-243.

33. Quaedvlieg M, Wouters EFM.

Early airway obstruction in young asymptomatic smokers after cold air challenge.

Respiration 1990;57:299-303.

34. Michels A, Beckers A, Portier P, Van de Woestijne KP.

The influence of smoking one cigarette on forced expiratory flows and volumes and the impedance of the respiratory system in young healthy smokers.

Eur Respir J 1991; 4: 420S.

35. Brochard L, Pelle G, de Palmas J, Brochard P, Care A, Lorino H, Harf A.

Density and frequency dependence of resistance in early airway obstruction.

Am Rev Respir Dis 1987; 135: 579-584.

36. Wouters EFM, Polko AH, Schouten HJA, Visser BF.

Contribution of impedance measurements of the respiratory system to bronchial challenge tests.

J Asthma 1988; 25: 259-267.

37. Wouters EFM, Polko AH, Visser BF.

Response localisation of the pharmacological agents histamine and salbutamol along the respiratory system by forced oscillations in asthmatic subjects.

J Asthma 1989; 26: 185-193.

38. Van Noord JA, Clément J, Van de Woestijne KP, Demedts M.

Total respiratory resistance and reactance as a measurement of response to bronchial challenge with histamine.

Am Rev Respir Dis 1989; 139: 921-926.

39. Wouters EFM, Verschoof AC, Polko AH, Visser BF.

Impedance measurements of the respiratory system before and after salbutamol in COPD patient.

Respir Med 1989; 83: 309-313.

40. Cauberghs M, Van de Woestijne KP.

Effect of upper airway shunt and series properties on respiratory impedance measurements.

J Appl Physiol 1989; 66: 2274-2279.

41. Ying Y, Peslin R, Duvivier C, Gallina C, Felicia da Silva J.

Respiratory input and transfer mechanical impedance in patients with chronic obstructive pulmonary disease.

Eur Respir J 1990; 3: 1186-1 192. 
42. Van Noord JA, Clément J, Cauberghs M, Martens I, Van de Woestijne KP, Demedts $M$.

Total respiratory resistance and reactance in patients with diffuse interstitial lung disease. Eur Respir J 1989; 2: 846-852.

43. Müller E. Vogel J.

Messung und Modellinterpretation neuer atemmechanischer Parameter.

Z Erkrank Atm Org 1981; 157: 340-344.

44. Depeursinge FB, Depeursinge CD, Boutaleb AK, Feihl F, Perret CH.

Respiratory system impedance in patients with acute left ventricular failure: pathophysiology and clinical interest.

Circulation 1987; 73: 386-395.

45. Van Noord JA, Wellens W, Clarysse I, Cauberghs M, Van de Woestijne KP,

Demedts $M$.

Total respiratory resistance and reactance in patients with upper airway obstruction. Chest 1987; 92: 475-480.

46. Van Noord JA, Cauberghs M, Van de Woestijne KP, Demedts $M$.

Total respiratory resistance and reactance in ankylosing spondylitis and kyphoscoliosis. Eur Respir J 1991; 4: 945-951.

47. Eiser NM, Kerrebijn KF, Quanjer PH.

Guidelines for standardisation of bronchial challenges with (nonspecific) bronchoconstricting agents.

Bull Eur Physiopathol Respir 1983; 19:495-514.

48. Gayrard P, Orehek J, Grimaud C, Charpin J.

Bronchoconstrictor effects of a deep inspiration in patients with asthma.

Am Rev Respir Dis 1975; 111:433-439.

49. Higenbottam T, Clark TJH.

Practical importance of a preceding full inhalation or exhalation upon the measurement of airway resistance.

Clin Sci 1980; 58: 249-253.

50. Orehek J, Nicoli MM, Delpierre S, Beaupré A.

Influence of the previous deep inspiration on the spirometric measurement of provoked bronchoconstriction in asthma.

Am Rev Respir Dis 1981; 123: 269-272.

51. Wilson M, Phagoo SB, Silverman M.

FEV $_{1}$ manoeuvres persistently attenuate the response to methacholine challenge in normal subjects.

Am Rev Respir Dis 1991; 143: A410.

52. Davidson RN, Greig CA, Hussain A, Saunders KB.

Within breath changes of airway calibre in patients with airflow obstruction by continuous measurement of respiratory impedance.

Br J Dis Chest 1986; 60: 335-352.

53. Kabiraj MU, Rolf C, Simonsson BG.

Drug-induced changes in airway obstruction reflected by forced expiratory flows and airway resistance measured with an oscillation method using quiet breathing. Respiration 1981; 41:215-220.

54. Snashall PD, Parker S, Ten Haave P, Simmons D, Noble MIM.

Use of an impedance meter for measuring airways responsiveness to histamine.

Chest 1991; 99: 1183-1185. 
55. Tjwa MKT, Smeets JJ, Janssen LPJ, Maessen FPV.

Measurement of the non-specific threshold stimulus for the bronchial tree by continuous monitoring of respiratory resistance using the oscillation method.

Respiration 1985; 48: 1-11.

56. Feihl F, Badan M, Depeursinge F, Depeursinge C, Leuenberger P, Pécoud A. Perret $C$. Respiratory acoustical impedance: a new technique to measure airway response during bronchial inhalation challenges.

Ann Allergy 1988; 61: 263-268.

57. Pimmel RL, Fullton JL, Ginsberg JF, Hazucha MJ, Haak ED, McDonnell WF, Bromberg PA.

Correlation of airway resistance with forced random noise resistance parameters.

J Appl Physiol 1981; 51: 33-39.

58. Chinet T, Pelle G, Macquin-Mavier I, Lorino H, Harf A.

Comparison of the dose-response curves obtained by forced oscillation and plethysmography during carbachol inhalation.

Eur Respir J 1988; 1: 600-605.

59. Van den Elshout F, Van Herwaarden C, Molema J, Folgering H.

Exercise-induced bronchocontriction detected with the forced oscillation technique.

Am Rev Respir Dis 1990 Suppl. A 83.

60. Mead J, Whittenberger JL.

Physical properties of human lungs measured during spontaneous respiration.

J Appl Physiol 1953; 5: 779-796.

61. Van den Elshout FJJ, Van de Woestijne KP, Folgering HTM.

Variations of respiratory impedance with lung volume in bronchial hyperreactivity.

Chest 1990; 98: 358-364.

62. Eiser NM, Macrae KD, Guz A.

Evaluation and expression of bronchial provocation tests.

Bull Eur Physiopathol Respir 1981; 17: 427-440.

63. Solymar L, Aronsson PH, Engström J, Bake B, Bjure J.

Forced oscillation technique and maximum expiratory flows in bronchial provocation tests in children.

Eur J Respir Dis 1984; 65: 486-495.

64. Duiverman EJ, Neijens HJ, van Strik R, van der Snee-van Smalen M, Kerrebijn KF.

Bronchial responsiveness in asthmatic children aged 3 to 8 years measured by forced pseudo-random noise oscillometry.

Bull Eur Physiopathol Respir 1986; 22: 27-34.

65. Duiverman EJ, Neijens HJ, van der Snee-van Smalen M, Kerrebijn KF.

Comparison of forced oscillometry and forced expirations for measuring dose-related responses to inhaled methacholine in asthmatic children.

Bull Eur Physiopath Respir 1986; 22: 433-436.

66. Lebècque P, Spier S, Lapierre J-G, Lamarre A, Zinman R, Coates AL.

Histamine challenge test in children using forced oscillation to measure total respiratory resistance.

Chest 1987; 92: 313-318. 
67. Wilson NM, Phagoo SB, Silverman M.

Use of transcutaneous oxygen tension, arterial oxygen saturation and respiratory resistance to assess the response to inhaled methacholine in asthmatic children and normal adults.

Thorax 1991; 46: 433-437.

68. Severingham JW, Stupfel $M$.

Respiratory dead space increase following atropine in man, and atropine, vagal or ganglionic blockade and hypothermia in dogs.

J Appl Physiol 1955; 8: 81-87.

69. MacFadden ER, Newton-Howes J, Pride NB.

Acute effcts of inhaled isoproterenol on the mechanical characteristics of the lungs in normal man.

J Clin Invest 1970; 49: 779-790.

70. Bouhuys A, Van de Woestijne KP.

Mechanical consequences of airway smooth muscle relaxation.

J Appl Physiol 1971; 30: 670-676.

71. Skinner C, Palmer KN.

Changes in specific airway conductance and forced expiratory volume in one second after a bronchodilator in normal subjects and patients with airways obstruction.

Thorax 1971; 29: 574-577.

72. Bobbaers H, Stanescu DC, Demedts M, Clément J, Pardaens J, Van de Woestijne KP. Action of isoprenaline on the mechanical properties of lungs and airways in healthy people and patients with obstructive airways disease.

Bull Eur Physiopathol Respir 1976; 12: 515-531.

73. Sobol BJ, Emirgil C, Waldie JR, Reed A.

The response to isoproterenol in normal subjects and in subjects with asthma.

Am Rev Respir Dis 1974; 109: 290-292.

74. Stanescu DC, Clément J, Van de Woestijne KP.

Pulmonary resistance and maximal expiratory flow rates following isoprenaline in patients with chronic obstructive lung disease.

Thorax 1973; 28: 716-720.

75. Làndsér FJ, Nagels J, Van de Woestijne KP.

Implementation by means of microprocessor techniques for the measurement of the respiratory impedance during spontaneous breathing.

Prog Respir Res 1979; 11:135-143.

76. Holle JP, Hartmann V, Heer G, Magnussen H.

Die kontinuierliche Messung des oszillatorischen Atemwiderstandes unter Salbutamol-, Aminophyllin- und Ipratropium bromid- Gabe.

Atemw Lungenkrkh 1978; 6: 418-420.

77. Takishima T, Mue S, Tamura G, Ishihara T, Watanabe $K$.

The bronchodilating effect of acupuncture in patients with acute asthma.

Ann Allergy 1982; 48: 44-49.

78. Hogg JC, Macklem PT, Thurlbeck WM.

Site and nature of airway obstruction in chronic obstructive lung disease.

N Eng J Med 1968; 278: 1355-1360.

79. Horsefield K, Cumming G.

Morphology of the bronchial tree in man.

J Appl Physiol 1968; 24: 373-383. 
80. Olson DE, Dart GA, Filley GF.

Pressure drop and fluid flow regime of air inspired into the human lung.

J Appl Physiol 1970; 28: 482-494.

81. Yanai M, Sekizawa K, Ohrui T, Sasaki H, Takishima H.

Site of airway obstruction in pulmonary diease: direct measurement of intrabronchial pressure.

J Appl Physiol 1992; 72: 1016-1023.

82. Cutillo AG, Renzetti AD.

Mechanical behaviour of the respiratory system as a function of frequency in health and disease.

Bull Eur Physiopathol Respir 1983; 19: 293-326.

83. Otis AB, McKerrow CB, Bartlett RA, Mead J, McIlroy MB, Selverstone NJ,

Radford EP.

Mechanical factors in distribution of pulmonary ventilation.

J Appl Physiol 1956; 8: 427-443.

84. Kappos AD, Rodarte JR, Lai-Fook SJ.

Frequency dependence and partitioning of respiratory impedance in dogs.

J Appl Physiol 1981; 51: 621-629.

85. Holle JP, Magnussen H, Hartmann V.

Die Messung der Oszillatorischen Impedanz während Luft- und $\mathrm{He} / \mathrm{O}_{2}$ - Atmung.

Atemw Lungenkrkh 1978; 4: 262-264.

86. Wouters EFM.

Impedance measurement during air and $\mathrm{He}-\mathrm{O}_{2}$ breathing before and after Salbutamol in nomal subjects.

J Appl Physiol 1990; 63: 1665-1669.

87. Cauberghs M, Van de Woestijne KP.

Mechanical properties of the upper airways.

J Appl Physiol 1983; 55:335-342.

88. Peslin R, Duvivier C, Didelon J, Gallina C.

Respiratory impedance measured with a head generator to minimize upper airway shunt.

J Appl Physiol 1985; 59: 1790-1795.

89. Jackson AC, Lutchen KR.

Modeling of respiratory system impedance in dogs.

J Appl Physiol 1987; 62: 414-420.

90. Dorkin HL, Lutchen KR, Jackson AC.

Human respiratory input impedance from 4 to $200 \mathrm{~Hz}$ : physiological and modeling considerations.

J Appl Physiol 1988; 64: 823-831.

91. Jackson AC, Giurdanella CA, Dorkin HL.

Density dependence of respiratory system impedances between 5 and $320 \mathrm{~Hz}$ in humans.

J Appl Physiol 1989; 67: 2323-2330.

92. Chalker RB, Celli BR, Habib RH, Jackson AC.

Respiratory input impedance from 4 to $256 \mathrm{~Hz}$ in normals and chronic airflow obstruction: Comparisons and correlations with spirometry.

Am Rev Respir Dis 1992; 146: 570-576. 



\section{Chapter III}

Oscillatory mechanics of the respiratory system in neuromuscular disease.

G.J. Wesseling

F.C.M. Quaedvlieg

E.F.M. Wouters 


\section{Oscillatory mechanics of the respiratory system in neuromuscular disease.}

\section{Abstract}

Respiratory impedance measurements by means of the technique of forced oscillations were performed together with spirometry and measurements of maximum mouth pressures in 27 severely disabled patients with a variety of neuromuscular disorders to assess the value of adding respiratory impedance measurements in the evaluation of lung function in neuromuscular disease. Using the technique of forced oscillations, impedance measurements are easily performed in physically disabled persons, since they require little active cooperation and no forced respiratory manoeuvres.

Normal respiratory impedance characteristics were found, although resistance values were somewhat higher than those found in normal subjects, signifying the absence of airflow limitation. Spirometric values were markedly reduced, as were maximum mouth pressures.

No significant correlations were found between the forced expiratory volume in $\left.1 \mathrm{~s}(\mathrm{FEV})_{1}\right)$ and the impedance data.

A strong curvilinear relationship was observed between $\mathrm{P}_{\mathrm{E}, \max }$ and the RV/TLC ratio and a strong correlation existed between $\mathrm{FEV}_{1}$ and $\mathrm{P}_{\mathrm{E} \text {,max }}$.

It is concluded from our study, that forced oscillometry is a useful tool for the assessment or exclusion of airflow obstruction in patients with neuromuscular disorders, when plethysmography is difficult to perform, and forced expiratory flow-volume data reflect muscle weakness rather than airflow limitation.

\section{Introduction}

In patients with neuromuscular disorders, respiratory impairment is often an early sign of progressive disease ${ }^{1-3}$. It is therefore important to evaluate the lung function in patients with neuromuscular disorders during the course of the disease. Generally, lung function measurements in these patients reflect respiratory muscle strength ${ }^{3-5}$ and little information on the mechanical characteristics of the respiratory system can be obtained. Thus, concomitant airflow obstruction can remain unnoticed. The use of maximun expiratory flow volume (MEFV) 
curves to detect airflow obstruction in patients with muscular weakness can be hampered by several limitations. In general, the MEFV curve is partitioned into an effort-dependent and an effort-independent part ${ }^{6}$, based on the presence of an equal pressure point. The occurence of an equal pressure point requires the generation of a critical pleural pressure. It can be hypothesized that a pleural pressure build-up high enough to generate an equal pressure point is impaired in severe neuromuscular weakness. In that case flow-volume data reflect the expiratory driving pressure rather than airway resistance-derived airflow limitation, over a larger part of the expired volume. Furthermore, the elastic recoil pressure largely determining maximum expiratory flow in the effort-independent phase of the MEFV curve is thought to be reduced in neuromuscular weakness ${ }^{5}$. A similar phenomenon is observed in normal subjects in rib cage strapping ${ }^{7}$.

With the use of the body plethysmograph, airway resistance can be measured, but this procedure requires complex equipment and is time consuming. Furthermore, patients with neuromuscular disorders may be immobile and unable to sit in a body plethysmograph without support and to undergo measurements while panting.

The technique of forced oscillations ${ }^{8}$ may be of particular value in the evaluation of respiratory mechanics in patients with neuromuscular disorders. The measurements can be performed in patients in a wheelchair. No forced respiratory manoeuvres are necessary for the measurements, since these are performed during spontaneous quiet breathing, and no active cooperation is required from the patient. Using modern computer techniques ${ }^{9}$, forced oscillations with different frequencies can now be applied simultaneously and the rapid analysis of pressures and flows at these frequencies is possible using fast Fourier techniques.

The aim of the present study was to analyse the oscillatory mechanical characteristics of the respiratory system using forced oscillations, and to compare these findings with spirometric and maximum mouth pressure measurements in patients with neuromuscular disorders.

\section{Materials and methods}

\section{Patient selection}

We studied 27 patients with various neuromuscular diseases. A summary of the patient characteristics is presented in Table 1. All patients were suffering from advanced stages of neuromuscular disease and were referred to the Department of Pulmonary Diseases with the purpose of screening for long-term mechanical ventilatory support. Two of the patients were current smokers (patients 8 and 26), one was ex-smoker (patient 20; 30 pack-years), all others were life-long 
nonsmokers. All patients denied having symptoms of asthma, more specifically episodic breathlessness with perceptible wheezing, and none of the patients used any form of bronchodilating medication. As is evident from Table 1, the majority of the patients had some degree of kyphoscoliosis and in five patients a surgical correction for kyphoscoliosis by means of spondylodesis had been performed at an earlier stage of the disease.

\section{Lung function measurements}

Forced expiratory volume in $1 \mathrm{~s}\left(\mathrm{FEV}_{1}\right)$ and inspiratory vital capacity (IVC) were measured using a wet spirometer (Gould Pulmonet III ${ }^{\circledR}$ ) with the patients in a seated position, and the highest value from three manoeuvres is reported and compared with reference values ${ }^{10}$. Because a flexion deformity in kyphoscoliosis systhematically reduces the height of the patient, results were related to predicted arm-span in all patients. Functional residual capacity (FRC) was determined by a closed circuit helium dilution method. Residual volume (RV) was calculated as the difference between TLC and IVC. In order to rule out bronchospasm contributing to eventually existing abnormalities, reversibility was tested after the inhalation of $0.5 \mathrm{mg}$ terbutaline (from a Turbuhaler).

The impedance of the respiratory system was measured with the technique of forced oscillations. This technique allows the determination of the impedance of the respiratory system at various frequencies simultaneously ${ }^{9}$. Briefly, a pseudorandom noise signal containing all harmonics of $4 \mathrm{~Hz}$ up to $52 \mathrm{~Hz}(4,8,12, \ldots .52$ $\mathrm{Hz}$ ) appearing with random phase shift, repeated every $0.25 \mathrm{~s}$ is applied at the mouth of the seated subject. The cheeks and the floor of the mouth are supported with the hands of either the patient or the investigator, while the subject breathes quietly via a screen type pneumotachograph through a high impedance side-tube (see figure 1, chapter II). A bias flow reduces the $\mathrm{CO}_{2}$ build-up at the mouth. The pseudo-random noise impulse is generated by an oscillator and ampified and transmitted by a loudspeaker. Mouth pressure relative to athmospheric pressure, and air flow transduced to a pressure signal are recorded by two identical differential transducers with equal frequency characteristics (MP 45, Validyne engineering, Northridge, CA). Pressure and flow signals are fed directly, without filtering, into a Fourier analysing system, dividing pressure by

\section{Table 1:}

Physical characteristics, respiratory function, impedance, and muscle strength data in 27 patients with neuromuscular disorders. DMD = Duchenne's muscular dystrophy; SMA = spinal muscular atrophy; $\mathrm{FA}=$ Friedreich's ataxia; $\mathrm{MG}=$ myasthenia gravis; $\mathrm{CM}=$ congenital myopathy; $\mathrm{PM}=$ poliomyelitis; $\mathrm{SHD}=$ scapulo-humoral dystrophy; $\mathrm{CP}=$ complete paraplegia; $\mathrm{KD}=$ Kugelberg's dystrophy; $\mathrm{SD}=$ spastic diplegia; $\mathrm{CW}_{\mathrm{W}}=$ chest wall compliance; $\mathrm{C}_{\mathrm{L}}=$ lung compliance; $\mathrm{RW}_{\mathrm{W}}=$ chest wall resistance. Scoliosis: $+^{1}=$ scoliosis corrected by spondylodesis. 


\begin{tabular}{|c|c|c|c|c|c|c|c|c|c|c|c|c|c|c|c|}
\hline $\begin{array}{l}\text { Patient } \\
\text { no. }\end{array}$ & Age & Sex & Diagnosis & Scoliosis & $\begin{array}{c}\text { RV } \\
\% \text { pred }\end{array}$ & $\begin{array}{c}\text { RV } \pi \text { TLC } \\
\%\end{array}$ & $\begin{array}{c}\text { IVC } \\
\% \text { pred }\end{array}$ & $\begin{array}{c}\text { FRC } \\
\% \text { pred }\end{array}$ & $\begin{array}{c}\mathrm{FEV}_{1} \\
\% \text { pred }\end{array}$ & $\begin{array}{l}\mathrm{Pl}_{\max } \\
\mathrm{kPa}\end{array}$ & $\begin{array}{c}\mathrm{PE}_{\max } \\
\mathrm{kPa}\end{array}$ & $\begin{array}{c}\text { Rrss } \\
\mathrm{kPa} / \mathrm{s}\end{array}$ & $\begin{array}{l}\text { Rrs28 } \\
\mathrm{KPa} / \mathrm{ls}\end{array}$ & $\begin{array}{c}\text { Xrs8 } \\
\mathrm{kPa} / \mathrm{s}\end{array}$ & $\begin{array}{l}10 \\
\mathrm{~Hz}\end{array}$ \\
\hline 1 & 25 & $M$ & DMD & +1 & 95 & 59 & 21 & 51 & 25 & 1.0 & 1.5 & 0.350 & 0.530 & -0.115 & 10.31 \\
\hline 2 & 14 & $M$ & DMD & + & 89 & 40 & 37 & 62 & 27 & 2.2 & 1.6 & 0.807 & 0.726 & -0.161 & 10.64 \\
\hline 3 & 13 & $M$ & DMD & + & 91 & 26 & 71 & 77 & 69 & 6.0 & 4.0 & 0.478 & 0.612 & -0.035 & 9.43 \\
\hline 4 & 15 & $M$ & DMD & + & 115 & 32 & 66 & 72 & 66 & 5.4 & 3.2 & 0.250 & 0.401 & 0.028 & 7.04 \\
\hline 5 & 7 & $F$ & SMA & + & 178 & 43 & 64 & 111 & 63 & 3.5 & 2.5 & 0.590 & 0.658 & -0.281 & 15.23 \\
\hline 6 & 19 & $F$ & FA & +1 & 108 & 36 & 68 & 76 & 64 & 4.0 & 3.4 & 0.305 & 0.351 & -0.032 & 10.64 \\
\hline 7 & 15 & $\mathbf{F}$ & SHD & - & 150 & 35 & 75 & 101 & 67 & 2.0 & 1.5 & 0.390 & 0.395 & -0.031 & 9.67 \\
\hline 8 & 26 & $\mathbf{F}$ & MG & - & 90 & 31 & 75 & 90 & 79 & 5.0 & 4.0 & 0.304 & 0.387 & -0.063 & 10.97 \\
\hline 9 & 13 & $F$ & SMA & +1 & 70 & 56 & 15 & 36 & 15 & 4.0 & 2.0 & 0.463 & 0.586 & -0.119 & 11.90 \\
\hline 10 & 17 & $F$ & $\mathrm{CM}$ & $+^{1}$ & 147 & 57 & 31 & 80 & 30 & 2.6 & 2.5 & 0.351 & 0.419 & -0.068 & 12.44 \\
\hline 11 & 16 & $F$ & SMA & - & 114 & 31 & 80 & 95 & 77 & 4.8 & 6.8 & 0.315 & 0.442 & -0.006 & 7.92 \\
\hline 12 & 19 & $M$ & DMD & + & 146 & 56 & 34 & 88 & 39 & 2.8 & 2.2 & 0.160 & 0.208 & -0.025 & 9.20 \\
\hline 13 & 52 & $F$ & SMA & + & 85 & 62 & 31 & 68 & 35 & 2.4 & 1.6 & 0.268 & 0.389 & -0.071 & 10.40 \\
\hline 14 & 60 & $F$ & SMA & + & 70 & 26 & 128 & 83 & 121 & 3.5 & 6.0 & 0.343 & 0.359 & -0.053 & 13.41 \\
\hline 15 & 16 & $M$ & DMD & - & 126 & 40 & 52 & 74 & 44 & 5.4 & 5.0 & 0.292 & 0.375 & 0.009 & 7.51 \\
\hline 16 & 18 & $F$ & SMA & + & 91 & 37 & 56 & 66 & 59 & 2.0 & 3.5 & 0.358 & 0.420 & -0.068 & 10.22 \\
\hline 17 & 42 & $M$ & SMA & +1 & 140 & 73 & 20 & 83 & 18 & 4.2 & 1.6 & 0.584 & 0.560 & -0.042 & 9.63 \\
\hline 18 & 68 & $\mathrm{~F}$ & PM & . & 91 & 59 & 49 & 85 & 46 & 1.4 & 1.0 & 0.419 & 0.405 & 0.012 & 7.77 \\
\hline 19 & 16 & $M$ & DMD & - & 119 & 29 & 81 & 85 & 91 & 5.4 & 4.0 & 0.279 & 0.449 & 0.048 & 6.58 \\
\hline 20 & 61 & $M$ & SMA & - & 81 & 34 & 82 & 88 & 83 & 5.6 & 5.6 & 0.467 & 0.267 & -0.188 & 21.28 \\
\hline 21 & 46 & $F$ & SMA & + & 96 & 26 & 141 & 124 & 141 & 11.6 & 10.8 & 0.234 & 0.310 & 0.003 & 7.93 \\
\hline 22 & 13 & $F$ & $\mathrm{CP}$ & + & 123 & 52 & 35 & 68 & 34 & 5.0 & 4.0 & 0.470 & 0.464 & -0.092 & 12.23 \\
\hline 23 & 50 & $\mathrm{~F}$ & KD & . & 102 & 45 & 66 & 88 & 67 & 5.8 & 3.2 & 0.309 & 0.289 & -0.048 & 10.57 \\
\hline 24 & 20 & $\mathrm{~F}$ & SMA & . & 73 & 21 & 97 & 84 & 97 & 7.6 & 9.2 & 0.393 & 0.381 & -0.030 & 10.47 \\
\hline 25 & 37 & $\mathbf{F}$ & SD & - & 92 & 30 & 93 & 105 & 91 & 3.6 & 4.2 & 0.484 & 0.552 & -0.034 & 9.52 \\
\hline 26 & 30 & $M$ & $K D$ & + & 191 & 65 & 32 & 115 & 35 & 6.4 & 3.0 & 0.371 & 0.379 & -0.037 & 11.27 \\
\hline 27 & 72 & $M$ & PM & + & 67 & 55 & 48 & 61 & 37 & 2.0 & 3.0 & 0.228 & 0.221 & -0.074 & 17.66 \\
\hline Mean & 29.6 & & & & 108.9 & 42.8 & 61.0 & 82.1 & 60.0 & 4.27 & 3.74 & 0.380 & 0.427 & -0.058 & 10.81 \\
\hline SD & 19.4 & & & & 32.5 & 14.4 & 31.3 & 19.4 & 31.2 & 2.24 & 2.33 & 0.136 & 0.127 & 0.070 & 3.21 \\
\hline
\end{tabular}


flow. The system calculates an impedance value for each of the investigated frequencies. To filter out disturbing signals produced by the breathing of the subject, an ensemble averaging is performed during $8 \mathrm{~s}$. Accordingly, the obtained impedance values are averaged over the same period, covering several breathing cycles. A coherence function is calculated for each of the frequencies as a criterium for the validity of the measurements. A perfect coherence is indicated by 1.0 , which means a complete absence of noise and alinearities in the obtained signals. Only those values with a coherence function $\geq 0.95$ are retained. Under these circumstances the error of the measurements is smaller than $10 \%$.

The impedance $(Z)$ of the respiratory system (rs) is partitioned into a resistance $(R)$ and a reactance $(X)$. The resistance corresponds with the total resistance in a resistance-inductance-capacitance $(R-L-C)$ circuit. The total resistance of the respiratory system is considered the sum of 3 resistances in series: the resistance of the central airways, the resistance of the peripheral airways and the resistance of the chest wall. The reactance depends on the compliant and inertial properties of the system: a negative reactance is found at lower frequencies since at lower frequencies the reactance is mainly determined by the capacitance of the system. At higher frequencies the reactance is influenced predominantly by the inertial qualities of the air in the airways ${ }^{11}$. The reactance then becomes positive. The frequency at which the reactance equals zero is called the resonant frequency $\left(f_{0}\right)$.

Values for $R$ at $8 \mathrm{~Hz}\left(R_{\mathrm{rs} 8}\right)$ and at $28 \mathrm{~Hz}\left(R_{\mathrm{rs} 28}\right)$, of $X$ at $8 \mathrm{~Hz}\left(X_{\mathrm{rs} 8}\right)$, of resonant frequency $\left(f_{0}\right)$, and of the frequency dependence (FD) of resistance were used for the study. FD was defined as $R_{\mathrm{r} 228}$ minus $R_{\mathrm{rs} 8}$ divided by 20 . This value stands for the slope of the resistance versus frequency curve. The values of three measurements were averaged to be used in the study.

Maximum inspiratory and expiratory mouth pressures were obtained using the method described by Black and Hyatt ${ }^{12}$. $P_{1, \max }$ and $\mathrm{P}_{\mathrm{E}, \max }$ were measured in triplicate. The highest (expiratory) and lowest (inspiratory) values were recorded. The values for $\mathrm{P}_{\mathrm{I}, \max }$ were expressed as a positive number.

In all instances, the impedance measurements preceded spirometry and the measurements of respiratory muscle strength. Linear regressions were calculated between the findings of spirometry and maximum mouth pressures and between spirometry and the impedance parameters.

\section{Results}

In all patients the spirometric, mouth pressure, and impedance measurements could be easily performed while the patients remained seated in their wheelchair. 
In Table 1, the physical characteristics and the indices of respiratory impedance, maximum mouth pressures, and ventilatory function are listed. For the total group, reduced values for IVC and FRC are found. Mean IVC as a percentage of predicted was 61.0 percent \pm 31.3 percent and mean FRC was 82.1 percent \pm 19.4 percent. The $F E V_{1}$ was 60.0 percent \pm 31.2 percent of predicted. The mean baseline $\mathrm{FEV}_{1}$ was $1.94 \pm 0.97 \mathrm{l}$; after inhalation of terbutaline mean $\mathrm{FEV}_{1}$ was $1.93 \pm 0.96 \mathrm{l}$. Residual volume (RV) averaged $108.9 \pm 32.5$ percent of predicted and the mean RV/TLC ratio was $42.8 \pm 14.4$ percent. As is shown in Table 1 , muscle strength varied widely; mean $\mathrm{P}_{\mathrm{I} \text {,max }}$ was $4.27 \pm 2.24 \mathrm{kPa}$ and $\mathrm{P}_{\mathrm{E}, \max }$ was $3.74 \pm 2.33 \mathrm{kPa}$. The mean $\mathrm{P}_{\mathrm{I}, \max } / \mathrm{P}_{\mathrm{E}, \max }$ ratio averaged $1.14 \pm 0.36$. $R_{\mathrm{rs} 8}(0.380 \pm 0.136 \mathrm{kPa} / \mathrm{l} / \mathrm{s})$ was found to be lower than $R_{\mathrm{rs} 28}(0.427 \pm 0.127$ $\mathrm{kPa} / \mathrm{l} / \mathrm{s}$ ) and thus a positive value for the frequency dependence of resistance was found. Mean reactance at $8 \mathrm{~Hz}\left(X_{\mathrm{rs}}\right)$ was $-0.058 \pm 0.070 \mathrm{kPa} / \mathrm{l} / \mathrm{s}$ and the resonant frequency averaged $10.81 \pm 3.21 \mathrm{~Hz}$.

Correlations between $\mathrm{FEV}_{1}$ and IVC and the various impedance parameters were not statistically significant $(\mathrm{p}>0.05)$.

Table 2 lists the coefficients of correlation between the results of spirometry and the maximum respiratory pressures in our patients. A strong correlation was found between $\mathrm{FEV}_{1}$ as a percentage of predicted and $\mathrm{PE}_{\mathrm{E} \text {, max }}(\mathrm{r}=0.79, \mathrm{p}<$ 0.0001 ) and an equally strong correlation was found between the IVC (percent predicted) and $\mathrm{PE}_{\mathrm{E}, \max }$. Correlations between $\mathrm{P}_{\mathrm{E} \text {,max }}$ en $\mathrm{P}_{\mathrm{I} \text {,max }}$ and total lung capacity and functional residual capacity were slightly lower, but still highly significant $(\mathrm{p}<0.001)$. A highly significant correlation was found between the RV/TLC ratio and $P_{E, \max }(r=-0.67, p<0.0001)$, but as is shown in Figure 1 , an even better logarithmic fit to the data was observed $(r=0.71, p<0.0001$ ). Furthermore, a strong correlation was calculated between $\mathrm{PE}_{\mathrm{E}, \max }$ and $\mathrm{FEV}_{1}(\mathrm{r}=$ $0.79, \mathrm{p}<0.0001$ ).

Table 2:

Correlation coefficients between maximal mouth pressures and spirometric indices.

\begin{tabular}{lllllll}
\hline & & \multicolumn{2}{c}{ Pe max } & & \multicolumn{2}{c}{ Pi max } \\
\cline { 3 - 4 } \cline { 6 - 7 } & & \% & p & & r & p \\
\hline IVC & \%pred & 0.79 & $* * *$ & & 0.56 & $* *$ \\
FEV1 & \%pred & 0.79 & $* * *$ & & 0.59 & $* *$ \\
TLC & \%pred & 0.57 & $* *$ & & 0.57 & $* *$ \\
FRC & \%pred & 0.34 & $*$ & & 0.45 & $* *$ \\
RV/TLC & $\%$ & 0.67 & $* * *$ & & 0.45 & $* *$ \\
\hline
\end{tabular}

${ }^{*}=p \leq 0.01 ; * *=0.001<p \leq 0.01 ; * * *=0.0001<p \leq 0.001$ 


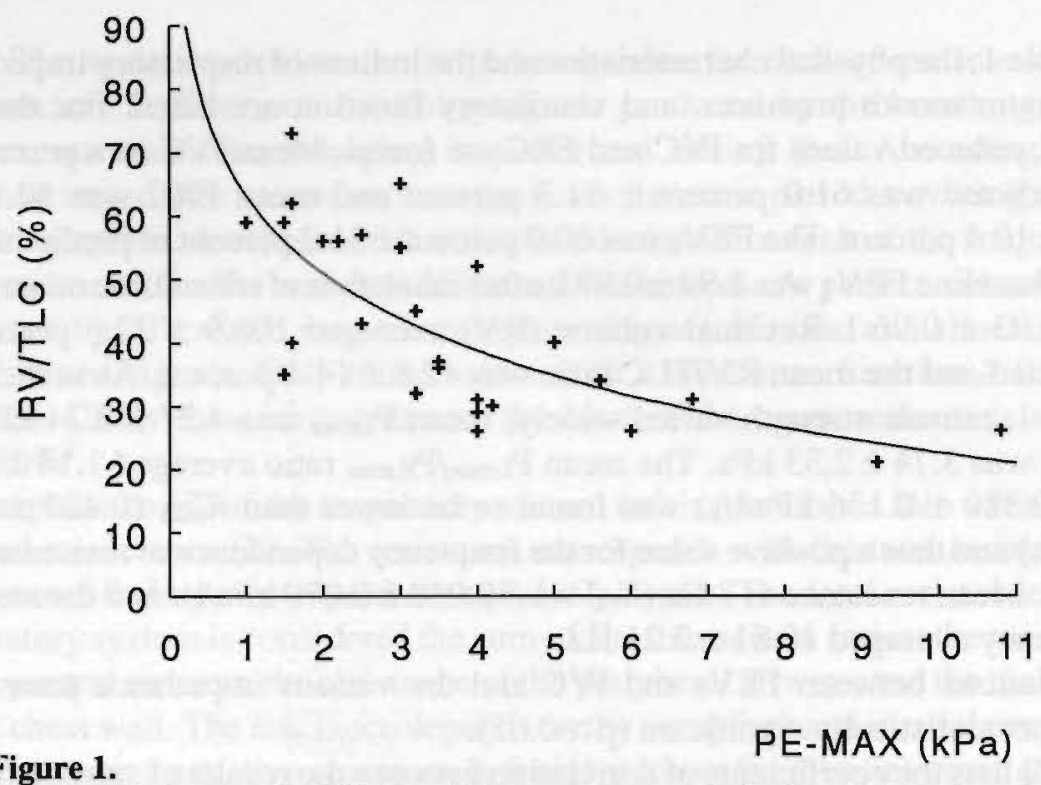

Figure 1.

Relationship between RV/TLC and $\mathrm{P}_{\mathrm{E} \text {,max }}$. The curve is the logarithmic fit to the data $(r=-0.71, p<0.0001)$.

\section{Discussion}

We have studied the oscillatory mechanics of the respiratory system in combination with maximum mouth pressures and spirometry in 27 patients with various neuromuscular disorders. The oscillatory mechanics were studied by means of the forced oscillation technique. The measurements require neither forced respiratory manoeuvres nor active cooperation from the subject, and the data related to the mechanical properties of the respiratory system can be collected rapidly in a noninvasive way. Indeed, all measurements could be performed in the severely disabled persons in our study without difficulties, with the subjects seated in their wheelchair.

When applying the technique of forced oscillations in these patients, it was observed that the resistance of the respiratory system increased slightly with increasing frequency. Also, a marginally negative value for $X_{\mathrm{rs}}$ at $8 \mathrm{~Hz}$ was observed, while resonant frequency was within the normal range. Thus, in these patients with severe neuromuscular weakness, respiratory impedance vs frequency curves are similar to those found in normal subjects. Clément et al ${ }^{13}$ reported that in normal subjects, the oscillatory resistance increases with increasing frequency, whereas reactance is negative only at lower frequencies and becomes positive at frequencies between 8 and $10 \mathrm{~Hz}$. In patients with airflow 
obstruction, however, resistance is higher at lower frequencies and decreases with increasing frequencies. This phenomenon is called negative frequency dependence of resistance. In these patients, reactance remains negative up to higher frequencies, usually between 20 and $24 \mathrm{~Hz}$, or sometimes as high as 38 $\mathrm{Hz}$ in severe COPD ${ }^{14}$.

It should be kept in mind that this normal impedance vs frequency pattern observed in our study, is found in the presence of moderate to severe kyphoscoliosis in the majority of our patients. This is contrary to findings reported by Van Noord $e t a l^{15}$. These investigators analysed the respiratory impedance in patients with kyphoscoliosis and a severe restrictive lung function impairment. They found a negative frequency dependence of resistance and much higher values for resonant frequency than was found in our study. Using an electric analog of the respiratory system, including the upper airways, the intrathoracic airways (including compliance and resistance of the airway walls), lung alveoli, compressibility, and the chest wall, Van Noord et $a^{15}$ concluded that changes in chest wall mechanics play an important role in the impedance values in kyphoscoliosis. A satisfactory fit was possible in the kyphoscoliosis group when chest wall tissue resistance was increased to $0.6 \mathrm{kPa} / \mathrm{l} / \mathrm{s}$ and chest wall compliance decreased to $0.08 \mathrm{l} / \mathrm{kPa}$; lung compliance was $0.9 \mathrm{l} / \mathrm{kPa}$ in that calculation. This resistance of the chest wall $\left(R_{\mathrm{W}}\right)$ is very much higher than is found in normal subjects and in patients with COPD: the value measured by Nagels $e t$ $a l^{16}$ was $0.054 \mathrm{kPa} / \mathrm{s}$. Similar values were reported by Grimby et $a l^{17}$ and by Sharp $e t \mathrm{al}^{18}$. In normal subjects, Nagels $e t \mathrm{al}^{16}$ measured a value for chest wall compliance $(C \mathrm{w})$ of $0.45 \mathrm{l} / \mathrm{kPa}$ : the proposed value for chest wall compliance by van Noord $e t \mathrm{al}^{15}$ is 40 times lower, and the value for $C_{\mathrm{W}}$ proposed by Nagels $e t$ $a l^{16}$ was already lower than found in most publications. Naimark and Cherniack $^{19}$ measured a value of $2.45 \mathrm{l} / \mathrm{kPa}$ in sitting position and $2.081 / \mathrm{kPa}$ in the supine position for $C \mathrm{~W}$. This value is comparable to that found by Sharp et $\mathrm{al}^{18}$. In younger persons, Mittman et $a l^{20}$ measured even higher values for $C_{\mathrm{W}}(4.75$ $1 / \mathrm{kPa})$ and a significant decrease in $C \mathrm{w}$ with age $(1.961 / \mathrm{kPa}$ for persons aged 70 to 79 years). A low value for the thoracic wall capacitance was also calculated by Dubois $e t a l^{8}(0.18 \mathrm{l} / \mathrm{kPa})$ and by Michaelson $e t a l^{21}$ : assuming a static lung compliance of $21 / \mathrm{kPa}$, these authors calculated an average $C \mathrm{w}$ of about $0.51 / \mathrm{kPa}$. Van Noord $e a^{15}$ explained this discrepancy in $C_{\mathrm{W}}$ values by the behaviour of the chest in oscillatory mechanics as a system, consisting of two compartments coupled in parallel: the rib-cage and the abdomen-diaphragm; the rib-cage, which is stiffer, should have a shorter time-constant than the diaphragm-abdomen.

The changes in lung mechanics in clinical disorders of the chest wall, for instance kyphoscoliosis, can be simulated by chest wall strapping in normal subjects. Van Noord $e t a l^{22}$ demonstrated an increase in $R_{\mathrm{rs}}$ at lower oscillatory frequencies between 4 and $14 \mathrm{~Hz}$, resulting in a negative frequency dependence 
of resistance. $X_{\mathrm{rs}}$ Was decreased at lower frequencies, resulting in an increase in resonant frequency from 6.3 to $10.6 \mathrm{~Hz}$. By partitioning total respiratory impedance into its pulmonary and chest wall components, these authors found an increase in $R_{\mathrm{w}}$ at lower frequencies, resulting in a more pronounced frequency dependence of $R_{\mathrm{w}}$ and a small increase in lung tissue resistance $\left(R_{\mathrm{L}}\right)$ mainly at lower frequencies. However, thoracic strapping only resulted in a twofold to threefold increase in $R_{\mathrm{w}}$ and a decrease in chest wall reactance to a minimal value of $-0.12 \mathrm{kPa} / \mathrm{l} / \mathrm{s}$. These values are markedly different from the data calculated by the same authors in the patients with kyphoscoliosis ${ }^{15}$. It is noticed that the changes in the static lung volumes were higher in the kyphoscoliosis patients. However, as demonstrated by De Troyer $e t a l^{2}$, thoracic strapping has a less pronounced stiffening effect on the chest at lower than at higher lung volumes.

A markedly decreased lung compliance $\left(C_{\mathrm{L}}\right)$ was measured in the patients with kyphoscoliosis by van Noord et $a l^{15}$. An average decrease in $C_{\mathrm{L}}$ of 40 percent was also found by De Troyer $e t a l^{2}$ in patients with respiratory muscle weakness, suggesting changes in the elastic properties of the lung. Comparable findings of a markedly reduced $C_{\mathrm{L}}$ in patients with respiratory muscle weakness were found by Gibson $e t a l^{5}$, and these authors pointed out that these changes were similar to those seen in normal subjects in whom chest wall expansion is prevented by means of strapping. However, by relating the slope of the pressure-volume (P-V) curve to the measured TLC, De Troyer $e t a l^{2}$ found a normal slope of the P-V curve, suggesting that in patients with long-standing respiratory muscle weakness, the largest number of the functioning alveoli retain their normal elastic properties. During submaximal neuromuscular blockade, De-Troyer and Bastenier-Geens ${ }^{23}$ found that weakness of the respiratory muscles is not associated with alterations in surface forces in spite of the associated low breathing volume and does not directly influence the elastic properties of the lung. Baydur ${ }^{4}$ recently reported an increase in the elastance of the respiratory system $\left(E_{\mathrm{rs}}\right)$ of 79 percent in patients with neuromuscular disease: he also concluded that the increase in $E_{\mathrm{rs}}$ was proportional to the loss of lung volume rather than to intrinsic abnormalities.

The changes in static lung volumes observed in our group of patients with neuromuscular disease are comparable with the changes observed after rib-cage strapping ${ }^{22}$. Based on these data of van Noord et $a l^{22}$, a normal respiratory impedance pattern in the measured frequency range of 8 to $28 \mathrm{~Hz}$ as found in our study can be expected. When the increase in the thoracic wall resistance is proportional to the decrease in chest wall compliance, the time constant of the rib-cage will remain unchanged and no increase in the difference in time-constants between the rib-cage and the diaphragm-abdomen will be observed. Thus, frequency dependence of resistance will not be found. 
Slightly increased resistance values are found in our patients. Previously it has been reported that specific airway conductance is within the normal range or slightly above the normal upper limit in patients with neuromuscular disease ${ }^{2}$. In the absence of time constant inhomogenenities, total respiratory resistance will be determined by airway resistance, tissue resistance, and chest wall resistance. An increase in lung tissue resistance was observed after chest wall strapping ${ }^{22}$. The influence on chest wall resistance was discussed above.

Reduced maximum respiratory pressures and reduced lung volumes as measured with spirometry are a common finding in patients with neuromuscular disease, and the values for $\mathrm{P}_{1, \max }$ and $\mathrm{P}_{\mathrm{E}, \max }$ measured with the technique described by Black and Hyatt ${ }^{1,12}$ and for the spirometric values found in our patients are in keeping with those published by others ${ }^{1-5,24,25}$. Inspiratory muscle weakness may result in hypoventilation and expiratory weakness interferes with coughing ${ }^{26}$. The ratio $\mathrm{P}_{\mathrm{I}, \max } / \mathrm{P}_{\mathrm{E}, \max }$ represents the relative effectiveness of the inspiratory and expiratory musculature. In normal subjects, a value of 0.5 is reported $^{3}$. The mean $P_{1, \max } / \mathrm{P}_{\mathrm{E} \text {, } \max }$ ratio of $1.14 \pm 0.36$ in our patients with neuromuscular disease was much higher, indicating a more pronounced loss of expiratory muscle strength in these patients. This is consistent with the findings of others, in patients with Duchenne's dystrophy and myotonic dystrophy ${ }^{26}$, and myasthenia gravis ${ }^{27}$.

Braun et $a l^{3}$ found that in patients with proximal myopathies, the deficit in respiratory muscle strength was evenly distributed between inspiratory and expiratory muscles. Despite the reduced lung volumes, an increase in RV is observed, indicating inability of the impaired expiratory musculature to exhale below FRC resulting in a loss in expiratory reserve volume. A strong curvilinear correlation was calculated between RV/TLC and $P_{E, m a x}$. A similar relationship has been described previously ${ }^{3,28}$. From the strong correlations between spirometric and mouth pressure values found in this and earlier studies ${ }^{2,3}$, it can be assumed that the lung volume abnormalities in patients with neuromuscular disease reflect reduced respiratory muscle strength rather than airflow obstruction.

In summary, we conclude from our study that impedance measurements of the respiratory system using the technique of forced oscillations allow the demonstration of normal relationships between resistance and reactance of the respiratory system and the frequencies of the forced oscillations indicating the absence of airflow limitation resulting from bronchus obstruction, even in the presence of impaired respiratory muscle strength, gross thoracic wall abnormalities, and reduced lung volumes. Forced oscillometry is therefore a helpful tool in the assessment of lungfunction and the exclusion of airflow obstruction in patients with neuromuscular disorders when body plethysmography is difficult to perform, and spirometric data reflect muscle weakness rather than airflow limitation. 


\section{References}

1. Black LF, Hyatt RE.

Maximal static respiratory pressures in generalized neuromuscular disease.

Am Rev Respir Dis 1971; 103: 641-650.

2. De Troyer A, Borenstein S, Cordier R.

Analysis of lung volume restriction in patients with respiratory muscle weakness. Thorax 1980; 35: 603-610.

3. Braun NMT, Arora NS, Rochester DF.

Respiratory muscle and pulmonary function in polymyositis and other proximal myopathies.

Thorax 1983; 38: 616-623.

4. Baydur A.

Respiratory muscle strength and control of ventilation in patients with neuromuscular disease.

Chest 191; 99: 330-338.

5. Gibson GJ, Pride NB, Newsom-Davis J, Loh LC.

Pulmonary mechanics in patients with respiratory muscle weakness.

Am Rev Respir Dis 1977; 115: 389-395.

6. Saunders KB.

Clinical Physiology of the lung.

Oxford: Blackwell Scientific Publications, 1977: 6-41.

7. Stubbs SE, Hyatt RE.

Effect of increased lung recoil pressure on maximal expiratory flow in normal subjects.

J Appl Physiol 1975; 39: 325-331.

8. Dubois AB, Brody AW, Lewis DH, Burgess BF Jr.

Oscillation mechanics of lungs and chest in man.

J Appl Physiol 1956; 8: 587-594.

9. Làndsér FJ, Nagels J, Demedts M, Billiet L, Van de Woestijne KP.

A new method to determine frequency characteristics of the respiratory system.

J Appl Physiol 1976; 41: 101-106.

10. Quanjer PH ed.

Standardized lung function testing.

Bull Eur Physiopath Respir 1983; 19 (suppl. 5): 7-44.

11. Wouters EFM.

Total respiratory impedance measurements by forced oscillations: a noninvasive method to assess bronchial response in occupational medicine.

Experimental lung research 1990; 16: 25-40.

12. Black LF, Hyatt RE.

Maximal respiratory pressures: normal values and relationship to sex and age.

Am Rev Respir Dis 1969; 99: 686-702.

13. Clément J, Làndsér FJ, Van de Woestijne KP.

Total respiratory resistance and reactance in patients with respiratory complaints with and without airways obstruction.

Chest 1983; 2: 215-220. 
14. Wesseling GJ, Mostert R, Wouters EFM.

A comparison of the effects of anticholinergic and 2-agonist and combination therapy on respiratory impedance in COPD.

Chest 1992; 101: 166-173.

15. Van Noord JA, Cauberghs M, Van de Woestijne KP, Demedts $M$.

Total respiratory resistance and reactance in ankylosing spondylitis and kyphoscoliosis. Eur Respir J 1991; 4: 945-951.

16. Nagels J, Làndsér FJ, Van der Linden L, Clément J, Van de Woestijne KP. Mechanical properties of lung and chest wall during spontaneous breathing. J Appl Physiol 1980; 49: 408-416.

17. Grimby G, Takishima T, Graham W, Macklem P, Mead J.

Frequency dependence of flow resistance in patients with obstructive lung disease.

J Clin Invest 1968; 47: 1455-1465.

18. Sharp JT, Henry JP, Sweany SK, Meadows WR, Pietras RY.

The total work of breathing in normal and obese man.

J Clin Invest 1964; 43: 728-739.

19. Naimark A, Chemiack RM.

Compliance of the respiratory system and its components in health and obesity.

J Appl Physiol 1960; 15: 377- 382.

20. Mittman C, Edelman NH, Narri AH, Shock NW.

Relationship between chest wall and pulmonary compliance and age.

J Appl Physiol 1965; 20: 1211-1216.

21. Michaelson ED, Grassman ED, Peters WR.

Pulmonary mechanics by spectral analysis of forced random noise.

J Clin Invest 1975; 56: 1210-1230.

22. Van Noord JA, Demedts M, Clément J, Cauberghs M, Van de Woestijne KP.

Effect of ribcage and abdominal restriction on total respiratory resistance and reactance.

J Appl Physiol 1986; 61: 1736-1740.

23. De Troyer A, Bastenier-Geens J.

Effects of neuro-muscular blockade on respiratory mechanics in conscious man.

J Appl Physiol 1979; 47: 1162-1163.

24. Rideau Y, Jankowski LW, Grellet J.

Respiratory function in the muscular dystrophies.

Muscle Nerve 1981; 4: 144-164.

25. Griggs RC, Donohœe KM, Utell MJ, Goldblatt D, Moxley RT.

Evaluation of pulmonary function in neuromuscular disease.

Arch Neurol 1981; 38: 9-12.

26. O’Donohue WJ, Baker JP, Bell GM, Muren O, Parker CL, Patterson JL.

Respiratory failure in neuromuscular disease.

JAMA 1976; 235: 733-735.

27. Ringqvist I, Ringqvist $T$.

Respiratory mechanics in untreated myasthenia gravis with special reference to the respiratory forces.

Acta Med Scand 1971; 190: 499-508.

28. Kreitzer SM, Saunders NA, Tyler HR, Ingram RH.

Respiratory muscle function in amyotrophic lateral sclerosis.

Am Rev Respir Dis 1978; 117: 437-447. 


\section{Chapter IV}

\section{The forced oscillation technique and spirometry in cold air provocation tests.}

G.J. Wesseling

I.M.L. Vanderhoven-Augustin

E.F.M. Wouters 


\title{
The forced oscillation technique and spirometry in cold air provocation tests.
}

\begin{abstract}
Background. Impedance measurements by means of the forced pseudo-random noise oscillation technique can be used to study the mechanical characteristics of the respiratory system. The objective of our study was to analyse the changes in impedance to a cold air provocation test in patients with asthma and to correlate these changes with those in the forced expiratory volume in one second $\left(\mathrm{FEV}_{1}\right)$.
\end{abstract}

Methods. In 60 patients with bronchial asthma ( $\mathrm{PD}_{20 \mathrm{FEV}, \text { histamine }} \leq 8.0 \mu \mathrm{mol}$ ), the response to isocapnic hyperventilation with cold air was assessed with respiratory impedance measurements and with spirometry.

Results. Cold air provocation resulted in a fall in $\mathrm{FEV}_{1}$ from $3.75(0.85)$ l to 3.10 (0.90) 1 . The mean decrease in $\mathrm{FEV}_{\mathrm{l}}$ as a percentage of predicted was 15.4 (3.8)\%. The oscillatory resistance at $8 \mathrm{~Hz}$ increased from $0.367(0.108) \mathrm{kPa} / \mathrm{l} / \mathrm{s}$ to $0.613(0.213) \mathrm{kPa} / \mathrm{l} / \mathrm{s}$ and the resistance at $28 \mathrm{~Hz}$ increased from $0.348(0.088)$ to $0.403(0.099) \mathrm{kPa} / \mathrm{l} / \mathrm{s}$. Frequency dependence of resistance became significantly more negative. The reactance at $8 \mathrm{~Hz}$ decreased from $-0.035(0.041)$ $\mathrm{kPa} / \mathrm{l} / \mathrm{s}$ to $-0.234(0.199) \mathrm{kPa} / \mathrm{l} / \mathrm{s}$, and the resonant frequency increased from 12.5 (4.9) $\mathrm{Hz}$ to $25.7(9.1) \mathrm{Hz}$. Significant correlations were calculated between the decrease in $\mathrm{FEV}_{1}$ and the changes in the various impedance parameters; especially between the decrease in $\mathrm{FEV}_{1}$ and the increase in resistance at $8 \mathrm{~Hz}(\mathrm{r}=$ $-0.66)$, and the decrease in $\mathrm{FEV}_{1}$ and the increase in the resonant frequency $(r=$ -0.63 ).

Conclusion. Cold air provocation in asthmatic subjects results in changes in the impedance of the respiratory system that correlate well with the changes in $\mathrm{FEV}_{\mathrm{l}}$. These changes in impedance reflect ventilatory inhomogeneities in the peripheral compartment of the bronchial tree. These observations demonstrate the value of this technique in the evaluation of induced bronchoconstriction, as not only a quantitative, but also a qualitative analysis of the response is possible. 


\section{Introduction}

Bronchial hyperresponsiveness is one of the key elements in the pathogenesis of asthma, and the assessment of bronchial hyperresponsiveness has become an important diagnostic tool in the lung function laboratory. Bronchial hyperresponsiveness can be assessed using a variety of methods. The forced expiratory volume in one second $\left(\mathrm{FEV}_{1}\right)$ is generally used as an index of the response in bronchial challenge tests ${ }^{1}$. However, spirometry is effort-dependent, requiring a full inspiratory manoeuvre which may influence bronchial tone ${ }^{2}$, and hence affect the outcome of bronchial provocation tests.

The measurement of the impedance of the respiratory system with the technique of forced oscillations ${ }^{3}$ has the benefit of being effort-independent, and it requires little or no cooperation from the patient. The method may therefore be well suited to provocation testing. Due to the use of modern computer techniques, the technique can now be easily implemented and the impedance of the respiratory system can be determined over a wide frequency range in a short period of time. The technique has been used in bronchial challenge tests by several investigators ${ }^{4-10}$. Only a few studies have provided comparisons of absolute changes in spirometric values and impedance data in induced bronchoconstriction ${ }^{4,5,7,11,12}$. The purpose of the present study was to evaluate the data obtained with the technique of forced oscillations in a provocation test with isocapnic hyperventilation with cold air in patients with bronchial asthma with documented bronchial hyperresponsiveness and to correlate these data with spirometric indices.

\section{Materials and methods}

\section{Subjects}

We studied 60 asthmatic subjects (35 male) with a mean age of 27.9 (10.7) yrs. All subjects had a characteristic history of recurrent attacks of dypnoea with perceptible wheezing. Mean (SD) forced expiratory volume in one second $\left(\mathrm{FEV}_{\mathrm{l}}\right.$ ) was 3.7 (0.9) 1 (97.2 (14.6)\% of predicted). All patients had evidence of bronchial hyperresponsiveness, reflected by a provocative dose of histamine, resulting in a $20 \%$ fall in $\mathrm{FEV}_{1}\left(\mathrm{PD}_{20}\right) \leq 8 \mu \mathrm{mol}$. Before the study all medication was withheld and short-acting inhaled bronchodilators were stopped at least eight hours before the provocation test.

Before provocation all subjects had to have an $\mathrm{FEV}_{\mathrm{I}}>70 \%$ of the reference values $^{13}$. 


\section{Experimental design}

Cold air challenge tests were performed using a heat exchanger (Jaeger G.M.B.H., Würzburg, Germany). The subjects inhaled dry air delivered from a cylinder. The temperature of the air leaving the cooling system was $-20^{\circ} \mathrm{C}$. The flow of air could be adjusted by a needle valve and was measured by a rotameter. The patients were instructed to breathe at a predetermined ventilation rate of $60 \%$ of the predicted indirect maximum breathing capacity ${ }^{14}$, by maintaining the size of a guide balloon. To avoid hypocapnia, $\mathrm{CO}_{2}$ was added to the system at a rate of $5 \%$ of the predetermined minute ventilation. Hyperventilation was sustained for 3 minutes, after quiet breathing into the system for 1 minute. FEV 1 was determined using a wet spirometer (Gould Pulmonet $\mathrm{UI}^{\circledR}$ ). The best value of 3 successive measurements was used in the statistical analysis.

The impedance of the respiratory system was measured using the technique of forced oscillations ${ }^{3.15}$ (see chapter $\mathrm{MI}$ ).

Three successive impedance and spirometric measurements were performed before and 1 minute after the cold air challenge, with the impedance measurements always preceeding forced expirations.

\section{Data analysis}

With the forced pseudo-random noise oscillation technique the frequency dependent behaviour of the respiratory system can be measured simultaneously at different frequencies. The differences between the response of the system to low and high frequencies allow the division of the mechanical characteristics into a central and a peripheral compartment. As a representation of low frequencies 8 $\mathrm{Hz}$ was chosen. The impedance at $4 \mathrm{~Hz}$ could not been used in our analysis as at this frequency the coherence coefficient was below 0.95 too often. To represent higher frequencies $28 \mathrm{~Hz}$ was chosen. Several investigators have demonstrated that at frequencies above 24 to $28 \mathrm{~Hz}$ the negative frequency dependence of resistance disappears ${ }^{5,15}$.

Thus, the resistance at low $(8 \mathrm{~Hz})$ and high $(28 \mathrm{~Hz})$ frequencies, the reciprocal value of the resistance at $8 \mathrm{~Hz}$, the reactance at $8 \mathrm{~Hz}$ and the resonant frequency (frequency at which $X$ equals zero) were studied. The slope of the resistance versus frequency curve is represented by the equation: $\mathrm{FD}=R_{28}-R_{8} / 20$.

Values of $\mathrm{FEV}_{1}$ and impedance before and after provocation were compared using Student's paired $t$ tests and coefficients of correlation (Spearman's) between $\mathrm{FEV}_{1}$ as a percentage of predicted and the various impedance measures were calculated. P-values lower than 0.05 were considered statistically significant. 


\section{Results}

Table 1 lists the values for $\mathrm{FEV}_{1}$, both in absolute values and as percentage of predicted, and the values for the various impedance data used in the analysis, before and after the cold air challenge tests. Mean FEV $(\mathrm{SD})$ decreased from $3.75(0.85) 1$ to $3.10(0.90)$ l ( $p<0.001)$. The mean decrease in $F^{2} V_{1}$ as a percentage of predicted was $15.4 \%$, the mean decrease as percentage of the baseline values was $16.8 \%(\mathrm{p}<0.001)$.

Statistically significant increases were observed in the resistance at $8 \mathrm{~Hz}$ from $0.367(0.108) \mathrm{kPa} / \mathrm{l} / \mathrm{s}$ to $0.613(0.213) \mathrm{kPa} / \mathrm{l} / \mathrm{s}$ and at $28 \mathrm{~Hz}$ from $0.348(0.089)$ $\mathrm{kPa} / \mathrm{l} / \mathrm{s}$ to $0.403(0.099) \mathrm{kPa} / \mathrm{l} / \mathrm{s}(\mathrm{p}<0.001)$. Frequency dependence of resistance (FD) decreased from $-0.00095(0.0037) \mathrm{kPa} / \mathrm{l} / \mathrm{s}$ to $-0.010(0.0077) \mathrm{kPa} / \mathrm{l} / \mathrm{s}(\mathrm{p}<$ $0.001)$. The reactance at $8 \mathrm{~Hz}$ decreased from $-0.035(0.041) \mathrm{kPa} / \mathrm{l} / \mathrm{s}$ to -0.234 $(0.199) \mathrm{kPa} / \mathrm{l} / \mathrm{s}(\mathrm{p}<0.001)$, with an increase in resonant frequency from 12.5 (4.9) $\mathrm{Hz}$ to $25.7(9.1) \mathrm{Hz}(\mathrm{p}<0.001)$.

Figures 1-4 show the relation between the changes in the forced expiratory volume in one second as a percentage of predicted $\left(\triangle \mathrm{FEV} \mathrm{F}_{1}\right)$ and in the various impedance parameters. Significant inverse correlations were found between the decrease in $\mathrm{FEV}_{1}$ and the increase in the resistance at $8 \mathrm{~Hz}(\mathrm{r}=-0.656, \mathrm{p}<0.001)$ and between the decrease in $\mathrm{FEV}_{1}$ and the increase in resonant frequency $(\mathrm{r}=$ $-0.630, \mathrm{p}<0.001)$. Correlations between $\triangle \mathrm{FEV}_{1}$ and the increase in the resistance at $28 \mathrm{~Hz}(\mathrm{r}=-0.458, \mathrm{p}<0.001)$, and between $\Delta F E V_{1}$ and the decrease in the reactance at $8 \mathrm{~Hz}(\mathrm{r}=0.538, \mathrm{p}<0.001)$ were also significant. There was a significant correlation between the decrease in the frequency dependence of resistance and the decrease in $\mathrm{FEV}_{1}(\mathrm{r}=0.596, \mathrm{p}<0.001)$.

\section{Table 1:}

Values (SD) of forced expiratory volume in 1 second in litres (FEV1 l) and as a percentage of predicted (FEV1 \%pred.) and impedance values before and after isocapnic hyperventilation with cold air (IHCA). All comparison p 0.001.

\begin{tabular}{|c|c|c|c|c|c|}
\hline & \multicolumn{2}{|c|}{ Before IHCA } & \multicolumn{2}{|c|}{ After IHCA } \\
\hline & & Mean & SD & Mean & $\mathrm{SD}$ \\
\hline FEV1 & (l) & 3.75 & 0.85 & 3.10 & 0.90 \\
\hline FEV1 & (\%pred.) & 97.2 & 14.6 & 81.8 & 19.3 \\
\hline Resistance at $8 \mathrm{~Hz}$ & $(\mathrm{kPa} / \mathrm{l} / \mathrm{s})$ & 0.367 & 0.108 & 0.613 & 0.213 \\
\hline Resistance at $28 \mathrm{~Hz}$ & $(\mathrm{kPa} / \mathrm{l} / \mathrm{s})$ & 0.348 & 0.089 & 0.403 & 0.099 \\
\hline Reactance at $8 \mathrm{HZ}$ & $(\mathrm{kPa} / \mathrm{l} / \mathrm{s})$ & -0.035 & 0.041 & -0.234 & 0.199 \\
\hline Resonant frequency & $(\mathrm{Hz})$ & 12.5 & 4.9 & 25.7 & 9.1 \\
\hline Frequency dependence & $(\mathrm{kPa} / \mathrm{l} / \mathrm{s})$ & -0.00095 & 0.0037 & -0.010 & 0.0077 \\
\hline
\end{tabular}




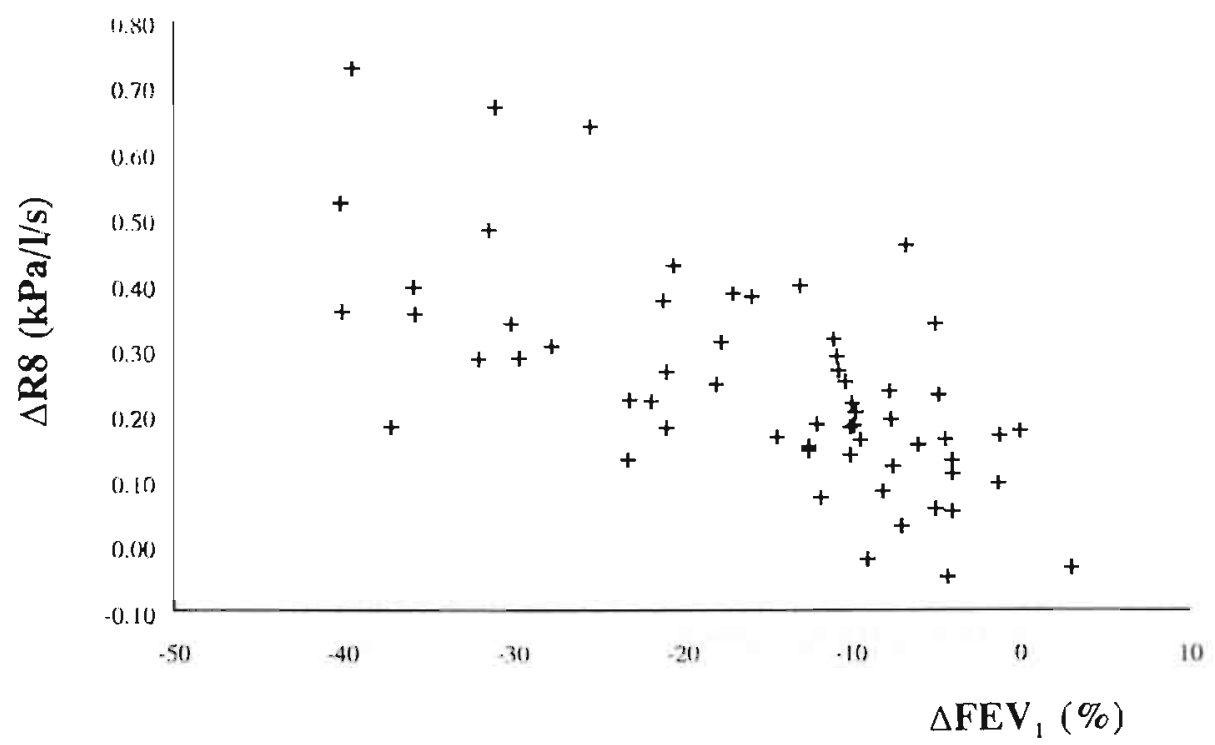

Figure 1:

Relationship between the increase in the resistance at $8 \mathrm{~Hz}\left(\Delta R_{8}\right)$ and the decrease in FEV 1 $\left.(\triangle \mathrm{FEV})_{1}\right)$ as \% from baseline after cold air provocation in 60 patients with asthma $(r=-0.656$, $\mathrm{p}<0.001)$.

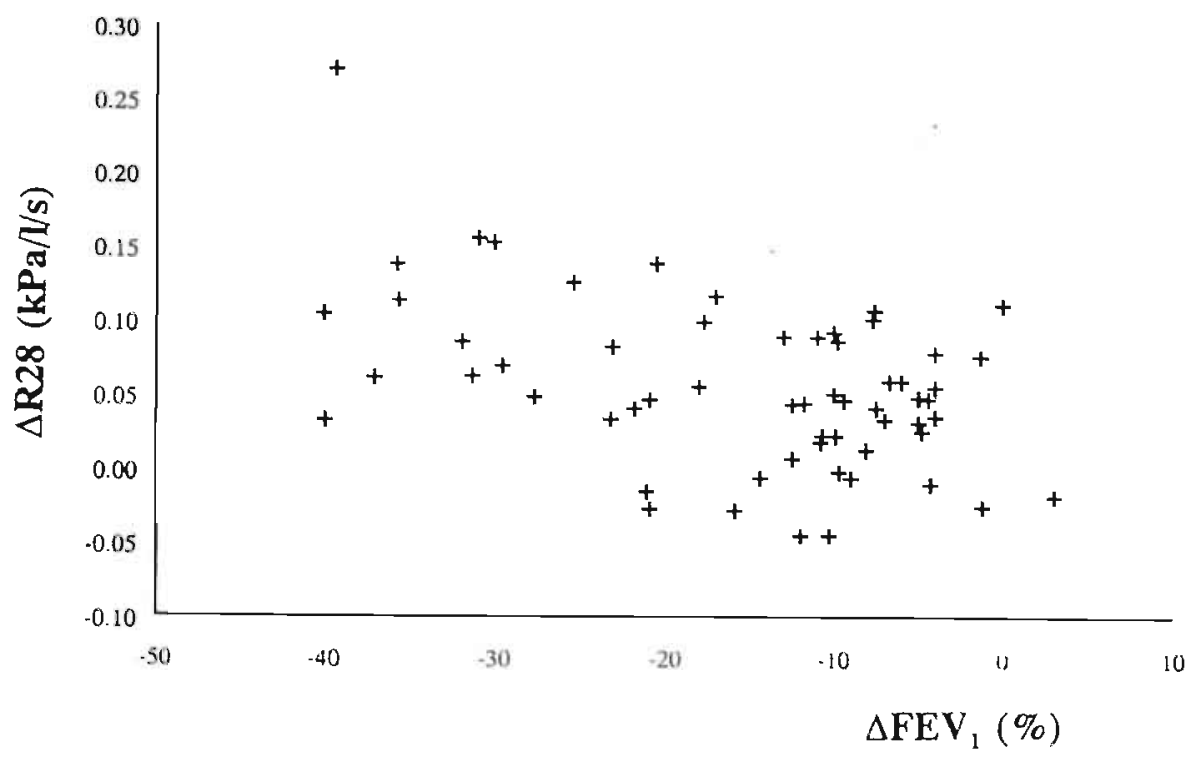

Figure 2:

Relationship between the increase in the resistance at $28 \mathrm{~Hz}\left(\Delta R_{28}\right)$ and the decrease in FEV 1 $\left(\Delta F E V_{1}\right)(r=-0.458, p<0.001)$. 


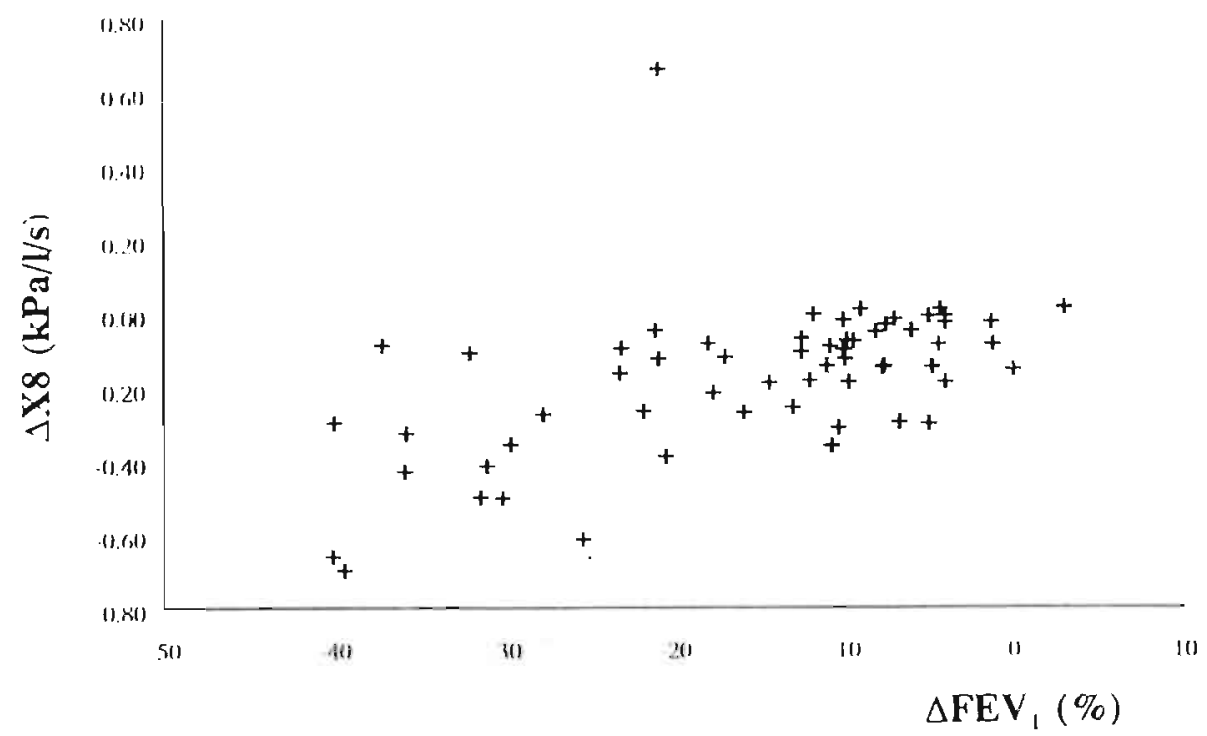

Figure 3:

Relationship between the reactance at $8 \mathrm{~Hz}\left(\Delta X_{8}\right)$ and the decrease in $\mathrm{FEV}_{1}\left(\Delta \mathrm{FEV}_{1}\right)(\mathrm{r}=$ $0.538, \mathrm{p}<0.001)$.

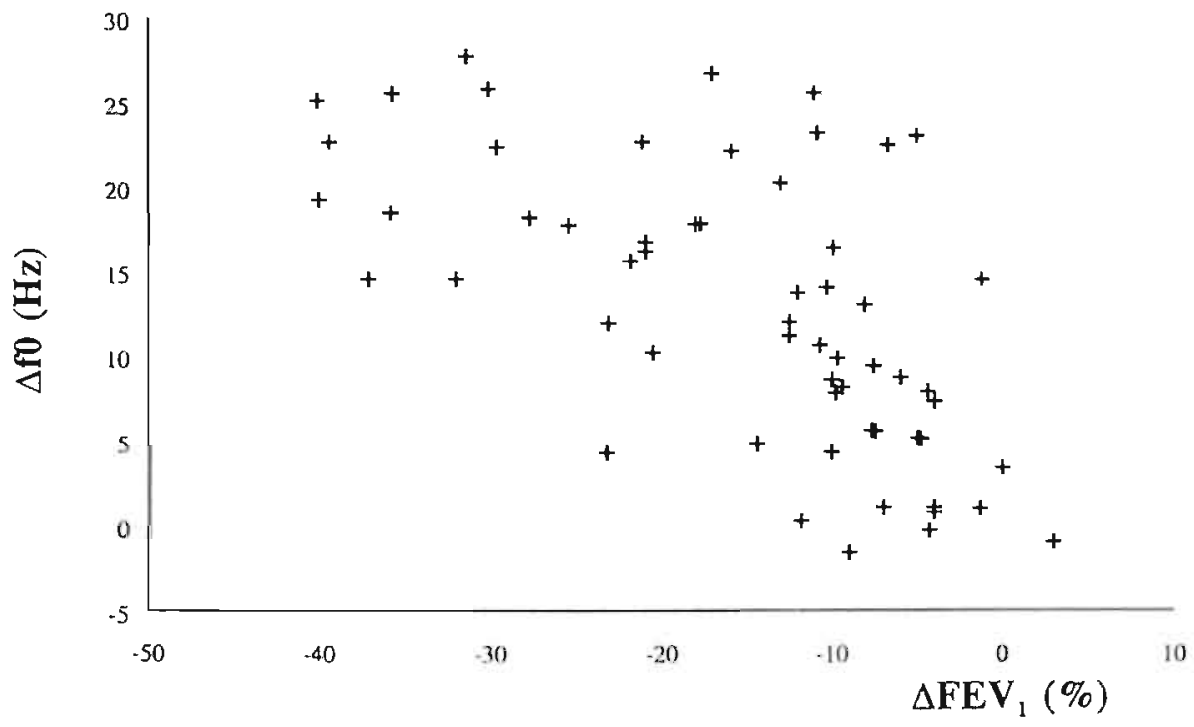

Figure 4:

Relationship between the increase in resonant frequency $\left(\Delta f_{0}\right)$ and the decrease in FEV $\left(\Delta \mathrm{FEV}_{1}\right)(\mathrm{r}=-0.630, \mathrm{p}<0.001)$. 


\section{Discussion}

In this study on the effects of isocapnic hyperventilation with cold air in 60 patients with bronchial asthma, we used the technique of forced oscillations and spirometry to measure the response of the respiratory system. Respiratory impedance measurements form a unique, noninvasive and effort-independent method for the assessment of the response to bronchoprovocating stimuli, providing insight into their pathophysiological effects on the respiratory system. An important advantage of the technique of forced oscillations is the fact that no forced respiratory manoeuvres are necessary for the measurements. Therefore, possible influences on bronchial tone are avoided ${ }^{2}$. In a recent study by Wilson et $\mathrm{al}^{16}$, the effects of forced expiratory manoeuvres on the outcome of bronchial provocation testing have been clearly demonstrated. These authors compared the response to methacholine challenge in normal subjects on 2 separate days, on one day impedance and $\mathrm{FEV}_{1}$ were measured, on the second day only impedance measurements were performed. No plateau was seen on the non$F E V_{1}$ day, despite a mean fall in FEV 1 of $46 \%$. On the non-FEV 1 day the increase in the resistance at $6 \mathrm{~Hz}$ was far greater than on the FEV 1 day. It was concluded from this study that forced expiratory manoeuvres as used in spirometry persistently reduce the bronchoconstrictor effect of methacholine. This could in part explain the plateau seen in other studies on bronchial challenge testing.

The sensitivity of the technique of forced oscillations in detecting induced bronchoconstriction has been evaluated by several authors $5,6,8,11,17,18$. Van Noord et $a l^{6}$ concluded that the forced oscillation technique is a sensitive indicator of induced changes in airway calibre. The reciprocal of the oscillatory resistance at $6 \mathrm{~Hz}$ was found to be a suitable index with a sensitivity intermediate between that of specific airway conductance ( $\mathrm{s} G \mathrm{aw}$ ) using a bodyplethysmograph, and $F E V_{1}$. Yet, response evaluation measuring $s G$ aw, allows only a quantitative assessment of the response, whereas the technique of forced oscillations provides not only a sensitive method for diagnosing induced bronchoconstriction, but also for a qualitative analysis of the response.

In our study, provocation with cold air hyperventilation resulted in an increase in the resistance of the respiratory system especially at lower frequencies and thus frequency dependence of resistance became highly negative. Also, reactance decreased, resulting in a marked increase in resonant frequency.

These changes in the impedance of the respiratory system are consistent with the findings of Clement et al ${ }^{19}$ in patients with airflow obstruction. These investigators compared the frequency dependence of the total respiratory resistance and reactance in patients with airflow obstruction to healthy subjects and reported that resistance decreases with increasing frequency and that the reactance is more negative in patients, resulting in increased values for resonant frequency. 
Similar findings in respiratory impedance have been described in induced bronchoconstriction. $^{5-8,11}$. The increase in resistance especially at lower frequencies, the decrease in resistance with increasing frequency and the more negative values of reactance can be explained by airway obstruction extending to the peripheral airways according to Mead's two-compartment lung model where two parallel units are represented by the expansible airways and the air spaces $^{20}$. In the presence of an increase in peripheral airway resistance inclusion of airway compliance into the lung model will result in negative frequency dependence of resistance. Nagels $e t a l^{21}$ measured the resistance and reactance of the respiratory system in healthy subjects and in patients with COPD. These authors found that in healthy subjects as well as in patients the chest wall had a low resistance which decreased with frequency and increased with decreasing lung volume. They concluded that the observed frequency dependence of resistance and the simultanous increase in resonant frequency can be simulated satisfactorily by Mead's two-compartment model ${ }^{20}$ assuming a large increase in peripheral airway resistance.

Our results are in agreement with the findings of Decramer $e t a l^{7}$. Analogous changes in impedance have been reported after provocation with various other stimuli, both in children and in adults, in particular histamine $e^{6,9-11,22}$, methacholine $^{20,23-25}$, carbachol $^{8}$, exercise ${ }^{26}$, and after allergen provocation ${ }^{4,27}$. This observation suggests that the response is independent of the type of stimulus used.

Cold air hyperventilation leads to cooling of the mucosa of the airways and hyperosmolarity of the periciliary fluid. It is known that beyond the 14th airway generation the surface area of the respiratory mucosa is thought to be sufficient to humidify the inspired air in cold air hyperventilation ${ }^{28,29}$. Therefore it is understandable how this stimulus leads to obstruction extending to the peripheral compartment of the bronchial tree ${ }^{30}$.

In our study significant correlations were found between the changes in impedance and the changes in $\mathrm{FEV}_{1}$. Significant correlations between forced expiratory flow and oscillometric impedance values have been reported by various investigators.

Wouters $e t a l^{31}$ found correlation coëfficients between frequency dependence of resistance and resonant frequency on the one hand and the forced vital capacity and $\mathrm{FEV}_{1}$ on the other ranging from 0.492 to 0.668 . Similar values were reported by Peslin $e t a l^{32}$.

In histamine challenge tests in children, even stronger correlations between $\mathrm{FEV}_{1}$ and impedance were reported by Lebècque et $a l^{33}$, especially for resistance at lower frequencies and for frequency dependence of resistance. A possible explanation for the somewhat weaker correlations between the changes in $F E V_{1}$ and in frequency dependence of resistance and resonant frequency found in our study may be that provocation results in air trapping and thus in an increase in the functional residual capacity. Nagels $e t a l^{21}$ demonstrated that at 
higher lung volumes the resistance decreases and the reactance increases resulting in a decrease in resonant frequency and lessening of the frequency dependence of resistance. In a study by Van den Elshout $e t a l^{26}$ on exercise-induced bronchoconstriction, correlations ranging from 0.46 to 0.89 were found between the changes in impedance and in flow-volume data.

In contrast with the findings of others ${ }^{6.33}$, use of the reciprocal value of the resistance at $8 \mathrm{~Hz}$ did not result in stronger correlations between the changes in impedance and in $\mathrm{FEV}_{1}$.

In this study, patients with bronchial asthma of wide-ranging severity, were challenged by isocapnic hyperventilation with cold air. The same provocative dose was used in all subjects. In view of the moderate response in terms of the decrease in $\mathrm{FEV}_{\mathrm{l}}$, isocapnic hyperventilation with cold air can be considered a safe method in provocation studies.

We conclude that isocapnic hyperventilation with cold air in asthmatics results in a decrease in $\mathrm{FEV}_{\mathrm{l}}$ and an increase in oscillatory resistance especially at lower frequencies, a decrease in reactance at $8 \mathrm{~Hz}$ and an increase in resonant frequency of the respiratory system as measured with the technique of forced oscillations. The changes in the impedance of the respiratory system correlate well with the changes in $\mathrm{FEV}_{1}$, and represent an inhomogeneity in the peripheral compartment of the bronchial tree.

These observations demonstrate the value of adding this technique to the evaluation of the response of the respiratory system to bronchoconstricting stimuli, since, compared with forced expiration indices and body plethysmography, it is possible to partition the results into central and peripheral airway components. 


\section{References}

1. Eiser NM, Kerrebijn KF, Quanjer PH.

Guidelines for standardisation of bronchial challenges with (nonspecific) bronchoconstricting agents.

Bull Eur Physiopathol Respir 1983; 19:495-514.

2. Gayrard P, Orehek J, Grimaud C, Charpin J.

Bronchoconstrictor effects of a deep inspiration in patients with asthma.

Am Rev Respir Dis 1975; 111:433-439.

3. Dubois $A B$, Brody AW, Lewis DH, Burgess BF.

Oscillation mechanics of lungs and chest in man.

J Appl Physiol 1956; 8: 587-594.

4. Solymar L, Aronsson PH, Engström J, Bake B, Bjure J.

Forced oscillation technique and maximum expiratory flows in bronchial provocation tests in children.

Eur J Respir Dis 1984; 65: 486-495.

5. Wouters EFM, Polko AH, Schouten HJA, Visser BF.

Contribution of impedance measurement to bronchial challenge tests.

J Asthma 1988; 25: 259-267.

6. Van Noord JA, Clément J, Van de Woestijne KP, Demedts M.

Total respiratory resistance and reactance as a measurement of response to bronchial challenge with histamine.

Am Rev Respir Dis 1989; 139: 921-926.

7. Decramer M, Demedts M, Van de Woestijne KP.

Isocapnic hyperventilation with cold air in healthy non-smokers, smokers and asthmatic subjects.

Bull Eur Physiopathol Respir 1984; 20: 237-243.

8. Chinet T, Pelle G, Macquin-Mavier I, Lorino H, Harf A.

Comparison of the dose-response curves obtained by forced oscillation and plethysmography during carbachol inhalations.

Eur Respir J 1988; 1:600-605.

9. Tjwa MKT, Smeets JJ, Janssen LPJ, Maessen FPV.

Measurement of the non-specific threshold stimulus for the bronchial tree by continuous monitoring of respiratory resistance using the oscillation method.

Respiration 1985; 48: 1-11.

10. Snashall PD, Parker S, Ten Haave P, Simmons D, Noble MIM.

Use of an impedance meter for measuring airways responsiveness to histamine.

Chest 1991; 99: 1183-1185.

11. Duiverman EJ, Neijens HJ, Van der Snee-van Smaalen M, Kerrebijn KF.

Comparison of forced oscillometry and forced expirations for measuring dose-related responses to inhaled histamine in asthmatic children.

Bull Eur Physiopathol Respir 1986; 22: 433-436.

12. Kabiraj MU, Rolf C, Simonsson BG.

Drug-induced changes in airway obstruction reflected by forced expiratory flows and airway resistance measured with an oscillation method using quiet breathing.

Respiration 1981; 41: 215-220. 
13. Quanjer PH. (ed).

Standardized lung function testing.

Bull Eur Physiolpathol Respir Suppl. 1983; 19(suppl.5): 7-10.

14. Assoufi BK, Dally MB, Newman-Taylor AJ, Denison DM.

Cold air test: a simplified standard method for airway reactivity.

Bull Eur Physiopathol Respir 1986; 22: 349-357.

15. Làndsér FJ, Nagels J, Demedts M, Billiet L, Van de Woestijne KP.

A new method to determine frequency characteristics of the respiratory system.

J Appl Physiol 1976; 41: 101-106.

16. Wilson $M$, Phagoo SB, Silverman $M$.

$\mathrm{FEV}_{1}$ manoeuvres persistently attenuate the response to methacholine challenge in normal subjects.

Am Rev Respir Dis 1991; 143: A410.

17. Pimmel RL, Fullton JL, Ginsberg JF, Hazucha MJ, Haak ED, McDonnell WF, Bromberg PA.

Correlation of airway resistance with forced random noise resistance parameters.

J Appl Physiol 1981; 51: 33-39.

18. Neild JE, Twort CHC, Chinn S, McCormack S, Jones TD, Bumey PGJ, Cameron IR.

The repeatability and validity of respiratory resistance measured by the forced oscillation technique.

Respir Med 1989; 83:111-118.

19. Clément J, Làndsér FJ, Van de Woestijne KP.

Total resistance and reactance in patients with respiratory complaints with and without airways obstruction.

Chest 1983; 2: 215-220.

20. Mead J.

Contribution of compliance of airways to frequency-dependent behaviour of lungs.

J Appl Physiol 1969; 26: 670-673.

21. Nagels J, Làndsér FJ, Van der Linden L, Clément J, Van de Woestijne KP.

Mechanical properties of lung and chest wall during spontaneous breathing.

J Appl Physiol 1980; 49: 408-416.

22. Wouters EFM, Polko AH, Visser BF.

Response localisation of the pharmacological agents histamine and salbutamol along the respiratory system by forced oscillations in asthmatic subjects.

J Asthma 1989; 26: 185-193.

23. Manço JC, Hyatt RE, Rodarte JR.

Respiratory impedance in normal humans: Effects of bronchodilation and bronchoconstriction.

Mayo Clin Proc 1987; 62:487-497.

24. Duiverman EJ, Neijens HJ, van Strik R, van der Snee-van Smalen M, Kerrebijn K.F.

Bronchial responsiveness in asthmatic children aged 3 to 8 years measured by forced pseudo-random noise oscillometry.

Bull Eur Physiopathol Respir 1986; 22: 27-34.

25. Wilson NM, Phagoo SB, Silverman M.

Use of transcutaneous oxygen tension, arterial oxygen saturation, and respiratory resistance to assess the response to inhaled methacholine in asthmatic children and normal adults.

Thorax 1991; 46: 433-437. 
26. Van den Elshout F, Van Herwaarden C, Molema J, Folgering $\mathbf{H}$.

Exercise-induced bronchocontriction detected with the forced oscillation technique.

Am Rev Respir Dis 1990; 141 Suppl. A 834.

27. Feihl F, Badan M, Depeursinge F, Depeursinge C, Leuenberger P, Pecoud A, Perret C. Respiratory acoustical impedance: a new technique to measure airway response during bronchial inhalation challenges.

Ann Allergy 1988; 61: 263-268.

28. McFadden ER, Lenner KAM, Strohl KP.

Postexertional airway rewanning and thermally induced asthma. New insights into pathophysiology and possible pathogenesis.

J Clin Invest 1986; 78: 18-25.

29. Freed AN, Kelly LJ, Menkes HA.

Airflow-induced bronchospasm: imbalance between airway cooling and airway drying? Am Rev Respir Dis 1987; 136: 595-599.

30. Anderson SD.

Exercise-induced asthma: Stimulus mechanism and management In: asthma: basic mechanism and clinical management.

PJ Barnes, IW Rodger, NC Thomson.

Academic Press London 1988: 503-522.

31. Wouters EFM, Mostert R, Polko AH, Visser BF.

Forced expiratory flow and oscillometric impedance measurement in evaluating airway obstruction.

Respir Med 1990; 84: 205-209.

32. Peslin R, Hannhart B, Pino J.

Impedance méchanique thoraco-pulmaire chez des sujets fumeurs et non-fumeurs.

Bull Eur Physiopathol Respir 1983; 19: 7-10.

33. Lebecque P, Spier S, Lapierre J-G, Lamarre A, Zinman R, Coates AL.

Histamine challenge test in children using forced oscillation to measure total respiratory resistance.

Chest $1987 ; 92: 313-318$. 



\section{Chapter V}

\section{Analysis of respiratory impedance characteristics in chronic bronchitis.}

G.J. Wesseling

E.F.M. Wouters

Respiration 1992; 59: 81-88 


\title{
Analysis of respiratory impedance characteristics in chronic bronchitis.
}

\begin{abstract}
Impedance measurements of the respiratory system were performed by means of the technique of forced oscillations to study the mechanical characteristics of the respiratory system in 33 patients with chronic bronchitis without spirometric evidence of airway obstruction ( $F E V_{1} \geq 70 \%$ predicted).

In 23 patients (69.7\%) respiratory impedance was found to be abnormal. Inhalation of a beta 2 adrenergic drug (terbutaline) resulted in acute reversibility of these findings.

In the 10 patients (30.3\%) with a normal baseline impedance, isocapnic hyperventilation with cold air resulted in impedance characteristics similar to the abnormalities spontaneously occurring in the other group. These changes were found to be completely reversible after the inhalation of terbutaline.

On the basis of these findings we conclude that impedance measurements of the respiratory system by means of the technique of forced oscillations allow the determination of mechanical airway abnormalities in patients with chronic bronchitis.
\end{abstract}

\section{Introduction}

Chronic bronchitis is a commonly encountered disease entity in clinical practice. Chronic bronchitis is usually defined in clinical terms according to the criteria provided by the American Thoracic Society ${ }^{1}$. The condition occurs predominantly in cigarette-smokers but may be found in non-smokers as well. Airflow obstruction is thought by some to be a complication in chronic bronchitis. Fletcher and Peto ${ }^{2}$ reported that clinically significant airflow obstruction does not develop in most non-smokers and many smokers, but Campbell $e t a l^{3}$ have reported that the rate of decline in $\mathrm{FEV}_{1}$ was greater in patients with chronic bronchitis than in normal subjects. From a study on the long term prognosis of patients with severe or less severe chronic airflow obstruction, Postma and Sluiter ${ }^{4}$ concluded that smoking cessation and an early therapy directed at the reversible part of airflow obstruction may be able to prevent deterioration. 
A number of authors have reported on lung function findings in patients with chronic bronchitis and in asymptomatic cigarette-smokers with normal $\mathrm{FEV}_{1}$. Woolcock $e t a l^{5}$ demonstrated frequency dependence of compliance in subjects with biopsy evidence of small airway disease and with normal airway resistance and maximum expiratory flow rate. Ingram and O'Cain ${ }^{6}$ demonstrated small airway changes reflected by frequency dependence of compliance even in apparently healthy cigarette-smokers.

Frequency dependent behaviour of the respiratory system can also be analyzed by means of the technique of forced oscillations. This technique, introduced by Dubois et $\mathrm{al}^{7}$, enables the characterisation of the mechanical impedance of the respiratory system during spontaneous quiet breathing. Thanks to microcomputers these oscillations can now be easily implemented. A further advantage is the fact that these measurements do not require active cooperation from the subject. Several investigators ${ }^{8-11}$ have reported that the technique of forced oscillations is a sensitive tool in distinguishing healthy smokers and non-smokers from patients with airway obstruction and that frequency dependence of total resistance and the resonant frequency are sensitive indicators of early airflow obstruction that remains undetected by other lung function tests.

Others ${ }^{12,13}$ have found no differences in impedance data between smokers and non-smokers under basal conditions, but a marked frequency dependence of resistance and a significant decrease in reactance, the imaginary part of the impedance, after cold air provocation. Similar, but more pronounced changes have been reported in asthmatics after cold air challenge ${ }^{12,14}$.

The present study was carried out in order to determine the impedance of the respiratory system in a group of patients with symptoms of chronic bronchitis, without marked airway obstruction and to evaluate the acute changes of the respiratory impedance after inhalation of a beta 2 adrenergic drug in case baseline impedance data were abnormal, and to assess possible inducible changes in impedance after cold air provocation in patients with normal baseline impedance values. Furthermore, $\mathrm{FEV}_{1}$ and various impedance parameters and changes in

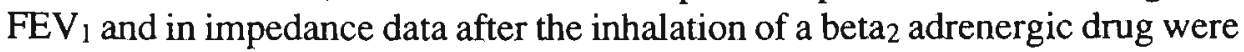
correlated. To our knowledge information on correlations between spirometry and impedance in patients with chronic bronchitis have not been presented before.

\section{Materials and methods}

\section{Selection of subjects}

We studied 33 patients, 19 male and 14 female, with a mean age of 50 years (range 30-68 years). All patients suffered from chronic bronchitis, defined as a history of chronic cough with or without expectoration of sputum for at least 3 
months during each of the last two years ${ }^{1}$. None of these patients complained of dyspnoea and all patients reported normal exercise tolerance. None of the patients had a history of asthma or allergic rhinitis, or of airway infections during the previous 6 weeks. 18 Patients were current smokers, all others were exsmokers. Only patients with a baseline $\mathrm{FEV}_{1} \geq 70 \%$ of the reference values ${ }^{15}$ were entered into the study. Mean FEV $\mathrm{F}_{1}$ of the total group was $95 \%$ of predicted (range $71-130 \%$ ).

\section{Study procedure}

After a wash-out period of one week during which all medication was stopped except for inhaled terbutaline used as required, baseline lungfunction data were obtained.

Impedance measurements were performed by means of the technique of forced oscillations introduced by Dubois $e t a l^{5}$, using a forced pseudo-random noise oscillation signal developed by Làndsér et al ${ }^{16,17}$. A description of this technique is presented in chapter III.

Three impedance measurements were performed consecutively, and an average was calculated.

To express the results 5 parameters were used: the total respiratory resistance $\left(R_{r s}\right)$ at $8 \mathrm{~Hz}$ and $28 \mathrm{~Hz}$, the respiratory reactance $\left(X_{\mathrm{rs}}\right)$ at $8 \mathrm{~Hz}$, the resonant frequency (the frequency at which reactance is zero), and the frequency dependence of resistance, defined as the ratio $R_{\mathrm{rs} 28}$ minus $R_{\mathrm{rs} 8}$ divided by 20 . A negative value for frequency dependence means a decrease in $R_{\mathrm{rs}}$ with increasing frequency.

Based on the impedance data subjects were divided into two groups: group A with normal baseline values $(n=10)$ and group $B$ with abnormal values $(n=23)$. Impedance was considered normal in case resonant frequency was $<16 \mathrm{~Hz}$ and frequency dependence $\geq 0^{11}$.

In group $\mathrm{A}$, a bronchial challenge test was performed by means of isocapnic hyperventilation with cold air at $60 \%$ of the predicted indirect maximum breathing capacity (IMBC), defined as $\mathrm{FEV}_{1}$ times 35 during 3 minutes. Next, reversibility of the induced changes in impedance was measured 15 minutes after the inhalation of $0.5 \mathrm{mg}$ terbutaline using a nebuhaler. When abnormal baseline impedance values were found (group B), the acute reversibility of these abnormalities was assessed 15 minutes after the inhalation of terbutaline. All measurements were performed at the same time of the day. Before the start of the procedure all subjects had been seated at room temperature for at least 15 minutes. In all instances, impedance measurements preceded spirometry. Impedance measurements are performed during spontaneous quiet breathing and require no forced expiratory manoeuvres, which can influence bronchial smooth muscle tone ${ }^{18}$.

Cold air challenge tests were performed using the method described in chapter IV. 
Spirometry was performed using a wet spirometer (Gould Pulmonet $\mathrm{III}^{\circ}$ ), the best of 3 consecutive measurements was retained.

\section{Statistical analysis}

All results shown are arithmetic means. Statistical analysis was performed using Student's $t$ test, paired or unpaired as appropriate. Linear regression analysis were performed between $\mathrm{FEV}_{1}$, both in absolute values and as a percentage of predicted, and the various impedance parameters, and between the changes in $\mathrm{FEV}_{1}$ and in the impedance values.

\section{Results}

All 33 patients completed the study. Anthropometric and baseline spirometric and impedance data are summarized in table 1 . Six patients of group $A$ and 11 patients of group B were current smokers. Ten patients (Group A) had normal baseline impedance values. 23 patients ( 7 female) had either a resonant frequency $\geq 16 \mathrm{~Hz}$ or frequency dependence of resistance $<0$ or both and were considered abnormal (Group B). Differences in all impedance parameters were highly significant between the 2 groups (table 1).

Table 1:

Anthropometric, spirometric and impedance values of patients with chronic bronchitis

\begin{tabular}{|c|c|c|c|c|c|c|}
\hline & \multicolumn{2}{|c|}{ Group A $(n=10)$} & \multicolumn{2}{|c|}{ Group $B(n=23)$} & \multirow{2}{*}{$\begin{array}{l}\text { p-values } \\
\text { A vs B }\end{array}$} \\
\hline & & Mean & SD & Mean & SD & \\
\hline Sex & $\mathrm{F} / \mathrm{M}$ & $7 / 3$ & & $7 / 16$ & & \\
\hline Age & $(\mathrm{yrs})$ & 46.9 & & 53.3 & & \\
\hline Height & (m) & 1.66 & & 1.67 & & \\
\hline Weight & $(\mathrm{kg})$ & 66.8 & & 81.3 & & \\
\hline FEV] & (1) & 2.98 & 0.83 & 2.70 & 0.51 & n.s. \\
\hline FEVl & $(\%)$ & 97.1 & 12.2 & 90.4 & 18.7 & $*$ \\
\hline $\mathrm{R}_{\mathrm{rs} 8}$ & $\mathrm{kPa} / \mathrm{l} / \mathrm{s}$ & 0.314 & 0.071 & 0.370 & 0.094 & $* * *$ \\
\hline$X_{\text {rs8 }}$ & $\mathrm{kPa} / \mathrm{l} / \mathrm{s}$ & -0.022 & 0.029 & -0.086 & 0.057 & $* * *$ \\
\hline $\mathrm{R}_{\mathrm{rs} 28}$ & $\mathrm{kPa} / \mathrm{l} / \mathrm{s}$ & 0.347 & 0.073 & 0.319 & 0.075 & $* * *$ \\
\hline$f_{0}$ & $\mathrm{~Hz}$ & 9.92 & 2.01 & 17.13 & 4.10 & $* * *$ \\
\hline FD & $\mathrm{kPa} / \mathrm{l} / \mathrm{s}$ & 0.0016 & 0.0019 & -0.0026 & 0.0024 & $* * *$ \\
\hline
\end{tabular}

Group $A(n=10)$, patients with normal baseline impedance values and group $B(n=23)$, patients with abnormal basline impedance values; n.s: not significant; *: $\mathrm{p} \leq 0.05$; *** $0.001<\mathrm{p} \geq 0.01$ 


\section{Table 2:}

Correlation coefficients between $\mathrm{FEV}_{1}$ both in litres and as a percentage of predicted and the resistance at $8 \mathrm{~Hz}\left(\mathrm{R}_{\mathrm{rs} 8}\right)$ and $28 \mathrm{~Hz}\left(\mathrm{R}_{\mathrm{rs} 28}\right)$, reactance at $8 \mathrm{~Hz}\left(\mathrm{X}_{\mathrm{rs} 8}\right)$, resonant frequency $\left(\mathrm{f}_{0}\right)$ and the frequency dependence of resistance $(F D, n=33)$.

\begin{tabular}{lcc}
\hline & FEV $_{1}(\mathrm{l})$ & FEV $_{1}(\%$ pred $)$ \\
\hline$R_{\text {rs8 }}$ & 0.028 & 0.163 \\
$R_{\text {rs28 }}$ & 0.150 & 0.374 \\
$X_{\text {rs8 }}$ & 0.191 & 0.026 \\
$f_{0}$ & -0.126 & -0.019 \\
FD & -0.149 & -0.227 \\
\hline
\end{tabular}

In table 2 the results of the correlation analysis between $\mathrm{FEV}_{1}$ and the various impedance parameters are summarized. Correlation coëfficients between $\mathrm{FEV}_{1}$ and $\mathrm{FEV}_{1} \%$ pred. and $R_{\mathrm{rs} 8}, R_{\mathrm{rs} 28}, X_{\mathrm{rs} 8}, f_{0}$ and $\mathrm{FD}$ ranged from 0.026 to 0.374 , and did not reach a level of significance.

Impedance data of the 10 patients in Group A before and after cold air provocation and subsequent inhalation of terbutaline are presented in figure 1 . After cold air challenge, $R_{\text {rs } 8}$ increased significantly ( $\mathrm{p}<0.05$ ) and reactance at $8 \mathrm{~Hz}$ became significantly more negative $(\mathrm{p}<0.05)$, and resonant frequency increased significantly. Changes in $R_{\mathrm{rs} 28}$ did not reach a statistically significant level. The slope of the $R_{\mathrm{rs}}$ vs frequency curve changed from positive before the challenge to negative, thus resistance became frequency dependent. All these changes were found to be fully reversible after the inhalation of terbutaline, and no significant differences were found between baseline values and values after terbutaline. Only a slight but statistically non-significant decrease in $\mathrm{FEV}_{1}$ as a $\%$ of predicted from 97.1 to 95.8 was found after the challenge procedure in this group of chronic bronchitis patients.

Figure 2 shows the impedance values of the 23 patients in Group B before and 15 minutes after the inhalation of $0.5 \mathrm{mg}$ terbutaline. Resistance at $8 \mathrm{~Hz}$ decreased significantly $(\mathrm{p}<0.01), X_{\mathrm{rs} 8}$ increased $(\mathrm{p}<0.01)$ and resonant frequency decreased $(p<0.01)$. Frequency dependence of resistance decreased but remained negative after the inhalation of terbutaline $(\mathrm{p}<0.001)$.

FEV $1 \%$ pred. increased significantly from 90.4 to 94.2 ( $p<0.01$ ), indicating some degree of acute reversibility. In all patients the increase in FEV, was less than $15 \%$ of baseline values.

In this group coëfficients of correlation were calculated between the changes in FEV 1 both in absolute values and as a percentage of predicted and the changes in the various parameters after the inhalation of terbutaline (table 3). Only the correlation between the increase in $\mathrm{FEV}_{1}$ (in litres) and the decrease in resonant frequency was statistically significant $(p<0.05)$. 

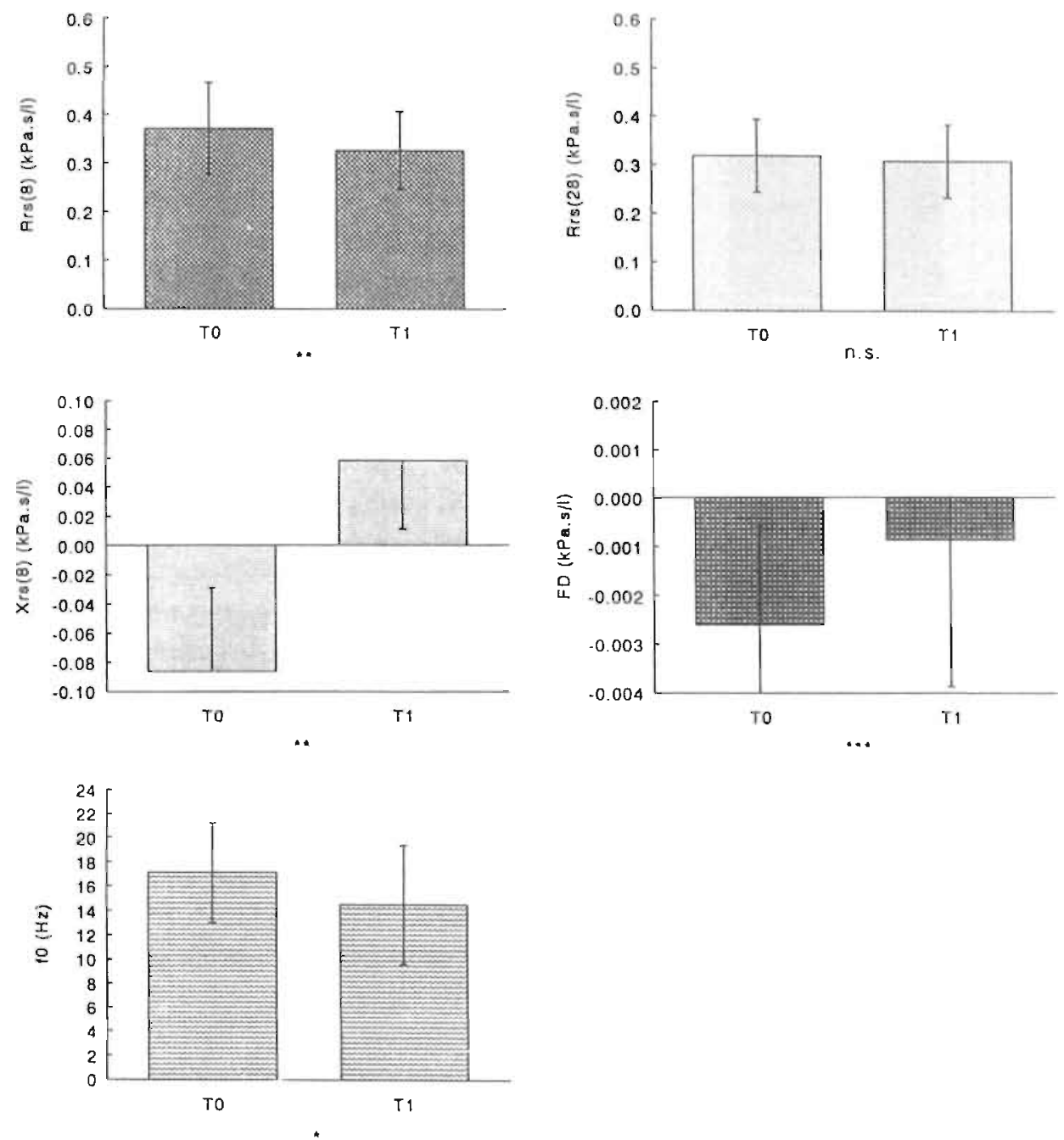

Figure 1:

Values for resistance at $8 \mathrm{~Hz}\left(R_{\mathrm{rs} 8}\right)$ and $28 \mathrm{~Hz}\left(R_{\mathrm{rs} 28}\right)$, reactance at $8 \mathrm{~Hz}\left(X_{\mathrm{rs} 8}\right)$ and frequency dependence of resistance $\mathrm{FD}$ in $\mathrm{kPa} / \mathrm{l} / \mathrm{s}$ and for resonant frequency $\left(f_{0}\right)$ in $\mathrm{Hz}$ before and after isocapnic hyperventilation with cold air, and after the inhalation of terbutaline in 10 patients with chronic bronchitis with normal baseline impedance values.

Levels of significance: * $p \leq 0.05 ; * * 0.01<p \leq 0.05 ; * * * 0.001<p \leq 0.01$ 

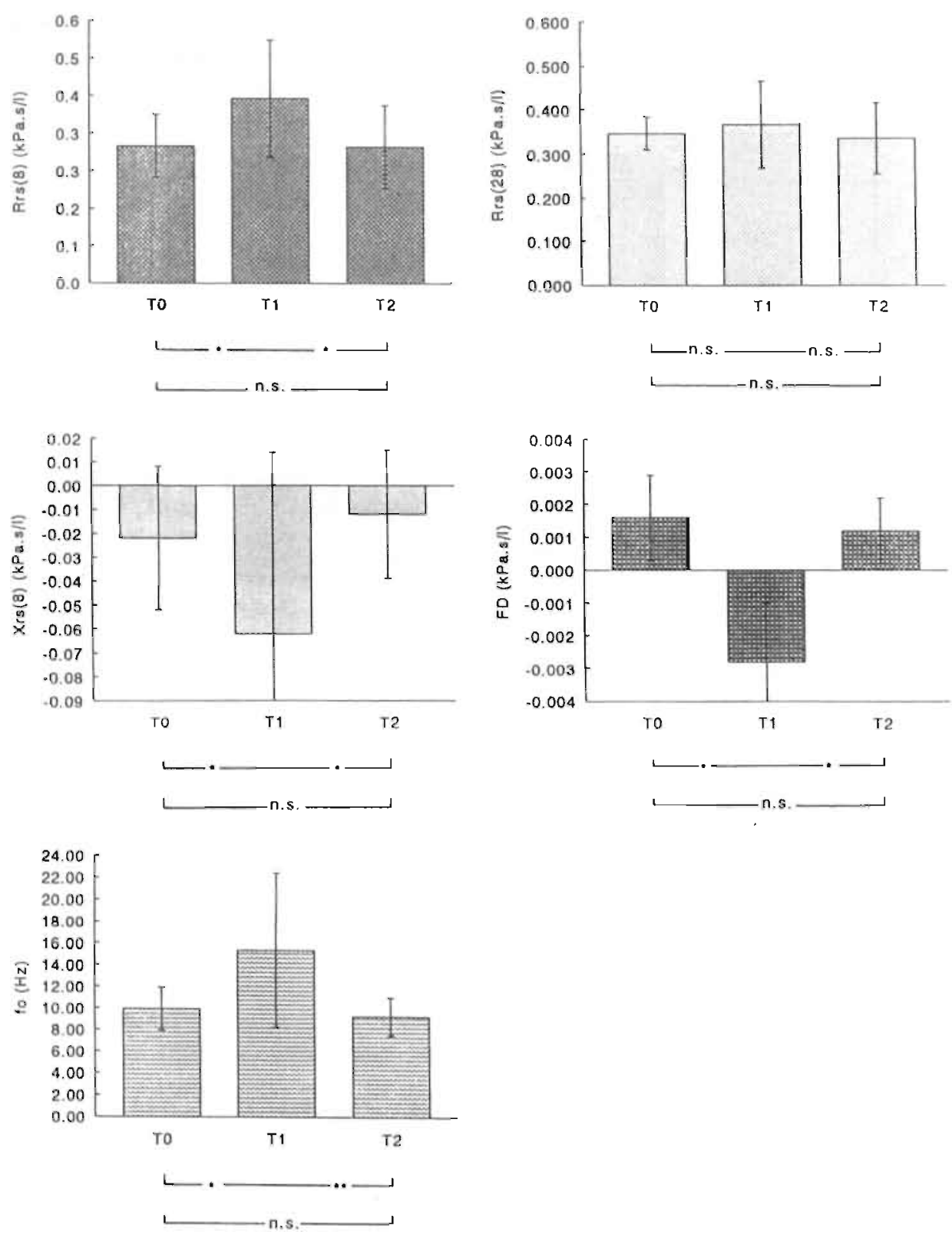

\section{Figure 2:}

Values for resistance at $8 \mathrm{~Hz}\left(R_{\mathrm{rS} 8}\right)$ and $28 \mathrm{~Hz}\left(R_{\mathrm{rs} 28}\right)$, reactance at $8 \mathrm{~Hz}\left(X_{\mathrm{rs} 8}\right)$ and frequency dependence of resistance FD in $\mathrm{kPa} / \mathrm{l} / \mathrm{s}$ and for resonant frequency $\left(f_{0}\right)$ in $\mathrm{Hz}$ before and after the inhalation of terbutaline in 23 patients with chronic bronchitis with abnomal baseline impedance values.

Levels of significance: * $p \leq 0.05 ; * * 0.01<p \leq 0.05 ; * * * 0.001<p \leq 0.01$ 
Table 3:

Correlation coefficients between changes in $\mathrm{FEV}_{1}$ in litres and as a percentage of predicted and in the resistance at $8 \mathrm{~Hz}\left(\mathrm{R}_{\mathrm{rs} 8}\right)$ and $28 \mathrm{~Hz}\left(\mathrm{R}_{\mathrm{rs} 28}\right)$, reactance at $8 \mathrm{~Hz}\left(\mathrm{X}_{\mathrm{rs} 8}\right)$, resonant frequency $\left(f_{0}\right)$ and the frequency dependence of resistance $(F D, n=23)$.

\begin{tabular}{llc} 
& $\Delta \mathrm{FEV} 1(\mathrm{l})$ & $\Delta \mathrm{FEV} 1(\%$ pred $)$ \\
\hline$\Delta \mathrm{R}_{\text {rs8 }}$ & -0.018 & 0.083 \\
$\Delta \mathrm{R}_{\mathrm{rS} 28}$ & -0.134 & -0.062 \\
$\Delta \mathrm{X}_{\text {rs8 }}$ & -0.110 & 0.078 \\
$\Delta \mathrm{f}_{0}$ & $-0.416^{*}$ & -0.172 \\
$\Delta \mathrm{FD}$ & -0.183 & -0.359 \\
\hline
\end{tabular}

${ }^{*} \mathrm{p}<0.05$

\section{Discussion}

Limited data on respiratory impedance in chronic bronchitis have been available so far. Impedance measurements by means of the technique of forced oscillations allow the simultaneous determination of the resistance and reactance of the respiratory system at various frequencies. Several studies ${ }^{3.8}$ have reported that frequency dependence of oscillatory resistance is a sensitive index in distinguishing smokers from non-smokers, although others ${ }^{19.20}$ have suggested that the forced oscillation technique lacks the sensitivity to detect early airway obstruction in smokers. Analyzing the sensitivity of the forced oscillation technique in detecting early airway obstruction caused by smoking or occupational hazards, Brochard et $a l^{21}$ concluded that frequency dependence of resistance was one of the factors that contributes significantly in distinguishing subjects exposed to respiratory irritants, including cigarette smoke, even at a stage when maximum expiratory flow volume parameters were not yet modified. From a study on the effects of smoking on changes in respiratory impedance with increasing age Coe $e t a l^{22}$ concluded that the forced oscillation technique allows the detection of abnormalities indicating airway narrowing in some smokers whose spirometric values are within normal limits. They found that the resistance of the respiratory system is often raised in middle-aged smokers and that this rise is associated with an enhanced decline in $R_{\mathrm{rs}}$ with increasing frequency of oscillation, especially in patients with $\mathrm{FEV}_{1}<80 \%$. This is in accordance with the findings in our study.

Clément et al ${ }^{11}$ studied respiratory impedance in patients with obstructive airway disease and in normal subjects and concluded that in patients higher values for resistance at lower frequencies, lower values for reactance resulting in increased values for resonant frequency and frequency dependence of resistance, representing a decrease in resistance with increasing frequency, are 
observed as compared to normal subjects. Based on the observations of Clément et al $^{11}$ we have chosen two criteria to divide patients with chronic bronchitis with normal baseline impedance values from those in whom baseline impedance values can be considered abnomal. The limit of $16 \mathrm{~Hz}$ for resonant frequency was based on arbitrary grounds. In normal subjects resonant frequency ranges from 6 to $10 \mathrm{~Hz}^{11}$ (see also chapter II). Application of these criteria resulted in 2 groups with statistically significant differences in all selected impedance parameters.

The differences in impedance values between both groups cannot be explained by the smoking habits of the patients. The percentage of current smokers was even higher in the patient group with normal impedance data. Seven of the 10 patients with normal baseline impedance values were women. Yet, resistance values were significantly lower and reactance values significantly higher in this group of patients, regard less of the expected higher mean resistance values resulting from the smaller lung volumes to be found in women ${ }^{23}$.

Mean age and mean body weight are slightly but not significantly higher in the group with abnormal impedance. Little is known of the effect of age and body weight on respiratory impedance. Recently, Michels et $a l^{24}$ reported no significant correlations between mean body mass index and oscillatory resistance and reactance in obese non-smoking women, although higher $R_{\mathrm{rs}}$ values were found in obese women.

The abnormal baseline impedance data were found in the absence of marked airway obstruction: mean $\mathrm{FEV}_{1}$ in this group of bronchitis patients was $90.4 \%$ $( \pm 18.7)$ of the reference values ${ }^{15}$, emphasizing the sensitivity of the impedance measurements in detecting airway abnormalities in chronic bronchitis patients. In contrast with the findings of Peslin $e t a l^{20}$, who have reported significant correlations between impedance and forced expiratory volume parameters in a group of smokers and non-smokers, we have found a poor correlation between spirometric and impedance values in our study.

After the inhalation of a standard dose of a beta 2 adrenergic drug, significant changes in impedance were found. Similar changes were described after inhalation of bronchodilating agents in patients with chronic obstructive pulmonary disease $^{25}$. Measuring the frequency dependence of dynamic compliance, Ingram and $\mathrm{O}^{\prime} \mathrm{Cain}{ }^{6}$ have found no significant acute reversibility after a beta 2 adrenergic drug in smokers. These investigators only found significant changes in the frequency dependence of dynamic compliance after cessation of smoking. Recently, Bosken et $a l^{26}$ performed morphometric studies on small airways in smokers with airway obstruction. They demonstrated increases in wall area and thickness with an increase in the amount of connective tissue, smooth muscle and epithelium in the airways of patients with airflow obstruction as compared to controls. Our observation of acute reversibility in patients with chronic bronchitis with impedance characteristics suggesting peripheral airway obstruc- 
tion is in keeping with the increased presence of smooth muscle in peripheral airway walls.

Low correlation coefficients were found between the changes in $F E V_{1}$ and the changes in the various impedance parameters after the inhalation of terbutaline. Only the correlation between the increase in $\mathrm{FEV}_{1}$ in litres and the decrease in $f_{0}$ reached a level of significance. One should bear in mind that the changes in FEV , observed in these patients are very small. In the chronic bronchitis patients with normal baseline impedance data, provocation tests resulted in changes that were opposite to the changes found in the reversibility tests in the other group. Cold air provocation ${ }^{27}$ resulted in significant changes in impedance in the absence of significant changes in $\mathrm{FEV}_{1}$ values. Similar changes in impedance have been described after cold air provocation in asymptomatic smokers ${ }^{12,13}$ and similar but more pronounced changes in impedance values have been described in asthmatics after cold air provocation by the same authors ${ }^{12,14}$, and in these studies the induced changes were also reversible after the inhalation of a beta2 adrenergic drug. The response to cold air in these patients indicates a certain degree of hyperresponsiveness. This is in keeping with previous studies, that have also demonstrated an increased bronchial reactivity in subjects with chronic bronchitis and normal ventilatory capacity ${ }^{28-31}$. Engel et $a l^{31}$ demonstrated that the degree of responsiveness in subjects with chronic bronchitis and normal ventilatory capacity was significantly correlated to prechallenge ventilatory capacity, age, and tobacco consumption.

In summary, this study demonstrates that acutely reversible impedance abnormalities indicating early airway obstruction could be observed in a large group of patients with chronic bronchitis with normal ventilatory capacity. In patients with normal baseline impedance values frequency dependence of resistance could be induced through cold air provocation. 


\section{References}

1. American Thoracic Society.

Chronic bronchitis, asthma and pulmonary emphysema. A statement by the Committee on Diagnostic Standards for non tuberculous respiratory diseases.

Am Rev Respir Dis 1962; 85: 762-768.

2. Fletcher C, Peto R.

The natural history of chronic airflow obstruction.

Br Med J 1977; 1: 1645-1648.

3. Campbell AH, Barter CE, O'Connell JM, Huggins R.

Factors affecting the decline of ventilatory function in chronic bronchitis.

Thorax 1985; 40: 741-748.

4. Postma DS, Sluiter HJ.

Prognosis of chronic obstructive pulmonary disease: the Dutch experience.

Am Rev Respir Dis 1989; 140: 5100-5105.

5. Woolcock AJ, Vincent NJ, Macklem PT.

Frequency dependence of compliance as a test for obstruction in the small airways.

$\mathrm{J}$ Clin Invest 1969; 48: 1097-1104.

6. Ingram $\mathrm{RM} \mathrm{jr}, \mathrm{O}^{\prime} \mathrm{Cain} \mathrm{CF}$.

Frequency dependence of compliance in apparently healthy smokers versus nonsmokers.

Bull Eur Physiopathol Respir 1971; 7: 195-210.

7. Dubois AB, Brody AW, Lewis DH, Burgess BF.

Oscillation mechanics of lungs and chest in man.

J Appl Physiol 1956; 8: 587-594.

8. Kjeldgaard JM, Hyde RW, Speers DM, Reichert WW.

Frequency dependence of total respiratory resistance in early airway disease.

Am Rev Respir Dis 1976; 114: 501-508.

9. Hayes DA, Pimmel RL, Fullton JM, Bromberg PA.

Detection of respiratory mechanical dysfunction by forced random noise impedance parameters.

Am Rev Respir Dis 1979; 120: 1095-1 100.

10. Michaelson ED, Grassman ED, Peters WR.

Pulmonary mechanics by spectral analysis of forced random noise.

J Clin Invest 1975; 56: 1210-1230.

11. Clément J, Làndsér FJ, van de Woestijne KP.

Total resistance and reactance in patients with respiratory complaints with and without airways obstruction.

Chest 1983; 83: 215-220.

12. Decramer $M$, Demedts $M$, van de Woestijne KP.

Isocapnic hyperventilation with cold air in healthy non-smokers, smokers and asthmatic subjects.

Bull Eur Physiopathol Respir 1984; 20: 237-243.

13. Quaedvlieg M, Wouters EFM.

Early airway obstruction in young asymptomatic smokers after cold air challenge. Respiration 1990; 57: 299-303. 
14. Wouters EFM, Quaedvlieg M, Mostert R, Polko AH, Visser BF.

Localization of bronchial response to ipratropium bromide by respiratory impedance measurements in asthmatics.

Int J Clin Pharmacol Toxicol 1989; 27: 145-149.

15. Quanjer PH (ed).

Standardized lung function testing.

Bull Eur physiopathol Respir 1983; 19: 7-44.

16. Làndsér FJ, Nagels J, Demedts M, Billiet L, van de Woestijne KP.

A new method to determine frequency characteristics of the respiratory system.

J Appl Physiol 1976; 41: 101-106.

17. Wouters EFM, Làndsér FJ, Polko AH, Visser BF.

Physiological analysis of extended spectrum oscillometry.

Respiration 1988; 54: 263-270.

18. Higenbottam T, Clark TJH.

Practical importance of a preceding full inhalation or exhalation upon the measurement of airway resistance.

Clin Sci. 1980; 58: 249-253.

19. Làndsér FJ, Clément J, van de Woestijne KP.

Normal values of total respiratory resistance and reactance determined by forced oscillations.

Chest 1982; 81: 586-591.

20. Peslin R, Hannhart B, Pino J.

Impédance mechanique thoraco-pulmaire chez des sujets fumeurs et non-fumeurs.

Bull Eur Physiopathol Respir 1981; 17: 93-105.

21. Brochard L, Pelle G, de Palmas J, Brochard P, Carre A, Lasino H, Harf A.

Density and frequency dependence of resistance in early airway obstruction.

Am Rev Respir Dis 1987; 135: 579-584.

22. Coe CI, Watson A, Joyce H, Pride NB.

Effects of smoking on changes in respiratory resistance with increasing age.

Clin Sci 1989; 76: 487-494.

23. Fisher A, Dubois A, Hyde R.

Evaluation of the forced oscillation technique for the determination of resistance to breathing.

J Clin Invest 1968; 47: 2045-2057.

24. Michels A, Vrijens C, Muls E, van de Woestijne KP.

Influence of obesity on lung volumes, respiratory resistance and reactance.

Eur Respir J 1991; 4: 248-249.

25. Wouters EFM, Verschoof AC, Polko AH, Visser BF.

Impedance measurements of the respiratory system before and after salbutamol in COPD patients.

Respir Med 1989; 83: 309-313.

26. Bosken CH, Wiggs BR, Paré PD, Hogg JC.

Small airway dimensions in smokers with obstruction to airflow.

Am Rev Respir Dis 1990; 142: 563-570.

27. Heaton R, Henderson A, Costello J.

Cold air as a bronchial provocation technique.

Chest 1984; 86: 810-814. 
28. Bahous J, Cartier A, Quimet G, Pineau L, Malo JL. Nonallergic bronchial hyperexcitability in chronic bronchitis.

Am Rev Respir Dis 1984; 129: 216-220.

29. De Vries K, Booy-Noord H, Goei JT, Grobler NJ, Sluiter HJ, Tammeling GJ, Orie NGM.

Hyperreactivity of the bronchial tree to drugs, chemical and physical agents. In: Orie NGM and Sluiter HJ (ed): Bronchitis.

Amsterdam, Royal van Gorcum, 1964 pp 167-180.

30. Ramsdale EH, Morris MM, Roberts RS, Hargreave FE.

Bronchial responsiveness to metacholine in chronic bronchitis: relationship to air flow obstruction and cold air responsiveness.

Thorax 1984; 39: 912-918.

31. Engel T, Heining JH, Madsen O, Hansen M, Weeke ER.

A comparison of airway responsiveness in smokers with chronic bronchitis and in asthmatic subjects.

Eur Respir J 1989; 2: 929-934. 


\title{
Chapter VI
}

\section{Inhaled budesonide in chronic bronchitis:}

Effects on respiratory impedance.

\author{
G.J. Wesseling \\ M. Quaedvlieg \\ E.F.M. Wouters
}

Eur Respir J 1991; 4: 1101-1105 


\section{Inhaled budesonide in chronic bronchitis: Effects on respiratory impedance.}

\section{Abstract}

In a placebo controlled study the effects of 6 weeks' treatment with inhaled budesonide (1.6 mg daily) on the impedance of the respiratory system, spirometry and symptom scores were evaluated in 35 patients with chronic bronchitis with forced expiratory volume in one second $\left(\mathrm{FEV}_{1}\right) \geq 70 \%$ predicted.

30 patients completed the study. No statistically significant differences in the changes in moming peak expiratory flow rate (PEFR), symptom scores, use of terbutaline rescue medication and $\mathrm{FEV}$, were found between the placebo and the active treatment group.

Budesonide treatment was found to result in a small decrease in resonant frequency and a less negative frequency dependence of resistance compared with the placebo group.

\section{Introduction}

The effects of anti-inflammatory drugs such as inhaled corticosteroids in asthma and chronic airflow obstruction have been extensively evaluated ${ }^{1-4}$. The effects of inhaled corticosteroids in patients with simple chronic bronchitis are less clear. Recently, Engel et al failed to demonstrate effects of inhaled budesonide on sputum expectoration, dyspnoea, sleep disturbances, ventilatory capacity and bronchial responsiveness in smokers with chronic bronchitis, and baseline forced expiratory volume in one second $\left(\mathrm{FEV}_{1}\right) \geq 70 \%$ predicted.

The present study was performed to evaluate the effects of treatment with inhaled budesonide ( $1.6 \mathrm{mg} /$ day) during 6 weeks on symptom scores, spirometric values and respiratory impedance in patients with chronic bronchitis without spirometric evidence of airflow obstruction. Impedance of the respiratory system was measured using the technique of forced oscillations, introduced by Dubois $e t a l^{6}$ in 1956 . This technique allows the determination of the resistance and reactance of the respiratory system during spontaneous, quiet breathing, and provides a method to study the mechanical characteristics of the respiratory system. 


\section{Material and methods}

\section{Study design}

In a double-blind, randomized, placebo-controlled study, the effects of treatment with 2 inhalations four times a day of budesonide $(1.6 \mathrm{mg} /$ day $)$ from a metered dose inhaler (MDI) during 6 weeks were studied in patients with chronic bronchitis without marked airflow obstruction $\left(\mathrm{FEV}_{1} \geq 70 \% \text { predicted }\right)^{7}$.

On the entry visit a full history was obtained, and spirometric and impedance values were recorded. Patients were instructed how to use metered dose inhalers and the mini-Wright peak flow meter (Airmed, Clement Clarke International Ltd, London, UK).

They were asked to register in a diary the moming peak expiratory flow rate (PEFR), the severity of cough, dyspnoea and sputum volume using a 0-3 point scale, to record fever and the use of the study medication and of concomitant medication and possible side effects. The patients entered a single blind placebo baseline wash-out period of one week, during which all medication was withheld except for inhaled terbutaline as rescue medication and 2 puffs 4 times daily from a placebo MDI using a Nebuhaler $\left.{ }^{(}\right)$.

One week later, at visit 2, respiratory impedance measurements were repeated to obtain baseline values. On the third visit, after a treatment period of 6 weeks, during which the patients continued to record symptoms and morning peak expiratory flow rates in their diary, impedance and spirometric values were again obtained, in the same sequence as prior to the treatment. Apart from the study medication and inhaled terbutaline as rescue medication, no other medication was allowed during the study period. Patients were asked to register the use of terbutaline in the diary.

The study was approved by the local Ethics Committee and written informed consent was obtained from all patients.

\section{Subjects}

35 subjects entered into the study. Anthropometric, spirometric and baseline impedance data at visit 2 are presented in table 1. All patients suffered from chronic bronchitis, as defined by a history of chronic cough and expectoration of sputum during 3 months of at least 2 years. Selection criteria included a forced expiratory volume in one second $\left(\mathrm{FEV}_{1}\right)$ of at least $70 \%$ of predicted ${ }^{7}$, and an increase in $\mathrm{FEV}_{1}$ less than $15 \%$, following inhalation of $0.5 \mathrm{mg}$ terbutaline. Patients with documented heart, liver or renal disease were excluded from the study, as were patients unable to use metered dose inhalers or to keep diaries. 13 Patients were female, mean age was 50.4 years (range 29-69) and 16 patients were current smokers, all others were ex-smokers. 
Table 1:

Anthropometric, spirometric and impedance characteristics $(n=35)$

\begin{tabular}{llll}
\hline & & Mean & SD \\
\hline Age & $(\mathrm{yrs})$ & 52 & \\
Sex & $(\mathrm{F} / \mathrm{M})$ & $11 / 24$ & \\
Height & $(\mathrm{cm})$ & 166 & \\
Weight & $(\mathrm{kg})$ & 77.1 & \\
$\mathrm{FEV}_{\mathrm{l}}$ & $(\mathrm{l})$ & 2.84 & 0.69 \\
$\mathrm{FEV}_{1}$ & $(\%$ pred. & 96 & 17.39 \\
$\mathrm{R}_{\mathrm{rs} 8}$ & $(\mathrm{kPa} / / \mathrm{s})$ & 0.347 & 0.095 \\
$\mathrm{R}_{\mathrm{rs} 28}$ & $(\mathrm{kPa} / \mathrm{s} / \mathrm{s})$ & 0.320 & 0.081 \\
$\mathrm{X}_{\mathrm{rs} 8}$ & $(\mathrm{kPa} / \mathrm{s})$ & -0.064 & 0.058 \\
fo & $(\mathrm{Hz})$ & 14.76 & 4.955 \\
\hline
\end{tabular}

\section{Lung function measurements}

Spirometric values were derived from the best of three maximum expiratory flow-volume curves (Transferscreen, Jaeger G.M.B.H., Würzburg, Germany) and values were recorded as absolute values and as a percentage of predicted. Reversibility was noted in terms of percentage increase in $\mathrm{FEV}_{1}$ above baseline after inhalation of $0.5 \mathrm{mg}$ terbutaline by Nebuhale ${ }^{\circledR}$.

Impedance of the respiratory system was measured by means of the technique of forced oscillations (FOT), as introduced by Dubois et at , using a pseudo-random noise oscillation signal consisting of frequencies ranging from 4 to $52 \mathrm{~Hz}$. The method is described in chapter MI. At each visit, three successive impedance measurements were performed and the results of each set of impedance measurements were averaged at each frequency.

The following impedance measures were evaluated: the resistance at 8 and 28 $\mathrm{Hz}\left(R_{\mathrm{rs} 8}\right.$ and $\left.R_{\mathrm{rs} 28}\right)$, the reactance at $8 \mathrm{~Hz}\left(X_{\mathrm{rs} 8}\right)$, resonant frequency $\left(f_{0}\right)$, frequency dependence (FD) of resistance defined as $R_{\mathrm{rs} 28}$ minus $R_{\mathrm{rs} 8}$ divided by 20 , reflecting the slope of the resistance versus frequency curve.

\section{Data analysis}

Diary card data averaged for days 1-7 and for days 29-42 and lung function values of visits 2 and 3 were compared using Student's $t$ tests for unpaired observations for the comparisons of the findings between the two treatment groups. Paired $t$ tests were used for comparisons within each group. P-values $\leq$ 0.05 were considered as statistically significant. 


\section{Results}

Of the 35 patients entered into the study 5 patients failed to complete the study, due to withdrawal of consent (1 patient), lack of cooperation (1), an intercurrent pertussis infection during the wash-out period (1), persistent coughing after inhalation of the study drug (budesonide, 1) and an intercurrent pneumonia after 4 weeks (placebo group, 1). Thus, it is thought that one patient dropped out due to side effects resulting from budesonide treatment. Of the 30 patients who completed the study, 14 were randomized to treatment with budesonide, 16 received placebo. Both treatment groups were comparable with respect to all demographic and lung function values.

Comparing $\mathrm{FEV}_{1}$, morning PEFR, scores for cough, dyspnoea, sputum volume and fever, and use of rescue medication between the two treatment groups before (days 1-7) and at the end (days 29-42) of the treatment period, it was found that the improvements were larger in the budesonide group, but the differences were not statistically significant between the 2 groups (table 2). In the budesonide group mean morning PEFR increased significantly from $362.2 \mathrm{l} / \mathrm{min}$. to 404.3 1/min., and in the placebo group PEFR increased from $354.8 \mathrm{l} / \mathrm{min}$. to 396.7 $1 / \mathrm{min}$. ( $\mathrm{p}<0.05)$. In the budesonide group the score for sputum volume decreased significantly from 1.74 (days $1-7$ ) to 1.31 (days 29-42, p $<0.05$ ). Apart from persistent coughing in 1 patient in the budesonide group, no serious side effects were reported.

Table 3 lists the changes in respiratory impedance values of the two treatment groups before and after the treatment period.

Inhalation of budesonide results in significant differences in the resonant frequency $(p<0.05)$ and in frequency dependence of resistance $(p<0.05)$ compared with the control group. No significant changes in impedance data within both groups could be demonstrated after the treatment period.

\section{Table 2:}

Symptom scores, morning peak-expiratory flow rate and use of terbutaline rescue medication at the start (days 1-7) and the end (days 29-53) of the treatment period

\begin{tabular}{llllccc}
\hline & & $\begin{array}{l}\text { PEFR } \\
\text { //min }\end{array}$ & $\begin{array}{l}\text { Cough } \\
(0-3)\end{array}$ & $\begin{array}{c}\text { Dyspnoea } \\
(0-3)\end{array}$ & $\begin{array}{c}\text { Sputum } \\
(0-3)\end{array}$ & $\begin{array}{c}\text { Terbutaline } \\
\text { (puffs/day) }\end{array}$ \\
\hline BUD & days 1 - 7 & 362.2 & 1.62 & 1.40 & 1.74 & 1.88 \\
& days 29 - 53 & $404.3^{*}$ & 1.28 & 1.10 & $1.31^{*}$ & 1.15 \\
\multirow{2}{*}{ PLAC } & days 1 - 7 & 354.8 & 1.40 & 0.86 & 1.91 & 0.56 \\
& days 29-53 & $396.7^{*}$ & 1.31 & 0.64 & 1.86 & 0.29 \\
\hline
\end{tabular}

$* p<0.05$ 


\section{Table 3:}

Values for FEV1 and for resistance at 8 and $28 \mathrm{~Hz}$, reactance at $8 \mathrm{~Hz}$, resonant frequency and frequency dependence of resistance of 30 patients with chronic bronchitis before (T1) and after the treatment period (T2)

\begin{tabular}{|c|c|c|c|c|c|}
\hline & \multicolumn{2}{|c|}{ BUD } & \multicolumn{2}{|c|}{ PLAC } & \multirow{2}{*}{$\begin{array}{l}\text { p-values } \\
\text { BUD vs PLAC }\end{array}$} \\
\hline & Mean & SD & Mean & SD & \\
\hline \multicolumn{6}{|c|}{ FEV 1} \\
\hline $\mathrm{T} 1$ & 88.4 & 19.0 & 92.5 & 15.0 & n.s. \\
\hline $\mathrm{T} 2$ & 90.8 & 19.3 & 92.5 & 15.5 & n.s. \\
\hline \multicolumn{6}{|c|}{$\mathbf{R}_{\text {rs8 }}$} \\
\hline $\mathrm{T} 1$ & 0.349 & 0.107 & 0.349 & 0.091 & n.s. \\
\hline $\mathrm{T} 2$ & 0.323 & 0.086 & 0.355 & 0.113 & n.s. \\
\hline \multicolumn{6}{|c|}{$R_{\text {rs28 }}$} \\
\hline $\mathrm{T} 1$ & 0.325 & 0.085 & 0.317 & 0.074 & n.s. \\
\hline $\mathrm{T} 2$ & 0.320 & 0.082 & 0.347 & 0.103 & n.s. \\
\hline \multicolumn{6}{|c|}{$\mathbf{X}_{\text {rs8 }}$} \\
\hline $\mathrm{T} 1$ & -0.064 & 0.053 & -0.074 & 0.066 & n.s. \\
\hline $\mathrm{T} 2$ & -0.052 & 0.052 & -0.069 & 0.055 & n.s. \\
\hline \multicolumn{6}{|l|}{$f_{0}$} \\
\hline $\mathrm{T} 1$ & 14.80 & 5.72 & 15.44 & 4.35 & n.s. \\
\hline$T 2$ & 13.31 & 5.51 & 17.34 & 7.54 & $*$ \\
\hline \multicolumn{6}{|l|}{ FD } \\
\hline $\mathrm{T} 1$ & -0.0012 & 0.0008 & -0.0010 & 0.0006 & n.s. \\
\hline $\mathrm{T} 2$ & -0.00015 & 0.0006 & -0.0004 & 0.0004 & $*$ \\
\hline
\end{tabular}

ns $=$ not significant, ${ }^{*} \mathrm{p}<0.05$

\section{Discussion}

A beneficial effect of inhaled corticosteroids on asthma and chronic airflow obstruction has been well established ${ }^{1-4}$, and recently, Weir $e t a l^{7}$ reported that inhaled beclomethasone diproprionate (1.5 mg daily) was more effective than placebo in non-asthmatic chronic airflow obstruction. Furthermore, inhaled corticosteroids have been demonstrated to reduce bronchial hyperresponsiveness ${ }^{8-10}$. It is thought that corticosteroids act by reducing airway inflammation ${ }^{11,12}$, a consistent finding in chronic asthma ${ }^{11}$ and in chronic bronchitis ${ }^{12}$. The effects of inhaled corticosteroids in chronic bronchitis without airflow obstruction are less clear. Recently, Engel $e t \mathrm{al}^{5}$ reported a study using inhaled budesonide in smokers with chronic bronchitis with normal ventilatory capacity. 
These authors found that budesonide $0.80 \mathrm{mg}$ daily did not improve symptom scores, ventilatory capacity or airway responsiveness as expressed by the provocative concentration of histamine causing a 20\% fall in $\mathrm{FEV}_{1}\left(\mathrm{PC}_{20}\right)$. Watson et $a l^{13}$ found no effect of treatment with $1.2 \mathrm{mg}$ inhaled budesonide on $\mathrm{FEV}_{1}$, bronchodilator response and $\mathrm{PC}_{20}$ in middle aged smokers with bronchial hyperresponsiveness.

In the present study we have found no significant reduction in cough, sputum volume, fever and use of rescue medication, or increase in PEFR or FEV 1 as compared to placebo after 6 weeks' treatment with inhaled budesonide $1.6 \mathrm{mg}$ daily. Apart from spirometry, we have used the technique of forced oscillations to assess possible effects of inhaled budesonide on the impedance of the respiratory system. This technique allows the evaluation of the mechanical characteristics of the respiratory system during spontaneous quiet breathing.

The sensitivity of this technique has been demonstrated especially in the abscence of gross abnormalities ${ }^{14}$.

In analysing impedance values obtained with the technique of forced oscillations, Clément $e t a l^{15}$ concluded that healthy subjects can be distinguished from patients with pulmonary complaints on the basis of increased resistance values especially at lower frequencies, negative frequency dependence of resistance (a decrease in resistance with increasing frequency), lower average reactance values resulting in higher values for resonant frequency, and a more linear course of reactance with frequency. In spite of the absence of evidence of airflow limitation in the values obtained with spirometry in our study population, frequency dependence of resistance was found to be slightly negative. Significant differences in resonant frequency and in frequency dependence of resistance were found between the budesonide group and the placebo group after the treatment period. The differences in the changes in $\mathrm{FEV}_{1}$ were not significant. To our knowledge, ours is the first study on changes in respiratory impedance after treatment with inhaled corticosteroids in patients with chronic bronchitis.

In summary, treatment with inhaled budesonide during 6 weeks in patients with chronic bronchitis without airflow obstruction induced no statistically signifi-

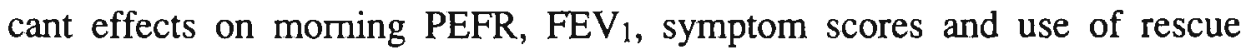
medication whilst statistically significant though limited effects on respiratory impedance could be demonstrated.

\section{Acknowledgement.}

This study was supported by a grant from ASTRA. 


\section{References}

1. Gelfland MC.

Administration of cortisone by the aerosol method in the treatment of bronchial asthma. N Eng J Med 1951: 245-293.

2. Clark TJH.

Effect of Beclomethasone diproprionate delivered by aerosol in patients with asthma. Lancet 1972; 1: 1361.

3. Wardman AG, Simpson FG, Knox AJ, Page KL, Cooke NJ.

The use of high dose inhaled beclomethasone diproprionate as a means of assessing steroid responsiveness in obstructive airway disease.

Br J Dis Chest 1988; 82: 168-171.

4. Salmeron S, Guerin JC, Godard Ph, Renon D., Henry-Amar M, Duroux P, Taytard A. High doses of inhaled corticosteroids in unstable chronic asthma.

Am Rev Respir Dis 1989; 140: 167-171.

5. Engel T, Heinig JH, Madsen O, Hansen M, Weeke ER.

A trial of inhaled Budesonide on airway responsiveness in smokers with chronic bronchitis.

Eur Respir J 1989; 2: 935-939.

6. Dubois $\mathrm{AB}$, Brody $\mathrm{AW}$, Lewis $\mathrm{DH}$, Burgess $\mathrm{BF}$.

Oscillation mechanics of lungs and chest in man.

J Appl Physiol 1956; 8: 587-594.

7. Weir DC, Gove RI, Robertson AS, Burge PS.

Corticosteroid trials in non-asthmatic chronic airflow bstruction: a comparison of oral prednisolone and inhaled beclomethasone diproprionate.

Thorax 1990; 45: 112-117.

8. Dutoit JI, Salome LM, Woolcock AJ.

Inhaled corticosteroids reduce the severity of bronchial hyperresponsiveness in asthma but oral theophylline does not.

Am Rev Respir Dis 1987; 136: 1174-1178.

9. Kraan J, Koëter GH, v.d. Mark ThW, Sluiter HJ, de Vries K.

Changes in bronchial hyperreactivity induced by 4 weeks of treatment with antiasthmatic drugs in patients with allergic asthma: a comparison between budesonide and terbutaline. J Allergy Clin Immunol 1985; 76: 628-636.

10. Juniper EF, Kline PA, Vanzieleghem MA, Ramsdale EH, O'Byme PM, Hargreave F.E. Effect of long-term treatment with an inhaled corticosteroid (Budesonide) on airway hyperresponsiveness and clinical asthma in nonsteroid-dependent asthmatics.

Am Rev Respir Dis 1990; 142: 832-836.

11. Mullen JBM, Wiggs BR, Wright J, Paré PD, Hogg JC.

Non specific airway reactivity in cigarette smokers. Relationship to airway pathology and baseline lungfunction.

Am Rev Respir Dis 1986; 133: 120-125.

12. Schleimer RP.

The mechanisms of anti-inflammatory steroid action in allergic diseases.

Ann Rev Pharmacol Toxicol 1985; 25: 381-412. 
13. Watson A, Lim TK, Joyce H, Pride NB.

Trial on the effect of inhaled corticosteroids on bronchoconstrictor and bronchodilator responsiveness in middle aged smokers.

Thorax 1988; 43: 23lP.

14. Manço JC, Hyatt RE, Rodarte JR.

Respiratory impedance in normal humans: Effects of bronchodilatation and bronchoconstriction.

Mayo Clin Proc 1987; 62: 487-497.

15. Clément J, Làndsér FJ, van de Woestijne KP.

Total resistance and reactance in patients with respiratory complaints with and without airways obstruction.

Chest 1983; 83: 215-220. 
, 


\section{Chapter VII}

Effects of inhalation of beta 2 sympathicomimetic and anticholinergic agents on the impedance of the respiratory system in normal subjects.

G.J. Wesseling H.M. Vonk

E.F.M. Wouters 


\title{
Effects of inhalation of beta 2 sympathicomimetic and anticholinergic agents on the impedance of the respiratory system in normal subjects.
}

\begin{abstract}
Impedance measurement of the respiratory system by forced oscillations is a sensitive and accurate method to detect mechanical parameters, especially in normal subjects. The effects of inhalation of $0.2 \mathrm{mg}$ of fenoterol and $0.02 \mathrm{mg}$ of ipratropium bromide on the impedance of the respiratory system was studied in 20 healthy subjects in a frequency spectrum between 4 and $52 \mathrm{~Hz}$. Both ages caused a statistically significant decrease in resistance $\left(R_{\mathrm{rs}}\right)$. Inhalation of fenoterol and ipratropium bromide caused a statistically significant increase in reactance $\left(X_{\mathrm{rs}}\right)$. The decrease in $R_{\mathrm{rs}}$ was greater after inhalation of fenoterol than after ipratropium bromide. Fenoterol and ipratropium bromide caused qualitatively similar changes in $R_{\mathrm{rs}}$ and $X_{\mathrm{rs}}$ of the respiratory system. The changes in $R_{\mathrm{rs}}$ can be explained by dilation of the central airways. The changes in $X_{\mathrm{rs}}$ are supposed to be the result of an increase in the capacitance of the lungs.
\end{abstract}

\section{Introduction}

Both beta2 sympathicomimetic and atropine-like agents are generally used in the inhaled form in treating airway obstruction ${ }^{1-3}$. These drugs are also known to dilate airways in healthy subjects ${ }^{4-6}$. Studies on the effect of beta 2 adrenergic stimulation on pulmonary mechanics in normal subjects have revealed a large decrease in airway resistance $\left(R_{\mathrm{aw}}\right)$ and a comparatively modest increase in maximum expiratory flow $\left(\mathrm{V}_{\mathrm{E}, \max }\right)^{5,7-10}$. Various effects of cholinergic receptor blockade on lung and airway function in man have been reported.

There has been considerable debate as to the site of action of these bronchodilators in the normal human bronchial system ${ }^{6,11-17}$. Some authors have observed different sites of action due to differences in the mode of administration of the drugs $^{7,14}$. 
By means of the technique of forced oscillations, first described by Dubois et $a l^{18}$, total respiratory impedance can be determined at different frequencies. Thanks to microcomputers, impedance measurements can now be easily implemented, and in contrast to spirometric investigations, they do not require active cooperation from the subject. Moreover, this technnique eliminates the necessity of forced respiratory manoeuvres since impedance measurements of the respiratory system are performed during quiet breathing, thus evading the changes in bronchial tone known to result from maximum respiratory manoeuvres ${ }^{19,20}$. In the present study we have compared the effects of the inhalation of the anticholinergic agent ipratropium bromide, a quarternary isopropyl derivative of atropine, and of fenoterol, a beta2 sympathicomimetic drug, on the acoustical respiratory input impedance in healthy, non-smoking subjects.

\section{Subjects and methods}

We have studied 20 healthy non-smoking subjects, 10 women and 10 men, with a mean age of 24 years (range 22 to 31 years). All subjects had normal basal impedance $(Z)$ values, as determined by an absence of frequency dependence of resistance $(R)$, and a resonant frequency $\left(f_{0}\right)$ lower than $16 \mathrm{~Hz}$.

Studies were performed on each subject in a randomized double-blind crossover manner on two separate days at least two days apart, and always at the same time of the day.

Impedance of the respiratory system was determined by the forced pseudo-random oscillation technique originally described by Làndsér $e t a l^{21}$ (see chapter III). All subjects had been seated at room temperature for at least 15 minutes before the start of the procedure. Under basal conditions, five impedance measurements were performed. Next, fenoterol or ipratropium bromide was administered in a double-blind manner by means of a metered dose inhaler using a $750 \mathrm{ml}$ pear-shaped spacer. In view of the sensitivity of the measuring procedure, low doses of both drugs were used: $200 \mu \mathrm{g}$ of fenoterol and $20 \mu \mathrm{g}$ of ipratropium bromide. Subjects were instructed to activate the inhaler on starting inspiration from residual volume and to inhale to near total lung capacity. Ten minutes after the inhalation of the drug, five consecutive impedance measurements were performed. Values of each set of five impedance measurements were averaged and compared by Student's paired $t$ tests. Comparison of means was not possible at $4 \mathrm{~Hz}$ since the coherence function was too often lower than 0.95 at this frequency.

$\mathrm{P}$-values lower than 0.05 were retained as statistically significant. 


\section{Results}

The values of $R_{\mathrm{rs}}$ and $X_{\mathrm{rs}}$ before and after fenoterol are illustrated in table 1 and values of $R_{\mathrm{rs}}$ and $X_{\mathrm{rs}}$ before and after ipratropium bromide are shown in table 2. The values of $R_{\mathrm{rs}}$ and $X_{\mathrm{rs}}$ under basal conditions were not significantly different between the two study days. As illustrated in tables 1 and $2, R_{\mathrm{rs}}$ values increased with frequency.

After inhalation of fenoterol, a highly significant decrease in $R_{\mathrm{rs}}$ values could be observed at all frequencies (table 1). The values of $X_{\mathrm{rs}}$ were slightly increased at most of the studied frequencies (table 1). Ipratropium bromide also decreased $R_{\mathrm{rs}}$ values significantly and increased $X_{\mathrm{rs}}$ values at almost all frequencies (table 2).

Comparing the mean decrease in $R_{\mathrm{rs}}$ after fenoterol and after ipratropium, it was found that the changes were greater after fenoterol at all frequencies. This difference was statistically significant at all frequencies except at 12 and $16 \mathrm{~Hz}$ (at $28,32,36 \mathrm{~Hz}: 0.001 \leq \mathrm{p}<0.01$; other frequencies: $0.01 \leq \mathrm{p}<0.05$ ). No significant differences were found between the mean increase in reactance that occurred after the inhalation of both drugs.

Table 1:

Mean values of resistance $\left(\mathrm{R}_{\mathrm{rS}}\right)$ and reactance $\left(\mathrm{X}_{\mathrm{rs}}\right)(\mathrm{kPa} / \mathrm{l} / \mathrm{s})$ before and after Fenoterol

\begin{tabular}{|c|c|c|c|c|c|c|c|c|c|}
\hline \multicolumn{10}{|c|}{ Frequency $(\mathrm{Hz})$} \\
\hline 8 & 12 & 16 & 2 & 32 & 36 & 40 & 44 & 48 & 52 \\
\hline
\end{tabular}

Resistance

$\begin{array}{lllllllllllll}\text { Before } & .278 & .279 & .283 & .302 & .348 & .346 & .377 & .382 & .405 & .399 & .394 & .398\end{array}$

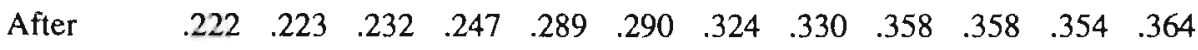

$\begin{array}{lllllllllllll}\text { p-value } & * & * & \text { n.s } & \text { n.s } & \# & \text { n.s } & \# & \# & * & \# & \text { n.s } & \text { n.s }\end{array}$

Reactance

$\begin{array}{lllllllllllll}\text { Before } & .000 & .060 & .104 & .165 & .202 & .239 & .227 & .244 & .253 & .284 & .304 & .340\end{array}$

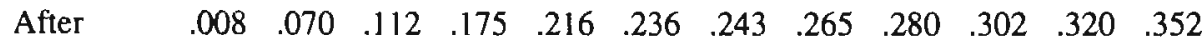

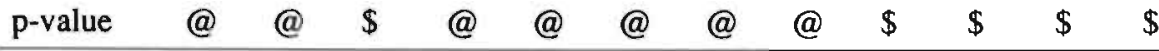

n.s: not significant; \#: $0.01 \leq \mathrm{p}<0.05 ; *$ : $0.001 \leq \mathrm{p}<0.01 ; \$$ : $0.0001 \leq \mathrm{p}<0.001$;

@: $\mathrm{p}<0.0001$. 
Table 2:

Mean values of resistance $\left(\mathrm{R}_{\mathrm{rs}}\right)$ and reactance $\left(\mathrm{X}_{\mathrm{rS}}\right)(\mathrm{kPa} / \mathrm{l} / \mathrm{s})$ before and after Ipratropium Bromide

\begin{tabular}{|c|c|c|c|c|c|c|c|c|c|c|c|c|}
\hline & \multicolumn{12}{|c|}{ Frequency $(\overline{\mathrm{Hz}})$} \\
\hline & 8 & 12 & 16 & 20 & 24 & 28 & 32 & 36 & 40 & 44 & 48 & 52 \\
\hline \multicolumn{13}{|c|}{ Resistance } \\
\hline Before & .267 & .265 & .273 & .292 & .331 & .335 & .371 & .375 & .398 & .391 & .385 & .387 \\
\hline After & .233 & .230 & .241 & .261 & .306 & .314 & .351 & .360 & .380 & .378 & .370 & .379 \\
\hline p-value & \# & $*$ & $*$ & \# & $\#$ & $\#$ & $\#$ & \# & $*$ & \# & n.s & n.s \\
\hline \multicolumn{13}{|c|}{ Reactance } \\
\hline Before & .001 & .061 & .103 & .166 & .206 & .228 & .229 & .246 & .252 & .282 & .307 & .344 \\
\hline After & .007 & .070 & .115 & .180 & .222 & .246 & .246 & .259 & .270 & .294 & .315 & .348 \\
\hline $\mathrm{p}$-value & $\$$ & $\$$ & $\$$ & $\$$ & * & $\$$ & * & \# & $\#$ & \# & $\#$ & n.s \\
\hline
\end{tabular}

n.s: not significant; \#: $0.01 \leq p<0.05 ; *$ : $0.001 \leq p<0.01 ; \$: 0.0001 \leq p<0.001$

\section{Discussion}

In the present study the resistance and reactance of the total respiratory system was measured simultaneously from 4 to $52 \mathrm{~Hz}$. As was shown by Nagels et al ${ }^{22}$ valid conclusions can be drawn for resistance and reactance of the lungs from the values of $R_{\mathrm{rs}}$ and $X_{\mathrm{rs}}$ without partitioning $Z_{\mathrm{rs}}$ into the impedance of the lungs and the impedance of the chest wall. We studied the effects of cholinergic receptor blockade and beta2 sympathicomimetic receptor stimulation on the impedance of the respiratory system in normal subjects.

Studies on the effects of both drugs on lung and airway function in man reported so far are inconclusive $e^{6,11-17}$. We found a parallel and significant decrease in $R_{\mathrm{rs}}$ at all frequencies after the administration of both fenoterol and ipratropium bromide. The changes in $R_{\mathrm{rs}}$ after the inhalation of both drugs differ only quantitatively. Supposing peripheral resistance to be very low in normal subjects $^{23}, R_{\text {rs }}$ in normal subjects will be determined by the resistance of the central airways and of the chest wall in series ${ }^{22}$. In case a considerable portion of total respiratory resistance is located in the peripheral airways, frequency dependence of resistance is found, i.e., a decrease in resistance with frequency instead of the increase in resistance at higher frequencies which is found in normal subjects as is confirmed in our group of normal subjects. Keeping in mind that no change in chest wall resistance results from the inhalation of these drugs, the observed parallel decrease in $R_{\mathrm{rs}}$ must be explained by dilation of the central airways. Previous studies, using different lungfunction methods, have suggested a pref- 
erential dilation of smaller and more peripheral airways after inhalation of beta 2 sympathicomimetic drugs, and a dilation of larger airways after inhalation of anticholinergic agents ${ }^{15,16}$. Other authors have concluded that these types of drugs have similar sites of action, both affecting large and small airways ${ }^{11,17}$.

The observed changes in impedance parameters in the present study occurred after inhalation of smaller doses than generally used in previous studies, thus underlining the sensitivity of the forced oscillation technique to detect changes in the mechanical behaviour of the respiratory system. Furthermore, our data illustrate the rapid onset of bronchodilation after the inhalation of ipratropium bromide. However, the quantitative difference between the effects of both drugs can be explained at least partly by the fact that the maximum effect of ipratropium bromide has been shown to occur after a longer interval than 15 minutes ${ }^{24.25}$. Remarkably, a slight but statistically significant increase in $X_{\mathrm{rs}}$ was demonstrated by means of the forced oscillation technique after the inhalation of fenoterol and ipratropium bromide.

In normal subjects, $X_{\mathrm{rs}}$ will be determined by the inertance of air in the airways and the capacitance of the respiratory system. When presuming the influence of airway wall compliance to be negligible in normal subjects, this capacitance will be mainly determined by the compliance of the lungs in series with the chest wall compliance ${ }^{22}$. Chest wall compliance is not modified by the inhalation of bronchodilating drugs, and doses of beta2 agonists and anticholinergic drugs higher than those used in this study failed to change the elastic properties of the lungs in previous studies $4,7,11,14,16,26-28$. Furthermore, in view of the parallel decrease in the real part of impedance after the administration of both drugs, a decrease in inductive reactance due to an increased central airway diameter has to be considered. The decrease in capacitative reactance has to be greater than the decrease in inductive reactance according to the observed net increase in total reactance. It must be emphasized that these effects on the capacitance of the lungs occurred after the inhalation of even low doses of both drugs.

In conclusion, fenoterol and ipratropium bromide caused qualitatively similar changes in resistance and reactance of the respiratory system. The changes in resistance are compatible with dilation of the central airways. Both drugs also significantly increased the reactance of the respiratory system, possibly by increasing the capacitance of the lungs.

Impedance measurement by the forced oscillation technique is a useful method to study the influences of bronchoactive drugs on the respiratory system as has been demonstrated in earlier studies performed in our laboratory ${ }^{29,30}$. As illustrated by the present study, it is possible not only to demonstrate the effects of bronchoactive drugs, but also to localize these effects along the human tracheobronchial tree, by simultaneous measurements of resistance and reactance of the respiratory system. Further advantages of the technique of forced 
oscillations are the short duration of the measuring procedure and the elimination of any active cooperation of the subject, thereby avoiding the influences of deep inspirations on bronchial tone. 


\section{References}

1. Gross NJ, Skorodin MS.

Anticholinergic, antimuscarinic bronchodilators.

Am Rev Respir Dis 1984; 129: 856-870.

2. Mann J, George C.

Anticholinergic drugs in the treatment of airways disease.

Br J Dis Chest 1985; 79: 209-228.

3. Yeager $H$, Weinberg RM, Kaufman LV, Katz M.

Asthma: comparative bronchodilator effects of ipratropium bromide and isoproterenol.

J Clin Pharmacol 1979; 141: 198-204.

4. Stamm AM, Clausen J, Tisi GM.

Effects of aerosolized isoproterenol on resting myogenic tone in normals.

J Appl Physiol 1976; 40: 525-532.

5. Tattersfield AE, Leaver DG, Pride NB.

Effects of beta-adrenergic blockade and stimulation on nornal human airways.

J Appl Physiol 1973; 35: 613-619.

6. Santamaria J, Guillemi S, Osbome S, Coppin C, Dahlby R, Pare PD.

Site of bronchodilation with inhaled ipratropium bromide and fenoterol in normal subjects.

Chest 1987; 91: 86-90.

7. De Troyer A, Yemault JC, Rodenstein D.

Effects of vagal blockade on lung mechanics in normal man.

J Appl Physiol 1979; 46: 217-226.

8. McFadden ER, Newton-Howes J, Pride NB.

Acute effects of inhaled isoproterenol on the mechanical characteristics of the lungs in normal man.

J Clin Invest 1970; 49: 779-790.

9. Skinner C, Palmer KNV.

Changes in specific airways conductance and forced expiratory volume in one second after a bronchodilator in normal subjects and patients with airways obstruction.

Thorax 1974; 29: 574-577.

10. Watanabe S, Renzetti AD, Bégin R, Bigler AH.

Airway responsiveness to a bronchodilator aerosol.

Am Rev Respir Dis 1974; 109: 530-537.

11. Douglas NJ, Sudlow MF, Flenley DC.

Effect of an inhaled atropinelike agent on normal airway function.

J Appl Physiol 1979; 46: 256-262.

12. Francis RA, Thomson ML, Pavia D, Douglas RB.

Ipratropium bromide: mucociliary clearance rate and airway resistance in normal subjects.

Br J Dis Chest 1977; 71: 173-178.

13. Vincent NJ, Knudson R, Leith DE, MackJem PT, Mead J.

Factors influencing pulmonary resistance.

J Appl Physiol 1970; 29: 236-243. 
14. Weiss JW, McFadden ER, Ingram RH.

Parenteral vs inhaled atropine: density dependence of maximal expiratory flnw.

J Appl Physiol 1982: 53: 392-396.

15. Hensley MJ, O'Cain CF, McFadden ER, Ingram RH.

Distribution of bronchodilation in normal subjects: beta agonist versus atropine.

J Appl Physiol 1978; 45: 778-782.

16. Ingram RH, Wellman JJ, McFadden ER, Mead J.

Relative contribution of large and small airways to flow limitation in normal subjects before and after atropine and isoproterenol.

$\mathrm{J}$ Clin Invest 1977; 59: 696-703.

17. MacNee W, Douglas NJ, Sudlow MF.

Effects of inhalation of beta sympathicomemitic and atropine-like drugs on airway calibre in normal subjects.

Clin Sci 1982; 63: 137-143.

18. Dubois AB, Brody AW, Lewis DH, Burgess BF.

Oscillation mechanics of lungs and chest in man.

J Appl Physiol 1956; 8: 587-594.

19. Orehek J, Nicoli MM, Delpierre S, Beaupré A.

Influence of the previous deep inspiration on the spirometric measurements of provoked bronchoconstriction in asthma.

Am Rev Respir Dis 1981; 123: 269-272.

20. Higenbottam T, Clark TJH.

Practical importance of a preceding full inhalation or exhalation upon the measurement of airway resistance.

Clin Sci 1980; 58: 249-253.

21. Làndsér FJ, Nagels J, Demedts M, Billiet L, Van de Woestijne KP.

A new method to determine frequency characteristics of the respiratory system.

J Appl Physiol 1976; 41: 101-106.

22. Nagels J, Làndsér FJ, Van der Linden J, Clément J, Van de Woestijne KP.

Mechanical properties of lungs and chest wall during spontaneous breathing.

J Appl Physiol 1980; 49: 408-416.

23. Pimmel RL, Tsai MJ, Winter DC, Bromberg PA.

Estimating central and peripheral respiratory resistance.

J Appl Physiol 1978; 45: 375-380.

24. Emirgil C, Dwyer K, Baskette P, Sobol BJ.

A new parasympatholytic bronchodilator: a study of its onset of effect after inhalation.

Curr Ther Res 1975; 17: 215-224.

25. Loddenkemper R.

Dose- and time-response of SCH $1000 \mathrm{MDI}$ on total (Rt) and expiratory (Re) airways resistance after inhalation of different doses in patients with chronic bronchitis and emphysema (Abstract).

Postgrad Med J 1975; 51 (suppl. 7): 97.

26. Bobbaers H, Stanescu DC, Demedts M, Clément J, Pardaens J, Van de Woestijne KP. Action of isoprenaline on the mechanical properties of lungs and airways in healthy people and patients with obstructive lung diseases.

Bull Eur Physiopathol Respir 1976; 12: 515-531. 
27. Bouhuys A, Van de Woestijne KP.

Mechanical consequences of airway smooth muscle relaxation.

J Appl Physiol 1971; 30: 670-676.

28. De Troyer A, Yemault JC, Rodenstein D.

Influence of beta-2 agonist aerosols on pressure-volume characteristics of the lungs. Am Rev Respir Dis 1978; 118: 987-995.

29. Wouters EFM, Quaedvlieg M, Mostert R, Polko AH, Visser BF. Localization of bronchial response to ipratropium bromide by respiratory impedance measurement in asthmatics.

Int J Clin Pharmacol Ther Toxicol 1989; 27: 145-149.

30. Wouters EFM.

Bronchial response in COPD measured by forced oscillation technique (thesis, 1987), University of Limburg, Maastricht, The Netherlands. 


\section{Chapter VIII}

A comparison of the effects of anticholinergic and beta 2 agonist and combination therapy on respiratory impedance in COPD.

G.J. Wesseling

R. Mostert

E.F.M. Wouters

Asthma Centre Hornerheide ${ }^{1}$, Horn, the Netherlands.

Chest 1992; 101: 166-173 


\section{A comparison of the effects of anticholinergic and beta 2 agonist and combination therapy on respiratory impedance in COPD.}

\section{Abstract}

The effects of three different regimens of inhaled bronchodilators on spirometry and respiratory impedance as measured with the technique of forced oscillations were compared in a double-blind crossover study in 22 patients with stable chronic obstructive pulmonary disease ( $\mathrm{FEV}_{1}<70 \%$ predicted).

On 3 trial days, patients inhaled, in random order, $40 \mu \mathrm{g}$ ipratropium bromide, $200 \mu \mathrm{g}$ fenoterol hydrobromide, or a combination of $40 \mu \mathrm{g}$ ipratropium and 100 $\mu \mathrm{g}$ fenoterol from a powder inhaler, followed by a second dose of the same drug after 60 minutes. The effects were measured at baseline and 20, 40,60 and 120 min after the first inhalation.

No significant decrease in total respiratory resistance at $8 \mathrm{~Hz}\left(R_{\mathrm{rs}} 8\right)$ was observed after ipratropium, whereas $R_{\mathrm{rs} 8}$ decreased significantly $20 \mathrm{~min}$ after fenoterol and 40 min after the combination regimen $(p<0.05)$. All 3 studied drugs resulted in a significant increase in the reactance $(p<0.01)$ and decrease in resonant frequency.

Both fenoterol $\left(\triangle F E V_{1} 34 \%, p<0.0001\right)$ and the combination regimen $\left(\triangle F E V_{1}\right.$ $38 \%, \mathrm{p}<0.0001)$ resulted in a significantly larger increase in $\mathrm{FEV}_{\mathrm{I}}$ than ipratropium alone $\left(\triangle F E V_{1} 17 \%, p<0.0001\right)$. A second dose of fenoterol and of the combination regimen resulted in a further significant increase in $F E V_{1}$ after $120 \mathrm{~min}(\mathrm{p}<0.05)$. A second dose of ipratropium did not result in a further significant increase in $\mathrm{FEV}_{1}$.

The changes in respiratory impedance were qualitatively similar for all 3 drug regimens, but larger in absolute terms after fenoterol and the combination regimen than after ipratropium. The similar effect of these drugs on the reactance can be explained by an increase in the capacitance of the respiratory system, and, in combination with a decrease in frequency dependence of resistance, by assuming a decrease in peripheral airway resistance. 


\section{Introduction}

Inhaled bronchodilators play an important role in the treatment of patients with chronic obstructive pulmonary disease (COPD). Until recently, beta2 adrenergic inhalants were by far the most widely used, but since the introduction of anticholinergic drugs as inhaled bronchodilators, these drugs have been increasingly popular especially in patients with $\mathrm{COPD}^{1}$.

Because decisions on bronchodilating treatment of patients with COPD are often based on the outcome of lung function measurements and reversibility tests, it is important to verify the exact response to bronchodilators. Generally, simple measurements of lung function have been used to assess the therapeutic efficacy of beta-adrenergic and anticholinergic drugs ${ }^{2,3}$. Occasionally, more complex measurements were used in an attempt to define the site along the airways at which the drugs are effective $e^{4,5}$.

In addition to the standard method of spirometry, impedance measurements of the respiratory system by means of the technique of forced oscillations ${ }^{6}$ may be useful to assess the effects of bronchodilating agents on the mechanical characteristics of the respiratory system of patients with COPD. This technique allows the determination of the resistance and reactance of the respiratory system over a wide frequency range during spontaneous quiet breathing, and, in contrast with spirometry, does not require forced expiratory manoeuvres. This makes this technique very suited for serial determinations, since the measurement itself does not modify bronchial smooth muscle tone ${ }^{7}$.

Additionally, this technique may provide information on the effects of bronchodilating agents, not obtainable with other lung function techniques ${ }^{8}$.

Numerous studies have been published on the comparitive effects of beta2 adrenergic and anticholenergic drug both in standard and in higher doses, and on the effectiveness of the combination of these drugs ${ }^{1-3,9-15}$. In the present study, we have used the technique of forced oscillations and spirometry in a study of the effects of the inhalation of standard doses of fenoterol, a beta2 adrenergic agent and ipratropium bromide, a quarternary isopropyl derivative of atropine and a combination of the two drugs on the impedance of the respiratory system and on FEV 1 in patients with COPD.

\section{Patients and methods}

\section{Patient selection}

Twenty-two male patients with chronic bronchitis and an obstructive ventilatory impairment, with a mean age of 66 years (range: 53 to 78), were selected for the study. Inclusion criteria were a clinical diagnosis of COPD and an obstructive lung function impairment as defined by $\mathrm{FEV}_{1}$ of less than $70 \%$ of predicted ${ }^{16}$, 
with an acute reversibility of less than $15 \%$ of the baseline value following the administration of an inhaled brochodilator. They had no documented upper respiratory tract infections in the two weeks before testing. Patients with documented serious renal, hepatic, endocrine, metabolic or cardiovascular disease were excluded from the study. All patients were familiar with the use of inhaled bronchodilators. All patients had a history of cigarette smoking of at least 20 pack-years.

At entry into the study, patients performed baseline spirometry, and the reversibility of the airflow obstruction was determined on 2 selection days. Sustained release theophyllines were continued during the selection days.

On selection day 1 , reversibility was determined $30 \mathrm{~min}$ after the inhalation of 2 puffs $(40 \mu \mathrm{g})$ ipratropium bromide and on selection day 2 , it was determined $30 \mathrm{~min}$ after the inhalation of 2 puffs $(400 \mu \mathrm{g})$ fenoterol hydrobromide, both from metered dose inhalers. These reversibility tests were performed within one week before starting the actual trial. None of the reversibility tests revealed an increase in $\mathrm{FEV}_{1}$ greater than $15 \%$ of the baseline value, or greater than $7 \%$ of the predicted value. The study was approved by the local Ethics Committee. Informed consent was obtained from all patients. In table 1, the characteristics of the subjects are summarized.

Table 1:

Anthropometric and spirometric data $(\mathrm{n}=22)$

\begin{tabular}{llll}
\hline & & Mean & SD \\
\hline Age & yrs & 66.2 & 8.0 \\
Height & $\mathrm{cm}$ & 171 & 6.5 \\
Weight & $\mathrm{kg}$ & 70.8 & 10.1 \\
FEV1, sel day FEN & 1 & 0.897 & 0.201 \\
FEV1, sel day FEN & $\%$ pred & 40.8 & 14.1 \\
FEV I/FVC, sel day FEN & $\%$ & 31.3 & 7.4 \\
FEV1, sel day IPR & 1 & 0.941 & 0.214 \\
FEV1, sel day IPR & $\%$ pred & 44.1 & 14.4 \\
FEV1/FVC, sel day IPR & $\%$ & 33 & 7.4 \\
$\triangle$ FEV1, FEN & 1 & 0.083 & 0.074 \\
$\triangle F E V 1$, IPR & 1 & 0.068 & 0.115 \\
\hline
\end{tabular}

IPR: ipratropium; FEN: fenoterol; sel: selection.

\section{Study design}

The study was of double-blind random crossover design. The actual studies were performed after abstinence from sustained-release theophyllines for $24 \mathrm{~h}$ and inhaled bronchodilators for $8 \mathrm{~h}$. None of the patients used any of the new 
long-acting sympaticomimetics. Treatment with inhaled and oral steroids was continued at the same dose throughout the study period. 5 patients used oral corticosteroids (prednisolone 5 to $10 \mathrm{mg} /$ day), one inhaled beclomethasone 1.6 $\mathrm{mg} /$ day. On three separate days, at least $48 \mathrm{~h}$ apart, the effects of the inhalation of three different test medications was determined.

Following baseline impedance and spirometric measurements, all patients received either $200 \mu \mathrm{g}$ fenoterol hydrobromide, $40 \mu \mathrm{g}$ ipratropium bromide or a combination of $100 \mu \mathrm{g}$ fenoterol and $40 \mu \mathrm{g}$ ipratropium, all from a powder inhaler (Inhalator, Ingelheim). All medication was administered in the morning between 8.00 and $10.00 \mathrm{AM}$ by the same investigator.

Impedance measurements and spirometry were performed 20,40 and $60 \mathrm{~min}$ after the inhalation of the drug. After $60 \mathrm{~min}$, a second dose of the test medication was given; $1 \mathrm{~h}$ after this second dose, lung function assessments were repeated. Impedance measurements always preceded spirometry.

Patients were asked for side effects and the pulse rate was recorded.

\section{Lungfunction assessment}

Spirometry was performed using a wet spirometer (Gould Pulmonet III). Three forced expirations were recorded at each measurement: the highest value of $\mathrm{FEV}_{1}$ was used for the subsequent calculations.

Impedance $(Z)$ of the respiratory system (rs) was determined with the technique of forced oscillations (chapter III).

All measurements were performed by the same laboratory staff member.

\section{Data analysis}

Three consecutive impedance measurements were performed and the values thus obtained were averaged. To express the results, 5 sets of impedance parameters were used: the total respiratory resistance at $8 \mathrm{~Hz}\left(R_{\mathrm{rs} 8}\right)$ and $28 \mathrm{~Hz}$ $\left(R_{\mathrm{rs} 28}\right)$, respiratory reactance at $8 \mathrm{~Hz}\left(X_{\mathrm{rs} 8}\right)$, resonant frequency, $i e$, the frequency at which the reactance is $0\left(f_{0}\right)$ and the frequency dependence of the resistance (FD) defined as the ratio $R_{\mathrm{rs} 28}-R_{\mathrm{rs} 8} / 20$, indicating the slope of the resistance versus frequency curve. A negative slope means a decrease in $R_{\mathrm{TS}}$ with increasing frequency.

Mean values were compared using Student's paired $t$ tests and p-values $<0.05$ were retained as statistically significant.

\section{Results}

Twenty patients completed the three-day study. Two patients failed to complete the study, one patient because of an upper respiratory tract infection during the 
study and one patient because he could not be familiarized with the impedance measurements.

Differences in baseline values for $\mathrm{FEV}_{1}$ and all analyzed impedance data among the three study days were not statistically significant.

All three study drugs caused a statistically significant increase in $\mathrm{FEV}_{1}$ at 20, 40 and $60 \mathrm{~min}$ after the inhalation (figure 1). After $20 \mathrm{~min}$ the mean increase in $\mathrm{FEV}_{1}$ after fenoterol was $34 \pm 14.2 \%$ of baseline value, after ipratropium bromide it was $17 \pm 9.6 \%$ and after the combination therapy it was $38 \pm 17.7 \%$. After 20 min, no further significant increase in $\mathrm{FEV}_{1}$ was observed, and significant increases in $\mathrm{FEV}_{1}$ persisted during the first hour for all three drugs. The second dose of fenoterol and of the combination regimen, but not of ipratropium bromide, resulted in a slight further increase in $\mathrm{FEV}_{1}$ at $120 \mathrm{~min}(\mathrm{p}<0.05)$.

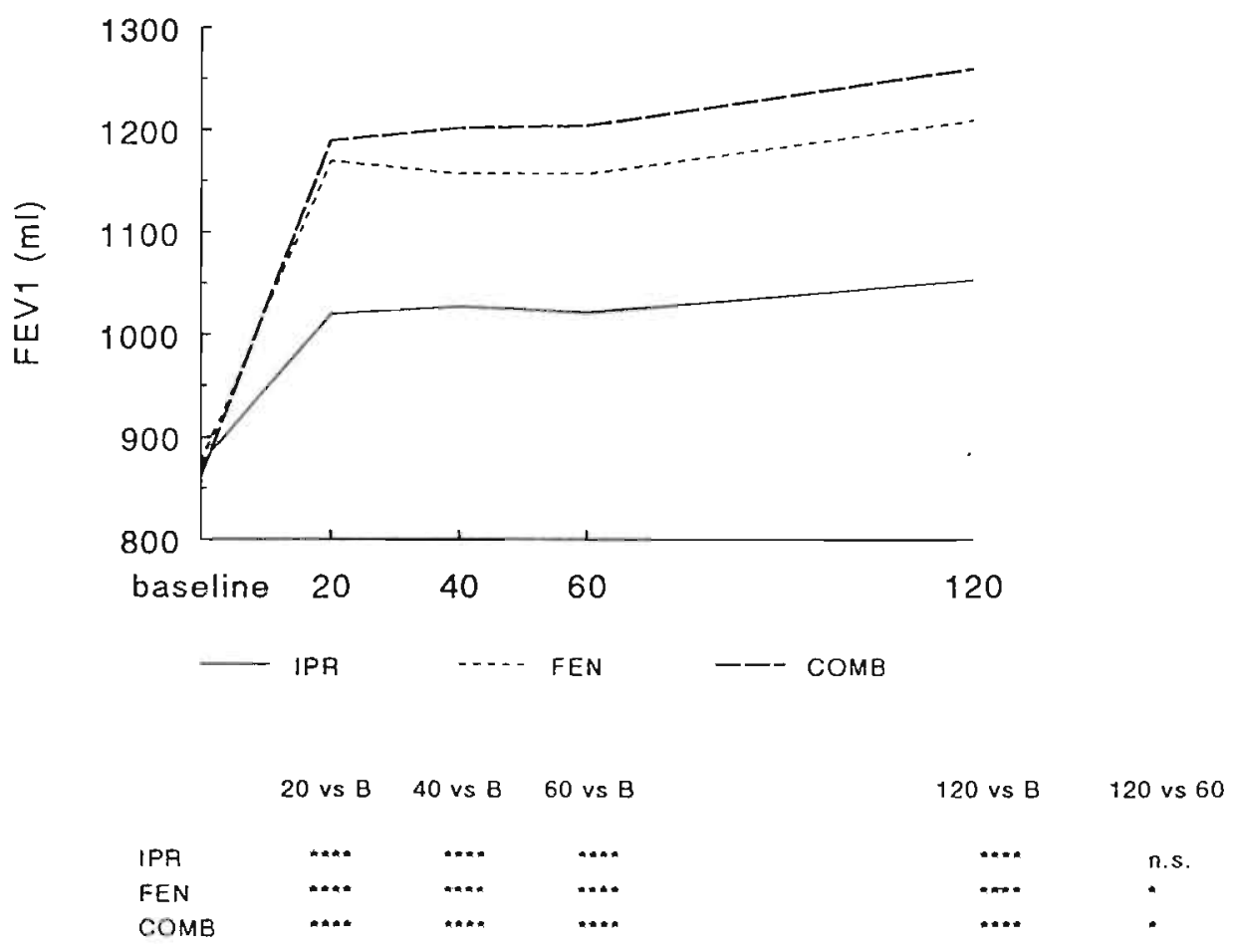

Figure 1:

mean values of $\mathrm{FEV}_{1}(\mathrm{ml})$ after $40 \mu \mathrm{g}$ ipratropium bromide, $200 \mu \mathrm{g}$ fenoterol hydrobromide and a combination of $40 \mu \mathrm{g}$ ipratropium and $100 \mu \mathrm{g}$ fenoterol.

Levels of significance: not significant n.s.; $0.01 \leq \mathrm{p}<0.05 * ; 0.001 \leq \mathrm{p}<0.01 * * ; 0.0001 \leq$ $\mathrm{p}<0.001^{* * *} ; \mathrm{p}<0.0001^{* * * *}$ 


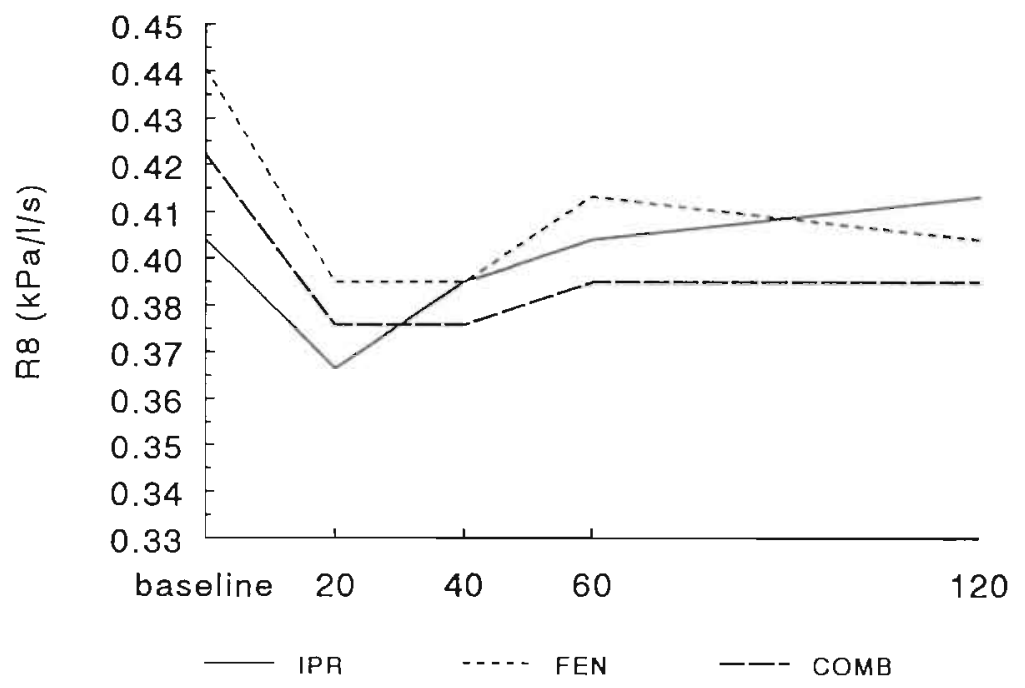

$\begin{array}{lccccc} & 20 \text { vs } B & 40 \text { vs } B & 60 \text { vs } B & 120 \text { vs } B & 120 \text { vs } 60 \\ \text { IPA } & \text { n.s. } & \text { n.s. } & \text { n.s. } & \text { n.s. } & \text { n.s. } \\ \text { FEN } & \text { n.s. } & \text { n.s. } & \text { n.s. } & \text { n.s. } & \text { n.s. } \\ \text { COMB } & \text { n.s. } & * & & \text { n.s. } & \text { n.s. }\end{array}$

Figure 2:

values for resistance at $8 \mathrm{~Hz}\left(R_{\mathrm{rs} 8}\right)$ in $\mathrm{kPa} / \mathrm{l} / \mathrm{s}$ after $40 \mu \mathrm{g}$ ipratropium bromide, $200 \mu \mathrm{g}$ fenoterol hydrobromide and a combination of $40 \mu \mathrm{g}$ ipratropium and $100 \mu \mathrm{g}$ fenoterol.

The values of $R_{\mathrm{rs}}$ at $8 \mathrm{~Hz}$ are illustrated in figure 2 . Twenty minutes after the inhalation of fenoterol, the resistance at $8 \mathrm{~Hz}$ decreased significantly by $0.043 \pm$ $0.017 \mathrm{kPa} / \mathrm{l} / \mathrm{s}$ from $0.436 \pm 0.154 \mathrm{kPa} / \mathrm{l} / \mathrm{s}$ to $0.393 \pm 0.142 \mathrm{kPa} / \mathrm{l} / \mathrm{s}$. Forty minutes after the combination regimen, $R_{\mathrm{rs} 8}$ had decreased significantly by $0.045 \pm 0.017$ $\mathrm{kPa} / \mathrm{l} / \mathrm{s}$ from $0.421 \pm 0.173 \mathrm{kPa} / \mathrm{l} / \mathrm{s}$ to $0.376 \pm 0.157 \mathrm{kPa} / \mathrm{l} / \mathrm{s}$. A second dose of the drugs did not result in a further significant decrease in $R_{\mathrm{rs}}$ values. The changes in $R_{\mathrm{r} s 8}$ after the inhalation of ipratropium bromide did not reach a level of significance at any time of measurement and the changes in $R_{\mathrm{rs} 28}$ were not statistically significant after any drug.

Under baseline conditions a marked frequency dependence of resistance was found, in that the oscillatory resistance decreased with increasing frequency resulting in negative values for FD as is shown in figure 3.

Frequency dependence of resistance became significantly less negative after fenoterol and the combination regimen, at 20 and $40 \mathrm{~min}$. FD increased significantly only at $20 \mathrm{~min}$ after the inhalation of ipratropium bromide. Only in the 


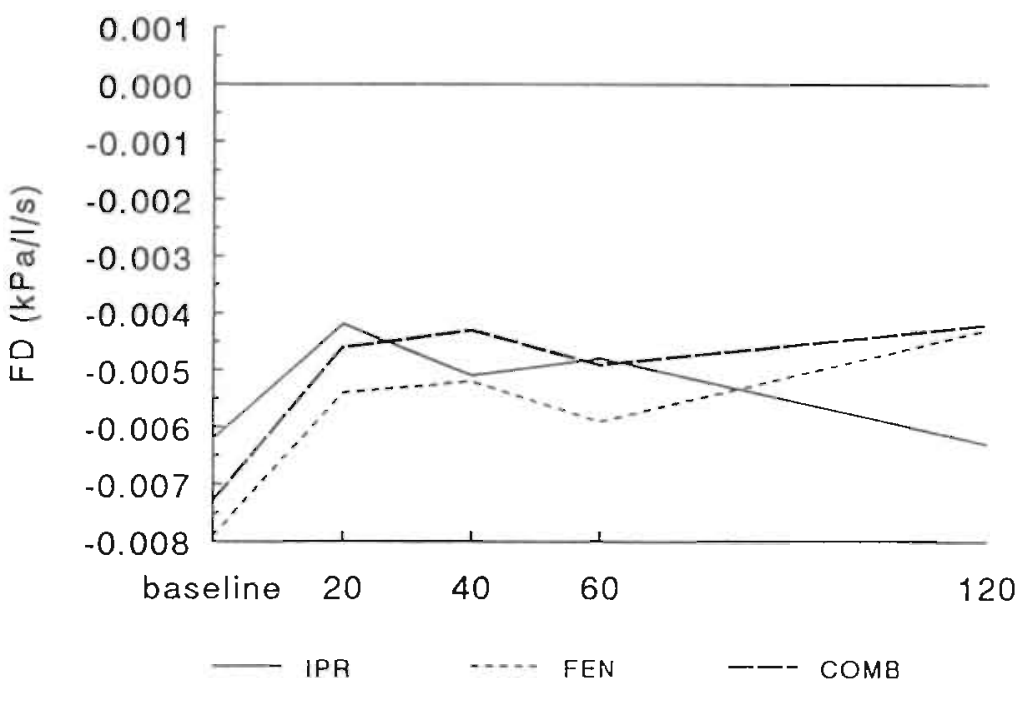

20 vs $B \quad 40$ vs B 60 vs $B$

120 vs $B \quad 120$ vs 60

$\begin{array}{llll}\text { IPR } & * & \text { n.s. } & \text { n.s. } \\ \text { FEN } & * & * & \text { n.s. } \\ \text { IOMB } & * & * & \text { n.s. }\end{array}$

$\begin{array}{ll}\text { n.s. } & \text { n.s. } \\ -. & n\end{array}$

Figure 3:

values for frequency dependence of resistance (FD) in $\mathrm{kPa} / \mathrm{s}$ after $40 \mu \mathrm{g}$ ipratropium bromide, $200 \mu \mathrm{g}$ fenoterol hydrobromide and a combination of $40 \mu \mathrm{g}$ ipratropium and $100 \mu \mathrm{g}$ fenoterol.

case of fenoterol did a second dose result in a further significant increase in frequency dependence values at $120 \mathrm{~min}$. Mean baseline reactance values at 8 $\mathrm{Hz}$ were highly negative on the 3 study days (figure 4). All three medications resulted in a significant increase in the reactance of the respiratory system at 8 $\mathrm{Hz}$. This effect lasted up to $60 \mathrm{~min}$ after ipratropium bromide $(\mathrm{p}<0.0001)$ and up to $120 \mathrm{~min}$ after fenoterol and the combination ( $p<0.0001$ ).

As a result of the highly negative values for reactance, increased baseline values for resonant frequency, ranging from 18 to $38 \mathrm{~Hz}$, were found. All three study drugs resulted in statistically significant decreases in $f_{0}$. After ipratropium bromide, the resonant frequency decreased from $28.1 \pm 3.4 \mathrm{~Hz}$ to $25.1 \pm 3.9 \mathrm{~Hz}$ at $20 \mathrm{~min}(\mathrm{p}<0.0001)$, after fenoterol $f_{0}$ decreased from $28.4 \pm 3.7 \mathrm{~Hz}$ to $24.7 \pm$ $5.4 \mathrm{~Hz}$ at $20 \mathrm{~min}(\mathrm{p}<0.001)$ and finally to $24.1 \pm 6.0 \mathrm{~Hz}$ after $120 \mathrm{~min}(\mathrm{p}<$ 0.001 ) and inhalation of the combination resulted in a maximum decrease in $f_{0}$ from $27.8 \pm 4.8 \mathrm{~Hz}$ to $22.3 \pm 5.6 \mathrm{~Hz}$ at $60 \mathrm{~min}$ ( $p<0.0001$ ). Decreases in resonant frequency were statistically significant throughout the observation period and 


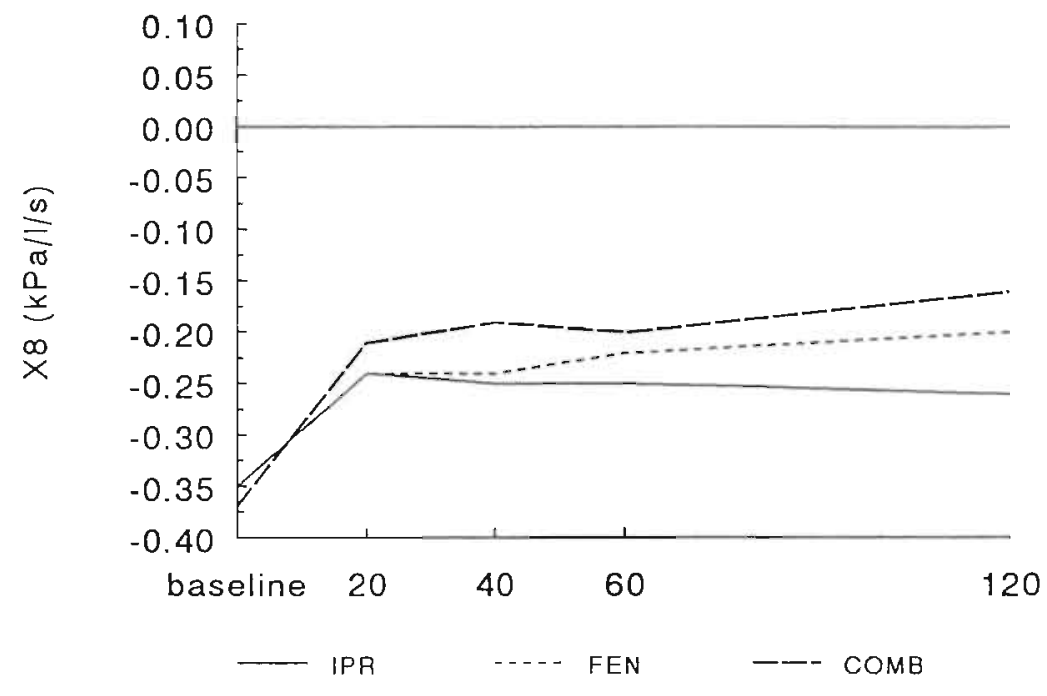

20 vs $B \quad 40$ vs $B \quad 60$ vs $B$

120 vs $B \quad 120$ vs 60

$\begin{array}{llllll}\text { IPR } & \ldots . & \ldots & \ldots & n . s . & \text { n.s. } \\ \text { FEN } & \ldots & \ldots & \ldots . & \ldots \ldots & \text { n.s. } \\ \text { COMB } & \ldots . . & \ldots . . & \ldots n+ & \ldots \ldots & \text { n.s. }\end{array}$

Figure 4:

values for reactance at $8 \mathrm{~Hz}\left(X_{\mathrm{rs} 8}\right)$ in $\mathrm{kPa} / 1 / \mathrm{s}$ after $40 \mu \mathrm{g}$ ipratropium bromide. $200 \mu \mathrm{g}$ fenoterol hydrobromide and a combination of $40 \mu \mathrm{g}$ ipratropium and $100 \mu \mathrm{g}$ fenoterol.

only in the case of fenoterol did a second dose result in a further significant decrease in $f_{0}$ (from $25.3 \pm 6.1 \mathrm{~Hz}$ to $24.1 \pm 6.0 \mathrm{~Hz}, \mathrm{p}<0.05$ ).

No serious side effects were reported by any of the patients throughout the entire study period. No significant differences in pulse rate were found between the 3 medications.

\section{Discussion}

In the present study we have used spirometry and the technique of forced oscillations to assess the effects of 3 regimens of bronchodilating agents on the lung function and mechanical characteristics of the respiratory system in patients with COPD. Both $40 \mu \mathrm{g}$ ipratropium bromide and $200 \mu \mathrm{g}$ fenoterol and the combination of $40 \mu \mathrm{g}$ iptratropium $+100 \mu \mathrm{g}$ fenoterol resulted in statistically and clinically significant increases in $\mathrm{FEV}_{1}$ and in the doses used in our study, 
fenoterol and the combination of fenoterol and ipratropium bromide had a more marked effect on $\mathrm{FEV}_{1}$ than ipratropium bromide alone.

It is observed that the increase in $\mathrm{FEV}_{1}$ on the study days was larger than on the selection days. An influence of the discontinuation of treatment with the sustained release theophyllines on the bronchodilator response seems unlikely since baseline $\mathrm{FEV}_{1}$ differed not significantly between the selection days and the actual study days. A possible explanation is the fact that on the selection days, reversibility was tested after the inhalation of bronchodilating agents from a metered dose inhaler, whilst on the study days the bronchodilators were inhaled from a dry powder inhaler. Although several studies have demonstrated no significant differences in efficacy between bronchodilators inhaled from pressure aerosols and dry powder delivery systems ${ }^{17,18}$, poor hand-lung coordination may have resulted in a smaller increase in $\mathrm{FEV}_{1}$ after the use of the aerosols.

It has been suggested that ipratropium bromide has a slower onset of action than isoproterenol ${ }^{19}$ and has a longer duration of action than albuterol ${ }^{3,19}$. In our study all 3 drug regimens resulted in a maximum or near maximum increase in $\mathrm{FEV}_{1}$ after $20 \mathrm{~min}$, with no further significant increase in $\mathrm{FEV}_{1}$, throughout the observation period of $2 \mathrm{~h}$. It is not impossible that a longer observation period would have revealed a superiority of ipratropium bromide over fenoterol.

Using the technique of forced oscillations in our patients, high values for oscillatory resistance at lower frequencies, and frequency dependence of resistance, ie a decrease in resistance with increasing frequencies, were demonstrated under baseline conditions. Also, high values for resonant frequency were found as a result of the highly negative values for reactance at lower frequencies. These findings have been described as characteristic for airway obstruction by Clément $e t a l^{20}$. The inhalation of all 3 study drugs resulted in relatively small and for the most part statistically non-significant decreases in the real part of the respiratory impedance. On the other hand, the changes in the imaginary part of impedance were highly significant with all 3 study drugs. Increases in the reactance values of the respiratory system, resulting from the inhalation of bronchodilators in patients with airway obstruction, have been reported previously $8,21-23$

The frequency dependence of $R_{\mathrm{rs}}$ and $X_{\mathrm{rs}}$ data in patients with COPD can satisfactorily be explained by the model of Nagels et $a^{24}$, based on the model of $\mathrm{Mead}^{25,26}$. In that algorithm, reactance is determined by the capacitance of the respiratory system, defined as the sum of lung compliance and airway compliance in series with chest wall compliance and the gaseous inertance, predominantly localized in the central airways. Since inductive reactance or inertance will only decrease by bronchodilation of the central airways ${ }^{8,24}$, the increase in the reactance values can be explained by an increase in the capacitance of the respiratory system. Since chest wall compliance will not be influenced by the inhalation of bronchodilating drugs ${ }^{27}$, the finding of an increase in reactance 
combined with a decrease in frequency dependence of resistance suggests an increase in the capacitance of the respiratory system resulting from a decrease in the resistance of the peripheral airways and/or an increase in the compliance of the airways ${ }^{24,26,27}$.

De Troyer $e t a l^{28}$ have demonstrated a decrease in elastic recoil pressure of the lung following the intravenous administration of atropine and a slight increase in lung compliance, whereas inhalation of ipratropium bromide did not modify the static mechanical properties of the lung. Since lung compliance is not likely to be of influence in the presence of increased peripheral airway resistance as is the case in patients with COPD, it is thought that the increase in the reactance results mainly from a decrease in peripheral airway resistance and an increase in airway compliance.

Shunt artifacts resulting from upper airway wall motion have been held responsible for errors in the estimation of respiratory impedance and its frequency dependence, especially in patients with airway obstruction ${ }^{21,24}$. Supporting the cheeks as was done by our patients does not fully eliminate this error ${ }^{29}$. These shunt properties cause an underestimation of the resistance values at lower frequencies in patients with airway obstruction ${ }^{30}$. Recently, Ying et $a^{31}$ confirmed the findings of negative frequency dependence of resistance and reactance in these patients comparing input impedance measured with a head generator to minimize transmural pressure across extrathoracic airway walls, to transfer impedance obtained with a pressure input at the chest in patients with COPD.

Our impedance data were not corrected for the influence of lung volume. A possible decrease in lung volume after bronchodilation may result in an increase in $R_{\mathrm{rs}}$ and a decrease in frequency dependence of resistance and in reactance in patients with COPD ${ }^{24}$. This increase in $R_{\mathrm{rs}}$ resulting from changes in lung volume may contribute to the discrepancy between spirometric and $R_{\mathrm{rs}}$ changes. On the other hand, the increase in frequency dependence of resistance and reactance values were found despite the possible opposite effects of lung volume changes in these patients.

We have observed a more pronounced effect of the combination therapy on the reactance of the respiratory system and on the resonant frequency, while the immediate effects of ipratropium bromide and fenoterol on these impedance parameters were qualitatively similar, suggesting equal sites of action of these drugs. Previous studies have provided conflicting information on the comparative effectiveness of standard doses of anticholinergic and beta-adrenergic agents in chronic airflow obstruction ${ }^{9-15}$. Most studies on the predominant site of action of anticholinergic and beta2 sympathicomimetic agents have been performed in patients with asthma. Information on this subject in patients with COPD is relatively scarce. In asthma, conflicting results have been reported. Storms $e a^{32}$ concluded that the major effect of ipratropium appears to be in the 
larger airways. This finding was later confirmed by Snow et $a l^{33}$ and Ashutosh $e t a l^{34}$. From a study on the effect of ipratropium on maximum mid expiratory flow and $\mathrm{FEV}_{1}$, Gross $^{35}$ concluded that ipratropium acts on central and peripheral airways.

In determing specific airway conductance as well as flow from maximum expiratory flow volume curves, Elwood and Abboud ${ }^{36}$ could not differentiate between predominant sites of action of fenoterol and ipratropium. In comparing the bronchodilator responses to atropine and terbutaline in asthma Chick and Jenne ${ }^{37}$ concluded that atropine exerts its bronchodilation action predominantly in larger airways, as is evidenced by an equal improvement in the plethysmographically determined airway resistance after use of terbutaline and atropine and by a greater increase in flow at $50 \%$ exhaled volume after use of terbutaline. Our observation of qualitatively similar bronchodilating effects of beta2 sympaticomimetic and anticholinergic agents on peripheral airways is in keeping with the identification of muscarinic receptors, especially $\mathrm{M}_{3}$ receptors in airway smooth muscle ${ }^{38}$. Based on autoradiographic visualization and selective muscarine antagonists, Mak and Barnes ${ }^{39}$ have demonstrated that muscarine receptors are localized in smooth muscle even in peripheral airways.

In our study no statistically significant additional effect was observed by doubling the dose in the second hour of the observation. This is in keeping with the findings of Le Doux et $a l^{10}$ who observed no objective benefit from doubling the standard dose of ipratropium bromide in patients with COPD.

In contrast with the findings observed after the inhalation of ipratropium bromide, a second dose of fenoterol did lead to a statistically significant, although clinically probably irrelevant, additional effect in our study. A similar finding has been reported by Larsson and Svedmyr ${ }^{40}$ with albuterol.

In summary, standard doses of fenoterol and ipratropium bromide and of a combination of these 2 drugs resulted in qualitatively similar changes in the impedance of the respiratory system, particularly a decrease in frequency dependence of resistance and an increase in reactance. These changes can be explained by an increase in the capacitance of the respiratory system due to an increase in airway compliance and/or a decrease in peripheral airway resistance. The combination of $40 \mu \mathrm{g}$ ipratropium bromide plus $100 \mu \mathrm{g}$ fenoterol resulted in a significantly larger increase in $\mathrm{FEV}_{1}$ than did ipratropium bromide alone, and a marginally larger increase in $\mathrm{FEV}_{1}$ than $200 \mu \mathrm{g}$ fenoterol alone.

\section{Acknowledgement.}

This study was supported by a grant from Boehringer Ingelheim. 


\section{References}

1. Poppius $\mathrm{H}$, Salorinne $\mathrm{Y}$.

Comparative trial of a new anticholinergic bronchodilator, Sch 1000, and Salbutamol in chronic bronchitis.

Br Med Clin Res 1973; 4: 134-136.

2. Hughes JA, Tobin MJ, Bellamy D, Hutchison DCS.

Effects of ipratropium bromide and fenoterol aerosol in pulmonary emphysema.

Thorax 1982; 37: 667-670.

3. Braun SR, Wayland N, Copeland C, Knight L, Elliersieck M.

A comparison of the effect of ipratropium and albuterol in the treatment of chronic obstructive airway disease.

Arch Intern Med 1989; 149: 544-547.

4. Hensley MJ, O'Cain CF, Mc Fadden ER, Ingram RH.

Distribution of bronchodilatation in normal subjects: beta-agonist versus atropine.

J Appl Physiol 1978; 45: 778-782.

5. Douglas NJ, Davidson J, Sudlow MF, Flenley DC.

Bronchodilation and the site of airway resistance in severe chronic bronchitis.

Thorax 1979; 34: 51-56.

6. Làndsér FJ, Nagels J, Demedts M, Billiet L, Van de Woestijne KP.

A new method to determine frequency characteristics of the respiratory system.

J Appl Physiol 1976; 41: 101-106.

7. Gayrard P, Orehek J, Grimaud C, Charpin J.

Bronchoconstrictor effects of a deep inspiration in patients with asthma.

Am Rev Respir Dis 1975; 111: 433-439.

8. Wouters EFM, Verschoof AC, Polko AH, Visser BF.

Impedance measurements of the respiratory system before and after salbutamol in COPD patients.

Respir Med 1989; 83: 309-313.

9. Tashkin DP, Ashutosh K, Bleeker ER, Britt EJ, Cugell DW, Cummiskey JM et al.

Comparison of the anticholinergic bronchodilator ipratroprium bromide with metaproterenol in chronic obstructive pulmonary disease.

Am J Med 1986; 81 (suppl. 5A): 81-90.

10. Le Doux EJ, Morris JF, Temple WP, Duncan C.

Standard and double dose ipratropium bromide and combined ipratropium bromide and inhaled metaproterenol in COPD.

Chest 1989; 95: 1013-1016.

11. Easton PA, Jadue C, Dhingra S, Anthonisen N.R.

A comparison of the bronchodilating effects of a beta2 adrenergic agonist (albuterol) and an anticholinergic agent (ipratropium bromide) given by aerosol alone or in sequence.

N Eng J Med 1986; 315: 735-739.

12. Petrie GR, Palmer KNV.

Comparison of aerosol ipratropium bromide and salbutamol in chronic bronchitis and asthma.

Br Med J 1975; 4: 134-136. 
13. Lightbody JM, Ingram CG, Legger JS, Johnston RN.

Ipratropium bromide, salbutamol and prednisolone in bronchial asthma and chronic bronchitis.

Br J Dis Chest 1978; 72: 181-186.

14. Howarth $\mathrm{PH}$, Stainforth JH, Holgate ST.

Bronchodilator efficacy of nebulized salbutamol and ipratropium bromide in chronic airflow obstruction.

Thorax 1982; 37: 789.

15. Starke ID, Parker RA, Turner-Warwick M.

Atropine methonitrate and salbutamol in chronic airway obstruction: Peak effect and duration of action.

Respiration 1982; 43: 51-56.

16. Quanjer PH.

Standardized lung function testing.

Bull Eur Physiopath Respir 1983; 10: 1-95.

17. Maesen FPV, Smeets JJ, Bernsen R, Comelissen PJG.

Ipratropium bromide (Atrovent) as inhalation powder.

Allergy 1986; 41: 37-42.

18. Town IG.

Comparison between aerosol and powder delivery system of fenoterol plus ipratropium bromide (Duovent) in patients with asthma and chronic bronchitis.

Pharmatherapeutica 1988; 5: 246-248.

19. Storms WS, Bodman SF, Nathan RA, Busse WW, Bush RK, Falliers C.J. et al. Use of ipratropium bromide in asthma.

Am J Med 1986; 81 S 5A: 61-66.

20. Clement J, Làndsér FJ, Van de Woestijne KP.

Total resistance and reactance in patients with respiratory complaints with and without airway obstruction.

Chest 1983; 83: 215-220.

21. Michaelson ED, Grassman ED, Peters WR.

Pulmonary mechanics by spectral analysis of forced random noise.

J Clin Invest 1975; 56: 1210-1230.

22. Nolte D, Berger D, Förster E.

Theoretical and clinical aspects of impedance measurements of the respiratory system.

Prog Respir Res 1979; 11: 172-178.

23. Làndsér FJ, Nagels J, Van de Woestijne KP.

Implementation by means of microprocessor techniques for the measurement of the respiratory impedance during spontaneous breathing.

Prog Respir Res 1979; 11: 135-143.

24. Nagels J, Làndsér FJ, Van der Linden L, Clément J, Van de Woestijne KP.

Mechanical properties of lungs and chest wall during spontaneous breathing.

J Appl Physiol 1980; 49: 574-577.

25. Mead J.

Contribution of compliance of airways to frequency dependent behaviour of lungs.

J Appl Physiol 1969; 26: 670-673.

26. Wouters EFM, Làndsér FJ, Polko AH, Visser BF.

Physiological analysis of extended-spectrum oscillometry.

Respiration 1988; 54: 263-270. 
27. Wouters EFM, Quaedvlieg M, Polko AH, Visser BF.

Localization of bronchial response to ipratropium bromide by respiratory impedance measurement in asthmatics.

Int J Clin Pharm Ther Tox 1989; 27: 145-149.

28. De Troyer A, Yernault JC, Rodenstein D.

Influence of beta2 agonist aerosols on pressure-volume characteristics of the lungs.

Am Rev Respir Dis 1978; 118: 987-995.

29. Peslin R, Duvivier C, Gallina C, Cervantes P.

Upper airway artifact in respiratory impedance measurements.

Am Rev Respir Dis 1985; 132: 712-714.

30. Cauberghs M, Van de Woestijne KP.

Mechanical properties of the upper airways.

J Appl Physiol 1983; 55: 335-342.

31. Ying Y, Peslin R, Duvivier C, Gallina C, Felicio da Silva J.

Respiratory input and transfer mechanical impedance in patients with chronic obstructive pulmonary disease.

Eur Respir J 1990; 3: 1186-1 192.

32. Storms WW, Dopico GA, Reed CE.

Aerosol Sch 1000: an anticholinergic bronchodilator.

Am Rev Respir Dis 1975; 111: 419-422.

33. Snow R, Miller W, Blair H, Rice D.

Inhaled atropine in asthma.

Ann Allergy 1979; 42: 286-289.

34. Ashutosh K, Mead G, Dickey JC jr., Berman P, Kuppinger M.

Density dependence of expiratory flow and bronchodilator response in asthma.

Chest 1980; 77: 68-75.

35. Gross NJ.

Sch 1000: a new anticholinergic bronchodilator.

Am Rev Respir Dis 1975; 112: 823-828.

36. Elwood RK, Abboud RT.

The short-term bronchodilator effects of fenoterol and ipratropium in asthma.

J Allergy Clin Immunol 1982; 69: 467-473.

37. Chick TW, Jenne JW.

Comparative bronchodilator responses to atropine and terbutaline in asthma and chronic bronchitis.

Chest 1977; 72: 719-723.

38. Anonymous.

Muscarinic receptor subtypes: implications for lung disease (editorial).

Thorax 1989; 44: 161-167.

39. Mak JCW, Barnes PJ.

Autoradiographic visualization of muscarinic receptor subtypes in human and Guinea pig lung.

Am Rev Respir Dis 1990; 141: 1559-1568.

40. Larsson S, Svedmyr N.

Bronchodilating effects and side effects of beta-adrenoreceptor stimulants by different modes of administration (tablets, metered aerosol and combinations thereof): a study with salbutamol in asthmatics.

Am Rev Respir Dis 1977; 116: 861-869. 



\section{Summary and conclusions.}

The aim of the study described in this thesis was to analyze the use of input impedance measurements by means of the technique of forced oscillations in clinical practice, to study the influence of health and disease on the impedance of the respiratory system and its frequency dependence and to analyze the effects of various agents known to affect the properties of the respiratory system, in an attempt to determine whether the technique of forced oscillations provides information on the mechanical characteristics of the respiratory system that cannot, or not easily, be obtained with other technique.

Introductory remarks on lung function measurements are made in chapter I.

In chapter II a survey on applications of input impedance measurements in various clinical conditions is presented, and the interpretation of the frequency dependence of impedance in clinical conditions is discussed.

In the study described in Chapter III, the technique was applied together with spirometry and measurements of maximum mouth pressures in a group of patients, severely disabled from various neuromuscular disorders. In all 27 sludy subjects who were referred with the purpose of pulmonary screening for longterm mechanical ventilatory support, the measurements could be performed without difficulties, in spite of severe physical limitations. Although resistance values were somewhat higher than those found in normal subjects, a normal relationship between respiratory impedance and oscillatory frequency was found, indicating the absence of air flow limitation resulting from bronchus obstruction even in the presence of grossly impaired respiratory muscle strength, thoracic wall abnormalities and reduced lung volumes. Impedance data were found not to correlate with the forced expiratory volume in 1 second $\left(F^{2} V_{1}\right)$ in these patients with severe ventilatory muscle weakness.

In chapter IV the changes in the impedance of the respiratory system resulting from a provocation test using isocapnic hyperventilation with cold air were analyzed in a group of 60 asthmatic subjects with proven bronchial hyperresponsiveness, with emphasis on the relationship between the changes in FEV $\left(\triangle F E V_{1}\right)$ and in the various impedance parameters that were analysed. After cold air provocation in these subjects the slope of the resistance versus frequency curve changed from positive before the challenge to negative, and thus resistance became frequency dependent. Also, more negative values for reactance 
and an increase in resonant frequency were found. These changes in impedance reflect ventilatory inhomogeneities in the peripheral compartment of the bronchial tree.

In this study the changes in the various impedance parameters were found to correlate significantly with the changes in $\mathrm{FEV}_{1}$, with coefficients of correlation ranching from -0.458 between $\Delta F E V_{1}$ and $\Delta R_{\mathrm{rs} 28}$, and -0.656 between $\Delta F E V_{1}$ and $\Delta R_{\mathrm{rs} 8 \text {. }}$

In chapter $\mathbf{V}$ we have performed impedance measurements in 33 patients with chronic bronchitis with no spirometrIC evidence of airflow obstruction as indicated by a $\mathrm{FEV}_{1}$ of at least $70 \%$ of predicted. In 10 patients $(30.3 \%)$ impedance characteristics were considered normal, namely an absence of negative frequency dependence of resistance and a resonant frequency below $16 \mathrm{~Hz}$. In these patients cold air provocation resulted in an increase in the resistance at $8 \mathrm{~Hz}$, a decrease in the reactance at $8 \mathrm{~Hz}$ and an increase in the resonant frequency, and the resistance became frequency dependent. All these changes were found to be completely reversible after the inhalation of a beta 2 adrenergic bronchodilator (terbutaline). In 23 patients (69.7\%) impedance abnormalities consisting of negative frequency dependence of resistance and/or an increased resonant frequency were found. Inhalation of terbutaline resulted in acute reversibility of these findings.

A similar reversibility in impedance abnormalities as was found after the inhalation of a beta 2 adrenergic drug in the patients described in chapter $\mathrm{V}$ was also found to result from treatment with an inhaled steroidal anti-inflammatory drug in a group of 30 patients with chronic bronchitis without marked airflow obstruction (FEV $1 \geq 70 \%$ predicted). In the placebo-controlled study described in chapter VI inhalation of budesonide $1.6 \mathrm{mg} /$ daily resulted in a small decrease in resonant frequency and a less negative frequency dependence of resistance compared with the placebo group. Changes in morning peak expiratory flow rate, symptom scores, use of beta 2 adrenergic rescue medication and $\mathrm{FEV}_{1}$ were somewhat larger in the active treatment group, but the differences were not statistically significant.

In chapter VII the bronchodilating effects of 2 different types of inhaled bronchodilators, one beta2 sympathicomimetic (fenoterol) and the other anticholinergic (ipratropium bromide) on the impedance of the respiratory system were studied in 20 normal subjects. Both $0.2 \mathrm{mg}$ fenoterol and $0.02 \mathrm{mg}$ ipratropium caused a decrease in the resistance at most frequencies, suggesting a dilation of the central airways, and an increase in the reactance of the respiratory system which is supposed to be the result of an increase in the capacitance of the lungs. The changes resulting from these to drugs were found to be qualitatively similar. This suggests that in normal subjects anticholinergic and beta2 adrenergic agents have similar sites of action along the tracheobronchial tree. 
As found in normal subjects (chapter VII), inhalation of anticholinergic and beta 2 adrenergic agents also resulted in qualitatively similar changes in respiratory impedance in patients with chronic obstructive pulmonary disease (COPD). In the double blind crossover study described in chapter VIII the effects of an inhaled anticholinergic drug (0.04 mg ipratropium bromide) a beta2 sympaticomimetic drug ( $0.2 \mathrm{mg}$ fenoterol) or a combination of $0.04 \mathrm{mg}$ ipratropium and $0.1 \mathrm{mg}$ fenoterol was studied on 3 separate days in 22 patients with stable COPD $\left(\mathrm{FEV}_{1}<70 \%\right.$ predicted). All 3 drug regimens resulted in relatively small decreases in the resistance of the respiratory system. The slope of the resistance versus frequency curve became less negative. Highly significant, qualitatively similar changes in the reactance were found with all 3 drug regimens, but the changes were larger in absolute terms after fenoterol than after ipratropium. The similar effect of these drugs on the reactance can be explained by an increase in the capacitance of the respiratory system and in combination with the decrease in negative frequency dependence of resistance by assuming a decrease in peripheral airway resistance.

From the results of the studies described in this thesis, it is concluded that respiratory impedance measurements using the technique of forced oscillations can be easily performed in many different categories of patients. Unlike spirometric tests, the measurments can be made at the low flow rates occuring during breathing at rest, thus avoiding the effects that forced respiratory manoeuvres may have on the smooth muscle tone of the respiratory system, and they do not necessitate active cooperation from the subjects. It forms a sensitive method to obtain information on the mechanical characteristics of the respiratory system in various disease entities. Analysis of the impedance measurements offers the possibility of not only a quantitative but also a qualitative analysis of the response to bronchoactive agents in patients with respiratory abnormalities, in that localisation of the effect of modulation of the mechanical characteristics of the respiratory system can be localised along the tracheobronchial tree, and appear to be attributable to different properties of the system. 
. 


\section{Samenvatting en conclusies}

Doel van de in dit proefschrift beschreven studie is na te gaan welke de bijdrage is van meting van de input impedantie van het respiratoire systeem met behulp van de techniek van geforceerde oscillatie aan het klinisch longfunctie-onderzoek, welke het effect is van ziekte en gezondheid op de impedantie en hoe verschillende agentia, waarvan bekend is dat ze de verschillende eigenschappen van het respiratoire systeem veranderen, de impedantie en haar frequentie afhankelijkheid beïnvloeden. Getracht wordt hiermee vast te stellen in hoeverre de geforceerde oscillatie techniek informatie aangaande de mechanische eigenschappen van het respiratoire systeem kan verschaffen, die op een andere wijze niet, of niet eenvoudig kan worden verkregen.

$\mathrm{Na}$ enkele inleidende opmerkingen over longfunctie-onderzoek in hoofdstuk I wordt in hoofdstuk II een overzicht gegeven van de literatuur aangaande toepassingen van input impedantie metingen onder verschillende klinische omstandigheden, en wordt de interpretatie van de frequentie afhankelijkheid van de impedantie besproken.

In de in hoofdstuk III beschreven studie werd de geforceerde oscillatietechniek samen met spirometrie en metingen van de maximale monddrukken toegepast in een groep patiënten lijdend aan verschillende neuromusculaire aandoeningen. $\mathrm{Bij}$ alle 27 ernstig geïnvalideerde patiënten, verwezen met het oog op evaluatie voor mogelijk chronische ademhalingsondersteuning, konden de metingen zonder moeilijkheden worden uitgevoerd, ondanks de ernstige lichamelijke beperkingen. Hoewel de gevonden waarden voor de totale respiratoire weerstand bij deze patiënten iets hoger was dan bij normale proefpersonen wordt gevonden, werd een normale relatie tussen impedantie en de frequentie van de oscillaties gevonden. Dit wijst erop dat geen sprake is van een uitademingsstoornis ten gevolge van bronchusobstructie, ondanks de aanwezigheid van een belangrijk afgenomen respiratoire spierkracht, thoraxwand deformaties en afgenomen longvolumina. Er bleek geen significante correlatie te bestaan tussen de impedantie waarden en de één seconde capaciteit in deze patiënten.

In hoofdstuk IV worden de veranderingen in de impedantie van het respiratoire systeem beschreven die het gevolg zijn van provocatie door isocapnische hyperventilatie met koude lucht bij 60 patiënten met astma bronchiale en aangetoonde bronchiale hyperreactiviteit. Met name werd de relatie tussen veranderingen in de één seconde capaciteit en de verschillende impedantie variabelen geanalyseerd. 
Gevonden werd dat door koude luchtprovocatie bij deze patiënten de helling van de kromme gevormd door de relatie tussen de weerstand en de oscillatoire frequentie van positief in negatief verandert, waarmee de weerstand frequentie afhankelijk wordt. Ook werden meer negatieve waarden voor de reactantie en een toegenomen resonantie frequentie gevonden. Deze veranderingen in de impedantie duiden op ventilatoire inhomogeniteiten in het perifere compartiment van het respiratoire systeem. In deze studie werden significante correlaties gevonden tussen de veranderingen in de één seconde capaciteit (ESC) en de verschillende impedantie waarden, variërend tussen $-0,458$ voor de relatie tussen de verandering in de ESC $(\triangle \mathrm{ESC})$ en de verandering in de respiratoire weerstand bij $28 \mathrm{~Hz}$, en $-0,656$ voor de relatie tussen $\triangle \mathrm{ESC}$ en de verandering in de weerstand bij $8 \mathrm{~Hz}$.

Voor de studie, beschreven in hoofdstuk $\mathbf{V}$, werden impedantie-metingen verricht bij 33 patiënten met chronische bronchitis zonder spirometrische aanwijzingen voor luchtwegobstructie, getuige een één seconde capaciteit van ten minste $70 \%$ van de voorspelde waarde. $\mathrm{Bij} 10$ patiënten (30,3\%) werden normale impedantie-karakteristieken gevonden, te weten afwezigheid van negatieve frequentie afhankelijkheid van de weerstand en een resonantie frequentie beneden $16 \mathrm{~Hz}$. Bij deze patiënten resulteerde koude luchtprovocatie in een stijging van de weerstand bij $8 \mathrm{~Hz}$, een daling van de reactantie bij $8 \mathrm{~Hz}$ en een toename van de resonantie frequentie; de weerstand werd hierbij frequentie-afhankelijk. Deze veranderingen bleken volledig reversibel na de inhalatie van een beta2 adrenerge luchtwegverwijder (terbutaline). Bij 23 patiënten $(69,7 \%$ ) werd een abnormale impedantie gevonden te weten negatieve frequentie afhankelijkheid van de weerstand en/of een verhoogde resonantie frequentie. Inhalatie van terbutaline leidde tot acute omkeerbaarheid van deze bevindingen.

Een vergelijkbare omkeerbaarheid van de afwijkingen in impedantie zoals die werd aangetroffen na de inhalatie van een beta 2 adrenerge medicament bij de patiënten beschreven in hoofdstuk $\mathrm{V}$ werd ook gevonden na behandeling met een inhalatie-corticosteroïd in een groep van 30 patiënten met chronische bronchitis zonder evidente uitademingsstoomis (ESC $\geq 70 \%$ van voorspeld). In de placebo-gecontroleerde studie beschreven in hoofdstuk VI, werd gevonden dat behandeling met 1,6 mg Budesonide gedurende 6 weken bij deze patiënten resulteert in een kleine daling van de resonantie frequentie en een minder negatieve frequentie afhankelijkheid van de weerstand vergeleken met placebo. Daarentegen werden geen significante veranderingen gezien in de 's morgens gemeten expiratoire piekstroom, gerapporteerde klachten, gebruik van beta2 adrenerge luchtwegverwijders en de ESC.

In hoofdstuk VII wordt het effect beschreven van 2 verschillende geïnhaleerde medicamenten, één beta 2 adrenerg (fenoterol), de andere anticholinerg (ipratropium bromide), op de impedantie van het respiratoire systeem bij 20 normale proefpersonen. Zowel $0,2 \mathrm{mg}$ fenoterol als $0,02 \mathrm{mg}$ ipratropium geven een 
daling van de weerstand bij de meeste onderzochte frequenties. Deze veranderingen suggereren een verwijding van de centrale luchtwegen. Voorts werd een stijging van de reactantie van het respiratoire systeem gevonden welke geacht wordt te berusten op een toename van de capacitantie van de longen. De veranderingen die optraden na toediening van deze medicamenten waren in kwalitatief opzicht vergelijkbaar. Dit suggereert dat bij normale proefpersonen anticholinerge en beta 2 adrenerge medicamenten werkzaam zijn in hetzelfde compartiment van het tracheobronchiale systeem.

Overeenkomend met wat werd gevonden bij normale proefpersonen (hoofdstuk VII) werden ook bij patiënten met ernstig chronisch obstructief longlijden (COPD) in kwalitatieve zin vergelijkbare veranderingen in de respiratoire impedantie gevonden na inhalatie van anticholinerge en beta $a_{2}$ adrenerge middelen. In de studie beschreven in hoofdstuk VIII werden de effecten geanalyseerd van inhalaties met 0,04 mg ipratropium bromide (anticholinerg), 0,2 mg fenoterol (beta 2 adrenerg) en de combinatie van $0,04 \mathrm{mg}$ ipratropium en $0,1 \mathrm{mg}$ fenoterol, toegediend op 3 verschillende dagen bij 22 patiënten met COPD in stabiele toestand (ESC $<70 \%$ van voorspeld). In alle drie de gevallen werden betrekkelijk geringe dalingen in de weerstand van het respiratoire systeem gevonden, en de helling van de weerstand versus frequentie kromme werd minder negatief. Kwalitatief vergelijkbare, in hoge mate significante veranderingen in de reactantie werden gevonden na toediening van elk van de drie medicaties, doch de veranderingen waren in absolute zin groter na fenoterol dan na ipratropium. De vergelijkbare effecten van deze medicaties kunnen worden verklaard door een stijging aan te nemen in de capacitantie van het respiratoire systeem en in combinatie met de afname in negatieve frequentie afhankelijkheid van de weerstand, door een daling te veronderstellen in de weerstand van de perifere luchtwegen.

Uit de resultaten van de in dit proefschrift beschreven onderzoeken wordt geconcludeerd dat metingen van de impedantie van het respiratoire systeem met behulp van de geforceerde oscillatietechniek eenvoudig uitvoerbaar is in veel verschillende patiëntencategorieën. In tegenstelling tot spirometrie kunnen de metingen worden verricht tijdens de lage luchtstroomsnelheid die optreedt tijdens rustademhaling. Op deze manier worden de effecten vermeden die geforceerde ademmanoeuvres kunnen hebben op de tonus van het respiratoire systeem. Voorts is geen actieve medewerking van de proefpersoon vereist. Deze techniek vormt een gevoelige methode om informatie te verkrijgen over de mechanische eigenschappen van het respiratoire systeem onder verschillende pathologische omstandigheden.

Analyse van impedantie metingen biedt de gelegenheid de respons op luchtwegvernauwende of -verwijdende factoren bij patiënten met respiratoire aandoeningen niet alleen in quantitatieve maar ook qualitatieve zin te analyseren, in die zin 
dat beïnvloeding van de mechanische eigenschappen van het respiratoire systeem toegeschreven kan worden aan verschillende componenten van het systeem. 


\section{List of publications}

Dose effects of inhaled ipratropium bromide on the impedance of the respiratory system.

Wesseling GJ, Vonk JM, Greve LH, Wouters EFM.

Int J Clin Pharm Ther Tox 1990; 28(1): 33-38.

Effects of inhalation of beta-2-sympathicomimetic and anticholinergic agents on the impedance of the respiratory system in normal subjects.

Wesseling GJ, Vonk HM, Wouters EFM.

Chest 1990; 97: 1137-1140.

Inhaled budesonide in chronic bronchitis. Effects on respiratory impedance.

Wesseling GJ, Quaedvlieg M, Wouters EFM.

Eur Respir J 1991; 4: 101-1105.

A comparison of the effects of anticholinergics, beta-2-agonists and combination therapy on respiratory impedance in COPD.

Wesseling GJ, Mostert R, Wouters EFM.

Chest 1992; 101 (1): 166-173.

Analysis of respiratory impedance characteristics in chronic bronchitis. Wesseling GJ, Wouters EFM.

Respiration 1992; 59: 81-88.

Postoperative pulmonary function abnormalities after coronary artery bypass surgery.

Van Belle AF, Wesseling GJ, Penn OCKM, Wouters EFM.

Respir Med 1992; 86: 195-199.

Oscillatory mechanics of the respiratory system in neuromuscular disease.

Wesseling GJ, Quaedvlieg FCM, Wouters EFM.

Chest 1992; 102: 1752-1757. 
Respiratory impedance measurements in a dose-response study of isocapnic hyperventilation with cold air.

Wesseling $G J$, Wouters EFM.

Respiration 1992; 59: 259-264.

The forced oscillation technique and spirometry in cold air provocation tests. Wesseling GJ, Vanderhoven-Augustin IML, Wouters EFM.

Thorax, in press.

Effects of inhaled corticosteroids in patients with simple chronic bronchitis. (abstract)

Wesseling G.J, Quaedvlieg M, Boorsma M, Wouters EFM.

Eur Respir J 1989; 2: 1035.

Effect of corticosteroids on total respiratory resistance in asthma and COPD. Wempe JB, Van der Mark TW, Wesseling GJ, Breederveld N, Koëter GH, Postma DS.

In: modulation of airflow limitation (JB Wempe, Thesis 1992 Groningen).

Diagnosing asthma in primary school children.

Cuypers CEJ, Swaen GMH, Wesseling GJ, Wouters EFM.

Eur Respir J 1992; 5; suppl. 15: 34s.

Forced oscillation technique in primary school children with and without respiratory complaints.

Cuypers CEJ, Swaen GMH, Wesseling GJ, Wouters EFM.

Eur Respir J 1992; 5; suppl. 15: 108s.

Frequency dependence of oscillatory resistance in dutch primary school children.

Cuypers CEJ, Swaen GMH, Wesseling GJ, Wouters EFM.

Eur Respir J 1992; 5; suppl. 15: 109s.

Asthma related symptoms and lung function in primary school children.

Cuypers CEJ, Wesseling GJ, Swaen GMH, Sturmans F, Wouters EFM.

Submitted.

Gastric asthma? No change in respiratory impedance during intraoesophageal acidification in adult asthmatics.

Wesseling GJ, Brummer RJM, Wouters EFM, Ten Velde GPM.

Accepted for publication in Chest. 


\section{Dankwoord}

Graag wil ik iedereen danken die heeft bijgedragen aan de totstandkoming van dit proefschrift. Zonder iemand te kort te willen doen, wil ik een aantal betrokkenen met name noemen.

Een speciaal woord van dank richt ik graag tot jou, Hooggeleerde Wouters, beste Emiel. Zonder jou was dit proefschrift er niet gekomen. Jouw belangstelling voor de geforceerde oscillatie techniek en jouw heldere inzicht en intensieve begeleiding zijn voor mij van onschatbare waarde geweest.

De leden van de beoordelingscommissie dank ik voor de moeite die zij hebben willen nemen voor de beoordeling van het manuscript en voor de nuttige adviezen.

Veel van het werk dat tot dit proefschrift heeft geleid, werd verricht gedurende mijn opleiding tot longarts. Ik dank mijn collega arts-assistenten uit die tijd, met name Tessa Brutel de la Rivière en Harrie Pouwels voor hun bereidheid zonodig taken van mij over te nemen.

Maurice Quaedvlieg ben ik zeer erkentelijk voor het beschikbaar stellen van onderzoeksgegevens verwerkt in hoofdstuk V.

Annemie Schols ben ik zeer dankbaar voor het feit dat zij ondanks alle drukle rond haar eigen promotie telkens weer kans zag te helpen met de statistische bewerking van de data, en vooral ook voor haar warme belangstelling voor de voortgang van het onderzoek.

Ingrid Vanderhoven, Marianne Kerckhofs, Francine Quaedvlieg, Marie-José Hermans en Simone Beckers, allen medewerkers van het longfunctie-laboratorium van het AZM, dank ik hartelijk voor hun hulp bij de metingen. Guus Martens dank ik hartelijk voor de hulp bij het verwerken van de onderzoeksgegevens.

De medewerkers van het Astmacentrum Hornerheide, en vooral Kitty Coenen, dank ik voor de geboden hulp en gastvrijheid gedurende de metingen voor hoofdstuk 8.

Manon Hijnens dank ik voor haar hulp bij het uittypen van het manuscript.

Marie-France Deckers ben ik zeer erkentelijk voor haar eindeloos geduld en zorg bij de voorbereiding van het manuscript.

Alle proefpersonen en patiënten wil ik danken voor hun bereidheid mee te werken aan het onderzoek en de vele longfunctie-metingen.

Mijn ouders dank ik voor het feit dat zij mij hebben laten worden wie ik ben.

Tot slot dank ik jou, Jetske en onze jongens, Pieter Maarten en Frederik, voor jullie liefde, geduld en vertrouwen. 



\section{Curriculum vitae}

Geertjan Wesseling werd geboren op 19 juni 1956 te Den Dolder. Hij behaalde het eindexamen Gymnasium $\beta$ aan het Willem de Zwijgerlyceum te Bussum. Vervolgens studeerde hij aan de Vrije Universiteit te Amsterdam achtereenvolgens Biologie (van 1974 tot 1977), en Geneeskunde (vanaf 1977). Het arts-examen werd behaald in juni 1984.

$\mathrm{Na}$ de interne vooropleiding in ziekenhuis "Mariastichting" te Haarlem (opleider J. Verwiel, internist) van 1984 tot 1986, werd de opleiding tot longarts voltooid in het Academisch Ziekenhuis Maastricht (opleiders wijlen Prof.dr. L.H. Greve en Dr. A.P.H. van der Vet).

Sinds de registratie als longarts op 1 april 1991 is de schrijver van dit proefschrift als longarts verbonden aan het Academisch Ziekenhuis Maastricht. 
Datawyse I Universitaire Pers Maastricht ISBN 9052780730 